\title{
WestVirginiaUniversity
}

THE RESEARCH REPOSITORY @ WVU

Graduate Theses, Dissertations, and Problem Reports

2010

\section{Religiousness, future time perspective, and death anxiety among adults}

James A. Henrie

West Virginia University

Follow this and additional works at: https://researchrepository.wvu.edu/etd

\section{Recommended Citation}

Henrie, James A., "Religiousness, future time perspective, and death anxiety among adults" (2010). Graduate Theses, Dissertations, and Problem Reports. 4605.

https://researchrepository.wvu.edu/etd/4605

This Thesis is protected by copyright and/or related rights. It has been brought to you by the The Research Repository @ WVU with permission from the rights-holder(s). You are free to use this Thesis in any way that is permitted by the copyright and related rights legislation that applies to your use. For other uses you must obtain permission from the rights-holder(s) directly, unless additional rights are indicated by a Creative Commons license in the record and/ or on the work itself. This Thesis has been accepted for inclusion in WVU Graduate Theses, Dissertations, and Problem Reports collection by an authorized administrator of The Research Repository @ WVU. For more information, please contact researchrepository@mail.wvu.edu. 
Religiousness, Future Time Perspective, and Death Anxiety among Adults

James A. Henrie

Thesis submitted to the Eberly College of Arts \& Sciences

At West Virginia University

in partial fulfillment of the requirements

for the degree of

Master of Science

in

Psychology

Julie Hicks Patrick, Ph. D., Chair

Amy Gentzler, Ph. D.

Amy Fiske, Ph. D.

Department of Psychology

Morgantown, West Virginia

2010

Keywords: Religiousness; Spirituality; Religious Doubt; Time Perspective; Death Anxiety; Terror Management

Copyright 2010 James A. Henrie 


\title{
ABSTRACT \\ Religiousness, Future Time Perspective, and Death Anxiety among Adults
}

\author{
James A. Henrie
}

The present study examined relations of death anxiety to age, gender, trait anxiety, future time perspective, religiousness, spirituality, and religious doubt. The primary goals of the investigation were to test for a curvilinear relation between religious meaning and death anxiety and to test whether the relations of age and gender with death anxiety were mediated by trait anxiety, future time perspective, religiousness, spirituality, and religious doubt. Participants were adults (18 to 89 years of age, $M=38.28$ years, $S D=19.30,79.1 \%$ female, $93.8 \%$ Caucasian) who completed the pertinent questionnaires online. Results indicated that there was indeed a curvilinear relation between religious meaning and death anxiety using one measure of death anxiety, the Death Anxiety Scale-Extended (Templer et al., 2006), but not another measure of death anxiety, the Death Anxiety Inventory (Tomás-Sábado \& Gómez-Benito, 2005). Additionally, while the relations of age and gender with death anxiety were only partially mediated by the variables of interest, religious belief and religious doubt were unique significant predictors of death anxiety, even with the inclusion of the demographic variables (age and gender) and the personality variable (trait anxiety). The results are discussed in terms of the roles of religious belief and religious doubt in death anxiety and how Socioemtional Selectivity Theory (Carstensen, 1992; Carstensen, Isaacowitz, \& Charles, 1999) and Terror Management Theory (Greenburg, Pyszczynski, \& Solomon, 1986) might approach those relations. 


\section{Acknowledgments}

First, I would like to express deep appreciation to Dr. Julie Hicks Patrick, my advisor and thesis committee chair, for her patience, guidance, and willingness to share her expertise throughout this entire project.

I would also like to thank my committee members, Dr. Amy Gentzler and Dr. Amy Fiske, for their efforts and advice throughout.

Furthermore, I’d like to thank Dr. Kerrie Smedley, my undergraduate mentor, for sparking my interest in psychology in general, and in developmental psychology specifically.

Finally, I thank the contributors to the West Virginia University Department of Psychology Alumni Fund, as their contributions helped to support this investigation. 


\section{Table of Contents}

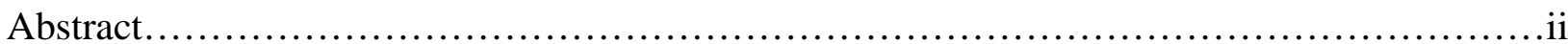

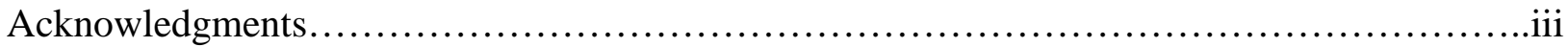

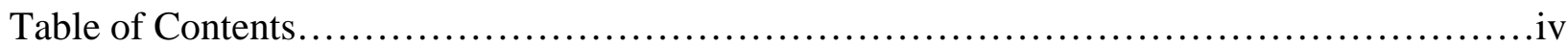

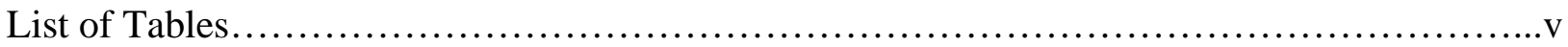

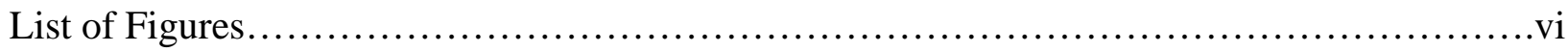

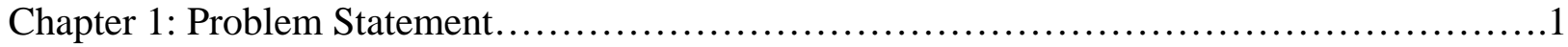

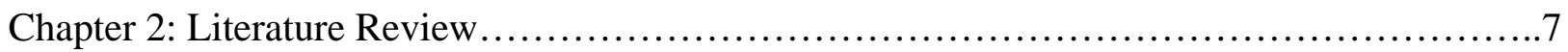

Chapter 3: Specific Aims and Research Hypotheses........................................ 18

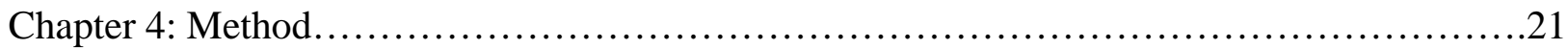

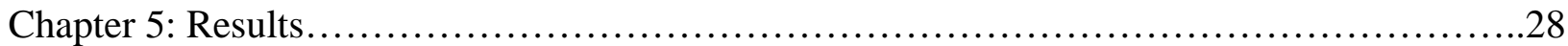

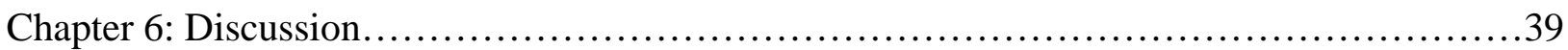

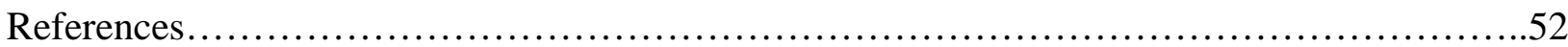

Appendices:

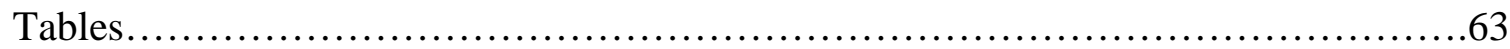

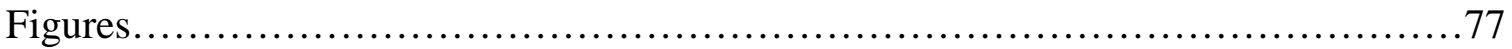

Measures:

Demographic Questionnaire.............................................101

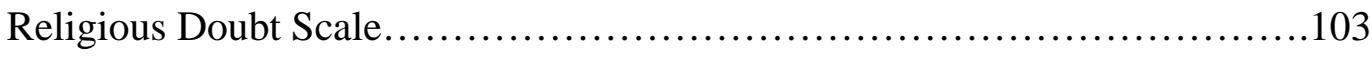




\section{List of Tables}

Table 1: Correlation Matrix for Variables in current study.

Table 2: 2 (gender) by 3 (age group) Multiple Analysis of Variance predicting scores on the

Death Anxiety Scale-Extended and the Death Anxiety Inventory.........................64

Table 3: 2 (gender) by 3 (age group) Analysis of Variance predicting Religious Doubt scores..65

Table 4: 2 (gender) by 3 (age group) Analysis of Variance predicting Future Time Perspective

scores.....................................................................................66

Table 5: 2 (gender) by 3 (age group) Analysis of Variance predicting Trait Anxiety scores......67

Table 6: 2 (gender) by 3 (age group) Multiple Analysis of Variance predicting Religious

Meaning, Religious Belief, Organizational Religiousness, and Daily Spiritual Experience scores.

Table 7: Tests of Trend from One-Way ANOVAs with Religious Meaning Groups predicting Death Anxiety Scale-Extended scores and Death Anxiety Inventory scores. . .69

Table 8: Curve Estimations with Religious Meaning predicting Death Anxiety Scale-Extended scores and Death Anxiety Inventory scores............................................70

Table 9: Tests of Trend from One-Way ANOVAs with Age Groups predicting Death Anxiety Scale-Extended scores and Death Anxiety Inventory scores...........................71

Table 10: Curve Estimations with Age predicting Death Anxiety Scale-Extended scores and Death Anxiety Inventory scores..................................................72

Table 11: Tests of Trend from One-Way ANOVAs with Age Groups predicting Trait Anxiety

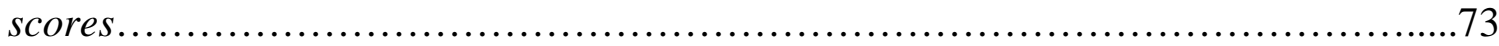

Table 12: Curve Estimations with Age predicting Trait Anxiety scores........................74

Table 13: Hierarchical Regression predicting Death Anxiety Scale-Extended scores..............75

Table 14: Hierarchical Regression predicting Death Anxiety Inventory scores...................76 


\section{List of Figures}

Figure 1: Graph of 2 (gender) by 3 (age group) Multiple Analysis of Variance predicting scores on the Death Anxiety Scale-Extended and the Death Anxiety Inventory: Death Anxiety Scale-Extended ..............................................................77

Figure 2: Graph of 2 (gender) by 3 (age group) Multiple Analysis of Variance predicting scores on the Death Anxiety Scale-Extended and the Death Anxiety Inventory: Death Anxiety

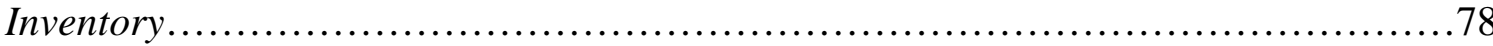

Figure 3: Graph of 2 (gender) by 3 (age group) Analysis of Variance predicting Religious Doubt scores.

Figure 4: Graph of 2 (gender) by 3 (age group) Analysis of Variance predicting Future Time Perspective scores.

Figure 5: Graph of 2 (gender) by 3 (age group) Multiple Analysis of Variance predicting Trait Anxiety scores.

Figure 6: Graph of 2 (gender) by 3 (age group) Multiple Analysis of Variance predicting Religious Meaning scores.

Figure 7: Graph of 2 (gender) by 3 (age group) Multiple Analysis of Variance predicting Religious Beliefs scores.

Figure 8: Graph of 2 (gender) by 3 (age group) Multiple Analysis of Variance predicting Organizational Religiousness scores.

Figure 9: Graph of 2 (gender) by 3 (age group) Analysis of Variance predicting Daily Spiritual

Experience scores.

Figure 10: Scatterplot of Religious Meaning (X) and Death Anxiety Scale-Extended (Y)........86

Figure 11: Scatterplot of Religious Meaning $(X)$ and Death Anxiety Inventory $(Y)$.............87

Figure 12: Graph of Means from Tests of Trend from One-Way ANOVA with Religious Meaning Groups predicting Death Anxiety Scale-Extended scores

Figure 13: Graph of Means from Tests of Trend from One-Way ANOVA with Religious Meaning Groups predicting Death Anxiety Inventory scores

Figure 14: Graph of Curve Estimation with Religious Meaning predicting Death Anxiety Scale-

Extended scores................................................................90

Figure 15: Graph of Curve Estimation with Religious Meaning predicting Death Anxiety Inventory scores...............................................................

Figure 16: Scatterplot of Age $(X)$ and Death Anxiety Scale-Extended $(Y) \ldots \ldots \ldots \ldots \ldots \ldots . \ldots . \ldots . \ldots 2$

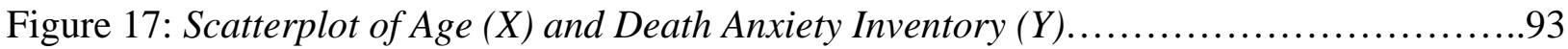

Figure 18: Graph of Means from Tests of Trend from One-Way ANOVA with Age Groups predicting Death Anxiety Scale-Extended scores....................................94

Figure 19: Graph of Means from Tests of Trend from One-Way ANOVA with Age Groups predicting Death Anxiety Inventory scores......................................95

Figure 20: Graph of Curve Estimation with Participants' Age predicting Death Anxiety Scale-

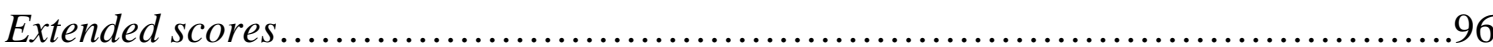


Figure 21: Graph of Curve Estimation with Participants’ Age predicting Death Anxiety Inventory scores.......................................................................97

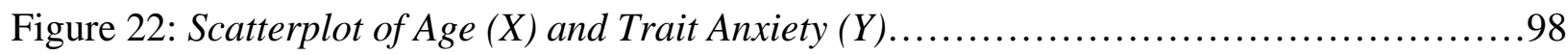

Figure 23: Graph of Means from Tests of Trend from One-Way ANOVA with Age Groups

predicting Trait Anxiety scores................................................99

Figure 24: Graph of Curve Estimation with Age predicting Trait Anxiety scores.................100 


\section{Religiousness, Future Time Perspective, and Death Anxiety among Adults Chapter 1: Problem Statement}

Examinations of death anxiety, the degree to which individuals experience uneasiness or concern in reference to death (Fortner \& Neimeyer, 1999), date back to at least the $17^{\text {th }}$ century (e.g., De Montaigne \& Coste, 1685) and have typically focused upon the negative effects of death anxiety. More recent findings have investigated links between death anxiety and risktaking behaviors, such that death anxiety was inversely related to the number of high-risk behaviors in which high schoolers had participated (e.g., Cotter, 2003), and physical and psychological distress, such that those with higher death anxiety had lower subjective well-being and more physical health issues (e.g., Rappaport, Fossler, Bross, \& Gilden, 1993; Wu, Tang, \& Kwok, 2002). Thus, it appears that having overly high death anxiety is related to more negative physical and psychological well-being, but exceedingly low death anxiety is related to more negative behavior. Given the nature of these findings, many researchers have investigated potential predictors of death anxiety. However, results from investigations of the relations between death anxiety and predictor variables, such as gender and age, have been mixed in terms of the magnitude and direction of associations. The purpose of the current study was to investigate whether other variables, such as religious belief, spirituality, religious doubt, future time perspective, and trait anxiety, serve to mediate age and gender associations with death anxiety. Thus, the study had the potential to clarify the mixed results that currently characterize this large and diverse literature.

\section{Operationalizing Death Anxiety}

Death anxiety has been measured by a number of different scales, but the scale most commonly used has been the Templer Death Anxiety Scale (DAS; Templer, 1970). It is a 
questionnaire in which individuals indicate whether they think about and/or fear death and its potential causes. It was developed to form an empirically-validated instrument with which to measure death anxiety at a time when researchers were using a number of different measures without reporting their validity or reliability. Over the last few decades, the DAS has remained the measure of choice for many researchers, although a few have argued that death anxiety is a more complex construct than originally thought (e.g., Lester, 2007; Lester \& Abdel-Khalek, 2003). Because of these arguments, and researchers' subsequent attempts to make their own measures of death anxiety, Templer and colleagues added questions to the original DAS to make it more comprehensive, thus creating the Death Anxiety Scale-Extended (DAS-E; Templer et al., 2006).

The Death Anxiety Inventory (DAI; Tomás-Sábado \& Gómez-Benito, 2005) is another empirically-validated measure of death anxiety. It was originally developed to investigate death anxiety among Spanish-speaking individuals, but has been translated into English. Similar to the DAS, the statements focus upon personal ideas about death and things associated with death, such as coffins and cemeteries. Unlike the DAS, a factor analysis of the statements revealed five significant factors in death anxiety: externally generated death anxiety, meaning and acceptance of death, thoughts about death, life after death, and brevity of life.

\section{Age and Death Anxiety}

A relatively consistent difference emerges in relation to the level of death anxiety and age. In general, younger adults express higher levels of death anxiety than do older adults (e.g., Rasmussen \& Brems, 1996; Stevens, Cooper, \& Thomas, 1980; Thorson, 1991). Even when investigating death anxiety solely among older adults, the oldest have the lowest death anxiety (Bengston, Cuellar, \& Ragan, 1977; Wu et al., 2002). However, in contrast to this general trend, 
Suhail and Akram (2002) found that older adults had significantly higher levels of death anxiety in a Pakistani sample. This change of direction in trend may indicate that other constructs, such as cultural values or different experiences, mediate the relation between age and death anxiety.

In addition to mean age differences, the direction and magnitude of associations among death anxiety and other variables may differ by age. Although a weak but significant negative correlation $(r=-.17)$ has been found between the number of high-risk behaviors and death anxiety among high school students (Cotter, 2003), mixed associations emerge for college students. Kasper and Vesper (1976) investigated death anxiety, using the DAS, among motorcycle riding and non-motorcycle riding male college students, and found that the motorcycle riders, the group taking the greater risk (United States Department of Transportation, 2007), had significantly lower levels of death anxiety. In contrast, college students who had been provoked to think about death reported a greater willingness to participate in high-risk sexual behaviors than those who had not been provoked (Ford, Ewing, Ford, Ferguson, \& Sherman, 2004), and 16- to 20-year-olds who had higher scores on the DAS also had higher scores on the Suicide Probability Scale (D’Attilio \& Campbell, 1990). Although the results among college students may appear contradictory, it seems that when pre-existing death anxiety is assessed it is negatively related to risk-taking (such that those lower in death anxiety are participating in more high-risk activities), while experimentally-induced death anxiety is positively related, such that those higher in death anxiety are more willing to participate in high-risk sexual behaviors. Thus, it seems as though the methodology influences the results.

When examining death anxiety among older adults, researchers often focus on physical and psychological well-being. Rappaport et al. (1993) studied the relation between death anxiety and perceived purpose in life in 52- to 94-year-old adults and found a negative correlation 
between death anxiety and perceived purpose in life $(r=-.33)$, suggesting that higher levels of death anxiety are associated with lower subjective well-being. Similarly, in a Spanish sample of older adults, Moreno, De La Fuente Solana, Rico, and Fernández (2009) report that older adults who believed that they had accomplished what they wanted to accomplish had less death anxiety. Furthermore, those with depression had higher death anxiety scores than the average population. In contrast to Wu et al. (2002), older adults with more health issues, especially those with sight and hearing problems, reported higher levels of death anxiety. However, compared with cancerfree groups, adults with terminal cancer reported lower mean death anxiety (Gibbs \& Achterberg-Lawlis, 1978), as do individuals with terminal AIDS compared to HIV-negative individuals (Hayslip, Luhr, \& Beyerlein, 1991-1992; Hayslip, Servaty, Christman, \& Mumy, 1997), suggesting a difference between general health issues and terminal health issues in relation to death anxiety. Finally, Devins (1979) found that older adults who scored higher on the DAS rated voluntary passive euthanasia as less acceptable for themselves.

In order to clarify conflicting results, Fortner and Neimeyer (1999) quantitatively reviewed 49 studies that investigated the relations among a number of variables and death anxiety in older adults. They found a negative association between ego integrity, the acceptance of yourself as your are, and death anxiety $(r=-.30)$, a positive association between psychological problems and death anxiety $(r=.28)$, and a positive association between physical problems and death anxiety $(r=.17)$. Thus, most studies appear to point toward higher levels of death anxiety being associated with poorer physical and psychological well-being, with few exceptions.

\section{Gender and Death Anxiety}

A relatively consistent gender difference has also been found in studies of death anxiety. In particular, females tend to have greater death anxiety. This difference has been found among 
high school students when investigating risk-taking (Cotter, 2003) and when investigating the effects of born-again status (Young \& Daniels, 1981). It has also been found among adolescents when investigating the effects of bereavement on death anxiety (Ens \& Bond, 2007), and among high school and college students when examining death anxiety in relation to Allport and Ross's (1967) intrinsic-extrinsic religiosity distinction (Pierce, Cohen, Chambers, \& Meade, 2007). Several investigations of college students have found this difference, including those that investigate the effects of belief in afterlife on death anxiety (Berman \& Hays, 1973) and those that have examined differences between Mormon and non-Mormon college students (McDonald, 1976). Studies examining large age ranges have also noted this gender difference. Rasmussen and Johnson (1994) found that females had greater death anxiety among 18- to 61-year-old adults while examining death anxiety in the context of psychosocial development, and Harding, Flannelly, Weaver, and Costa (2005) found the same difference when investigating death anxiety among 22- to 84-year-old parishioners of the Episcopal Church. Finally, females have been found to have greater death anxiety among both Pakistani (Suhail \& Akram, 2002) and Iranian adults (Roshdieh, Templer, Cannon, \& Canfield, 1999).

Thorson, Powell, Abdel-Khalek, and Beshai (1997) also found greater death anxiety in females among Kuwaiti and American university students. However, they found that the Kuwaitis in general had higher death anxiety scores, with an even greater difference found between American and Kuwaiti females, suggesting that other factors, such as culture, may mediate the relation between gender and death anxiety.

Although investigations of death anxiety suggest links between death anxiety and age, gender, risk-taking behavior, and both physical and mental health, this area of research has been limited by a focus on group differences to the exclusion of identifying explanations for these 
differences and for the mixed results. Relatively few studies have moved beyond these mean comparisons to examine possible mediators.

Of the studies that have examined factors that could be mediators of age and gender relations with death anxiety, the most common variables investigated may be religiousness. Specifically, spirituality (e.g., Rasmussen and Johnson, 1994), holding particular religious beliefs (e.g., Alvarado, Templer, Bresler, \& Thomas-Dobson, 1995), relative importance of religion (Wink \& Scott, 2005), and attendance of religious services (e.g., Thorson, 1991) have been investigated in relation to death anxiety.

Two potential mediators that hold promise but have been under-examined include religious doubt, questioning the existence and/or benevolence of a higher power as well as questioning beliefs and practices of specific religions, and future time perspective, the degree to which one perceives their future as limited or extensive. Religious doubt holds promise as a potential mediator because both death anxiety and religious doubt appear to involve consideration of an existential crisis: death anxiety concerns a consideration of mortality, while religious doubt involves questioning beliefs that may have played a significant role in identity and development (e.g., Furrow, King, \& White, 2004). Thus, if you experience religious doubt, perhaps through questioning the existence of an afterlife, you may experience increased death anxiety, as that religious perspective may have caused you to believe you would not truly cease to exist. Future time perspective holds promise because future time orientation, an apparently similar concept, has been studied in association with death anxiety (e.g., Rappaport et al., 1993), and because future time perspective is your perception of how long you have left to live.

Overall, mixed results characterize this area of inquiry. The current study was an attempt to disentangle these mixed results and contribute to the literature on death anxiety by 
investigating predictors that have not yet been examined. Therefore, the purpose of the present study was to investigate whether the relations of gender and age with death anxiety are mediated by aspects of spirituality, religious belief, religious doubt, and future time perspective in younger, middle-aged adults, and older adults.

\section{Chapter 2: Literature Review}

\section{Religion and Death Anxiety}

The relations between different aspects of religiousness and death anxiety have been investigated quite frequently. The different aspects of religiousness have included comparisons between different types of belief systems, Allport and Ross's (1967) intrinsic-extrinsic religiosity distinction, spirituality, strength of religious belief, specific beliefs (such as belief in afterlife, belief in the existence of a god, belief in the benevolence of their god, and belief in the literal interpretation of the Bible), and frequency of attendance of religious services, among many other aspects of religiousness.

When considering comparisons between different belief systems, Mormons and nonMormons had similar levels of death anxiety (McDonald, 1976) and self-identified born-again Christian high school students in the rural south had lower death anxiety than those who did not identify themselves as born-again Christians (Young and Daniels, 1980; Young and Daniels, 1981).

A number of studies have used Allport and Ross’s (1967) intrinsic-extrinsic religiosity distinction. Intrinsic religiosity refers to an internal motivation for and perceived importance of religious belief/spirituality, while extrinsic religiosity refers to external motivation for religious behavior, such as meeting people within your community, seeking social support, or being pressured into religious behavior. Studies using this intrinsic-extrinsic religiosity distinction have 
found differences between American and Middle Eastern individuals (Thorson et al., 1997), a negative association between intrinsic religiosity and death anxiety (Roff, Butkeviciene, \& Klemmack, 2002), a positive correlation between extrinsic religiosity and death anxiety (Ens \& Bond, 2007), and differences between Protestant and Catholic young adults (Cohen, Pierce, Chambers, Meade, Gorvine, \& Koenig, 2005). However, Kirkpatrick and Wood (1990) have argued that, despite its frequency of use, Allport and Ross’s (1967) intrinsic-extrinsic religiosity distinction has not truly informed us about the psychology of religious belief. They contend that religiousness is far more complicated, as extrinsic religiosity and intrinsic religiosity seem to touch on a number of different aspects of religiousness, but are too ambiguous for findings associated with them to be fully disentangled. Therefore, Kirkpatrick and Wood (1990) argue for the study of religion to focus on very specific aspects of religiousness.

Several specific aspects of religiousness have been considered in relation to death anxiety. For example, the relations of spirituality, specific religious beliefs, importance of beliefs, and organizational religiousness with death anxiety have been examined. Given that religiousness has been shown to vary by age, with older adults typically reporting higher levels of religiousness (e.g,. Pew Research Forum, 2010), and gender, with females typically reporting higher levels of religiousness (e.g., Levin \& Taylor, 1993), it is of import to consider whether religiousness may mediate the relations of age and gender with death anxiety. However, like age and gender, there have been mixed results concerning the relation between religiousness and death anxiety.

Spirituality. Few studies have considered the relations between non-religion-specific spirituality and death anxiety. Wink and Dillon (2003) discuss the difference between spirituality and religious belief in terms of what they offer for the individual. Specifically, spiritually 
involves feeling a connection between the self and a higher cause or power and tends to involve a search for answers in which answers may not always be concrete or reinforced. For example, spiritually speaking, there is not necessarily going to be reassurance about life after death. In religious practice, most religions have beliefs about the afterlife that are reinforced in religious services.

Investigations of the relation may help distinguish whether associations between religion and death anxiety are about spiritual belief or religious practice. Rasmussen and Johnson (1994) examined the relation between death anxiety (using the Templer DAS) and spirituality in 18- to 61-year-old adults. A regression found a significant negative relation between death anxiety and spirituality, such that higher levels of spirituality were associated with lower levels of death anxiety. Wink (2006) also investigated this relation, but found that the relation between spirituality and death anxiety was not significant. These apparently contradictory findings need to be investigated further in order to clarify the role of spirituality in death anxiety relative to other variables.

Religious beliefs. Several studies have investigated the role of specific beliefs in the relation between religion and death anxiety. Belief in afterlife is a common variable of interest, as many researchers believe that death anxiety could be directly affected by what people think follows death. In studies of college students, Templer and Dotson (1970), Berman and Hays (1973), and Alvarado et al. (1995) did not find a significant relation between death anxiety and belief in afterlife. However, it appears that their findings were atypical, as Templer and Ruff (1975) found that stronger belief in life after death was associated with lower death anxiety in more religiously involved college students, Ochsmann (1984) found that those with lower scores on a scale of belief in afterlife showed a greater concern with death among college students in 
non-theology majors, Thorson (1991) found significant positive correlations between uncertainty about life after death and death anxiety for females $(r=.51)$ and males $(r=.42)$, Harding et al. (2005) found that death anxiety was negatively correlated with belief in afterlife $(r=-.25)$ among parishioners of the Episcopal Church (22 to 84 years of age), Lundh and Radon (1997) found a negative association between death anxiety and religious beliefs among Swedish college students, and the above-mentioned Roshdieh et al. (1999) and Rasmussen and Johnson (1994) studies found similar results.

In addition, Harding et al. (2005) found that belief in the existence of a god was also negatively correlated with death anxiety $(r=-.27)$. Naidu and Sinha (1992) studied death anxiety in Indian adults who have had varying amounts of exposure to death and found that those who reported a stronger belief in the existence of a god and had a stronger belief in the benevolence of their god had lower death anxiety.

Another aspect of religious belief that Templer and Dotson (1970) studied in their investigation was the relation between belief in the literal interpretation of the Bible and death anxiety. Once again, they found no significant relation between the two variables of interest, but Templer and Ruff (1975) found that, among more religiously involved college students, stronger belief in the literal interpretation of the Bible was associated with less death anxiety.

Overall, in terms of the relation between death anxiety and specific religious beliefs, there once again appears to be somewhat inconsistent findings, though a trend predominates. Specifically, it appears that death anxiety is negatively related to specific religious beliefs. However, the inconsistencies suggest that these relations need to be investigated further.

Religious meaning. A number of studies have examined the relation between religious meaning, the relative importance that individuals find in their religion, and death anxiety. Similar 
to spirituality, results are equivocal, as some found a negative relation, some a positive relation, and still others a curvilinear relation.

Templer and Dotson (1970) found no significant relation between death anxiety and religious meaning. However, Templer and Ruff (1975) found a negative relation in college students that were more religiously involved, and Alvarado et al. (1995) also found a small negative correlation $(r=-.19)$.

In direct contrast to Templer and Ruff (1975) and Alvarado et al. (1995), Thorson (1991) found that self-rating of religiousness was positively correlated with death anxiety $(r=.21)$ for females, with a similar but non-significant trend for males. Lundh and Radon (1997) found that believers had less death anxiety than agnostics and atheists using a death anxiety questionnaire, while agnostics and atheists did not differ. In the Suhail and Akram (2002) study mentioned above, using the DAS, they found that those with weaker Muslim religious beliefs had higher death anxiety. Long and Elghameni (1987) investigated this relation among Saudi Arabian Muslim males, finding that perceived relative religiosity was significantly related to a major aspect of death anxiety, fear of death for significant others. Roshdieh et al. (1999) studied the relations between different war-related experiences, overall religious belief, and death anxiety in Iranian college students, finding that, along with having experienced a war-related trauma or injury to a friend or relative, having less overall religious belief was associated with greater death anxiety.

In contrast to both the positive and negative relations mentioned, Leming (1980) reviewed 23 studies that investigated the relation between religious meaning and death anxiety to consider contradictory findings. His conclusion was that those who found the most importance on their religion, and those who found the least (that is, the non-religious), had the least death 
anxiety, while those in the middle had the most death anxiety. Wink and Scott (2005) found a similar relation between religiosity and death anxiety in a group of older adults that had been followed longitudinally since their birth in the 1920s. This outlines a curvilinear relation between death anxiety and religious meaning, and thus might explain the contradictory findings when looking for a linear relation.

Overall, research has found mixed results, with some finding no relation (e.g., Templer \& Dotson, 1970), others finding a negative association (e.g., Alvarado et al., 1995), still others finding a positive relation (e.g., Thorson, 1991), and yet others found a non-linear relation (Leming, 1980; Wink \& Scott, 2005). These equivocal findings also suggest a need for more precise research with a more operationalized definition of religious meaning.

Organizational religiousness. Another aspect of religion that has received empirical attention is the role of religious services, specifically considering frequency of attendance. It was yet another aspect of religious belief investigated by Templer and Dotson (1970), and similar to their other findings, they did not find a significant association between death anxiety and frequency of attendance. Alvarado et al. (1995) had similar results. However, once again, Templer and Ruff (1975) found a different result; specifically, they found a negative relation between death anxiety and frequency of attendance of religious services in more religiously involved college students.

Similar to Templer and Ruff (1975), Aday (1985) found that more frequent attendance was associated with less death anxiety among college students, and Long and Elghameni (1987)'s study of Saudi Arabian Muslim males found a negative relation between frequency of current religious service attendance and an aspect of death anxiety, fear of premature death. In contrast, Thorson (1991) found a significant relation between death anxiety and frequency of 
attendance of religious services, except Thorson found a positive association. Specifically, frequency of religious service attendance was positively related to death anxiety $(r=.16)$ for females, and a similar but non-significant trend was found for males.

Not surprisingly, there are inconsistent overall findings concerning organizational religiousness. Some find no relation between death anxiety and frequency of attendance of religious services (Templer \& Dotson, 1970; Alvarado et al., 1995), some found a negative relation (Aday, 1985; Long \& Elghameni, 1987; Templer and Ruff, 1975), and one found a positive relation (Thorson, 1991). Obviously, clarity is needed for our understanding the relation between death anxiety and organizational religiousness.

An underlying assumption of the relation between religiousness and death anxiety is that religiousness (or lack thereof) has a direct influence on death anxiety. This is often viewed as being due to the impact of a particular belief that accompanies most religions: belief in an afterlife. The inverse relation between death anxiety and religiousness in general (and belief in an afterlife specifically) suggests that individuals who believe in an afterlife would not need to worry about the cessation of their being, as they believe they will live eternally. Essentially, if you don't believe you are going to die, why would you worry about dying? Thus, the assumption is that an individual's religiousness influences their death anxiety, rather than death anxiety affecting their religiousness.

Overall, research investigating how religiousness relates to death anxiety has typically been done without much use of theory. However, of late, Terror Management Theory (TMT; Greenburg, Pyszczynski, \& Solomon, 1986) has been used as an explanation for findings in religiousness-death anxiety research. TMT argues that the human ability to ponder our own mortality results in emotional turmoil, but culturally-provided worldviews can offer us protection 
from that distress. From this point of view, religious beliefs may be one of those worldviews (Vail, Rothschild, Weise, Solomon, Pyszczynski, \& Greenburg, 2010), as several studies suggest a negative relation between religiousness and death anxiety (e.g., Harding et al., 2005; Thorson, 1991).

Given that there are cultural differences and inconsistencies in the relations between death anxiety and different aspects of religiousness, as there were with the relations of death anxiety with age and gender, other variables may also be mediating the relation between demographic variables and death anxiety. Specifically, religious doubt, future time perspective, and trait anxiety are variables of interest that have not been previously studied in relation to death anxiety.

\section{Religious Doubt}

Religious doubt, or questioning the existence and/or benevolence of a higher power as well as questioning beliefs and practices of specific religions, may affect many different aspects of individual's religious beliefs, including their spirituality (doubt may decrease feelings of closeness to a higher power), beliefs (doubt may affect how certain you are of an afterlife), religious meaning (higher levels of doubt may result in finding less importance in religion), and frequency of attendance (higher levels of doubt may lead to less frequent attendance).

Hecht (2003) suggests that doubt in religion has been around as long as there has been religion. Given that religion requires faith in conclusions that may not be supportable or refutable, it may be in the nature of religion to give rise to its own doubt, and thus doubt may be inescapable. Religious doubts have involved issues with the foundations of the religion and issues concerning whether changes are needed within the religious community (Hunsberger, 
Alisat, Pancer, \& Pratt, 1996), and have also been linked to individuals not having their expectations met by their religion (Nipkow \& Schweitzer, 1991).

Similar to death anxiety, research on religious doubt has focused on negative effects with which it is associated. Higher levels of religious doubt have been associated with a number of psychological issues, including greater general psychological distress and diminished feelings of well-being (Krause, Ingersoll-Dayton, Ellison, \& Wulff, 1999), as well as being less satisfied with personal health and experiencing more depression (Krause \& Wulff, 2004). Also, experiencing religious doubt due to seeing suffering and evil in the world appears to have deleterious effects on mental health, including higher levels of depression, anxiety, paranoia, hostility, and obsessive-compulsive symptoms, although the effects of religious doubt appear to diminish with age (Galek, Krause, Ellison, Kudler, \& Flannelly, 2007), and having higher levels of doubt over time is associated with declines in self-esteem and optimism and, in those with less education, with life satisfaction (Krause, 2006). Also predictive of life satisfaction was the interaction of religious belief, religious doubt, and need for cognition, such that those who had a higher need for cognition and lower religious doubt had higher life satisfaction, but those who had higher need for cognition and higher religious doubt had lower life satisfaction (Gauthier, Christopher, Walter, Mourad, \& Marek, 2006). Gauthier et al. also found that males scored higher in religious doubt. In addition, Beck (1981) noted that religious doubt in evangelicals can result in an obsession with death, and religious doubt in adolescents has also been associated with greater family problems (Hunsberger, Pratt, \& Pancer, 2002).

Pratt, Hunsberger, Pancer, \& Roth (1992) investigated religious reflection among men and women aged 18 to 26 years, 27 to 45 years, and 60 to 85 years. They found that younger 
adults reason in more complex ways about conflictual religious dilemmas than older adults (Pratt et al., 1992).

Thus, research investigating relations between death anxiety and religion have been relatively inconsistent, and have not considered the relation between religious doubt and death anxiety. One area of interest within the current study involves clarification of the relations between death anxiety and different aspects of religious belief, and to include in the investigation the relation between death anxiety and religious doubt as a potential mediator of relations of gender and age with death anxiety.

\section{Future Time Perspective}

Future time perspective, the degree to which people perceive their future as limited or extensive (Lang \& Carstensen, 2002), is a relatively new construct of interest in psychological research. For the most part, it has been studied within the context of Socioemotional Selectivity Theory (Carstensen, 1992; Carstensen, Isaacowitz, \& Charles, 1999). Socioemotional Selectivity Theory very generally argues that our perceptions of the amount of time we have remaining in our lives and our changing motivations for social contact influence with whom we interact. Given that future time perspective has been investigated in this context, it has been typically studied in association with different aspects of social behavior. In those studies, consistent age differences emerge, with healthy older adults typically having a shorter future time perspective relative to healthy younger adults (e.g., Lang \& Carstensen, 2002), however some studies have found the inverse (e.g., Padawer, Jacobs-Lawson, Hershey, \& Thomas, 2007).

A number of slightly older studies have investigated future time orientation, which appears to be a similar construct to future time perspective. Results from these studies are mixed. In a study of Finnish teenagers, von Wright \& von Wright (1977) found that males had greater 
future time orientation, and Tismer (1985) replicated the finding with German adolescents. In contrast, Gjesme (1979) found that, among Norwegian sixth graders, girls had greater future time orientation. Finally, Rappaport et al. (1993) found that those with a more dense (shorter) future time orientation had greater death anxiety.

Given findings suggesting that older adults have shorter future time perspective, that males have greater future time orientation, and that shorter future time orientation is associated with greater death anxiety, it is pertinent to investigate whether future time perspective is a predictor of death anxiety and whether it mediates the relations of age and gender with death anxiety.

\section{Trait Anxiety}

Trait anxiety, how uneasy an individual generally feels (Spielberger, Gorsuch, \& Lushene, 1970), may be strongly related to death anxiety. Trait anxiety has been studied for several decades and primarily has been studied in clinical studies investigating the relations between trait anxiety and psychological disorders, such as depression and post traumatic stress disorder (e.g., Naragon-Gainey, 2010).

There is a long history of studying trait anxiety, with many studies investigating differences by age and gender in trait anxiety. In a similar fashion to the constructs discussed above, inconsistent results have been found concerning age. Specifically, Jorm (2000) reviewed epidemiological studies of anxiety across the adult years and found that no consistent pattern emerged, although some indicate an initial rise in anxiety in adulthood, followed by a decline. In contrast, a relatively consistent gender difference emerges concerning anxiety, with females typically having greater anxiety (e.g., Feingold, 1994), although the differences are not always large (Spielberger, Gorsuch, Lushene, Vagg, \& Jacobs, 1983). 
Given the known gender difference in death anxiety, and the possible similarity in death anxiety and trait anxiety, it is of interest to investigate the possibility that trait anxiety may mediate the relation between gender and death anxiety.

Overall, research investigating relations between death anxiety and other variables have been relatively inconsistent. Seemingly consistent trends involving age, gender, and death anxiety appear to have exceptions, studies involving different aspects of religious belief have conflicting findings, and some variables haven't truly been considered (religious doubt, future time perspective, and trait anxiety). Therefore, as mentioned above, the purpose of the current study was to investigate whether the relations of gender and age with death anxiety were mediated by aspects of religious belief, religious doubt, future time perspective, and trait anxiety in younger, middle-aged, and older adults.

\section{Chapter 3: Specific Aims and Research Hypotheses}

The overall aim of the proposed study is to examine whether differences among age groups and between genders in death anxiety are mediated by different aspects of religiousness and spirituality, as well as religious doubt, future time perspective, and trait anxiety.

\section{Specific Aim 1: Confirmation of differences by gender and age in death anxiety, religious} doubt, future time perspective, trait anxiety, religious meaning, religious beliefs, organizational religiousness, and spirituality.

H1a: It was expected that females would report greater death anxiety than males, based on current empirical findings (e.g., Cotter, 2003; Ens \& Bond, 2007; Pierce et al., 2007).

H1b: A main effect for age was expected, such that older adults would report lower death anxiety than middle-aged adults, who would report lower death anxiety than young adults (e.g., Rasmussen \& Brems, 1996; Thorson, 1991; Wu et al., 2002). 
H2a: It was expected that males would express more religious doubt than females (Gauthier et al., 2006).

H2b: A main effect for age was expected, such that older adults would express less religious doubt than middle-aged adults, who would express less religious doubt than young adults (Pratt et al., 1992).

H3a: It was expected that males would report greater future time perspective (Padawer et al., 2007).

H3b: A main effect for age was expected, such that older adults would report having a more compressed (shorter) future time perspective than middle-aged adults, who would report having a more compressed future time perspective than young adults (Lang \& Carstensen, 2002).

H4a: It was expected that females would report greater trait anxiety (Feingold, 1994).

H4b: A main effect for age was expected, such that older adults would report lower trait anxiety than middle-aged adults, who would report lower trait anxiety than young adults (Jorm, 2000).

H5a: It was expected that females would report higher levels of religiousness and spirituality (e.g., Levin \& Taylor, 1993).

H5b: A main effect for age was expected, such that older adults would report higher levels of religiousness and spirituality than middle-aged adults, who would report higher levels of religiousness and spirituality than young adults (e.g., Levin \& Taylor, 1993).

\section{Specific Aim 2: Examine differences in death anxiety as a function of religious meaning.}

H6: It was expected that religious meaning would have a curvilinear relation with death anxiety, rather than a linear relation (Leming, 1980; Wink \& Scott, 2005). That is, those who 
find the least and most meaning from religion would have lower death anxiety, while those who find a moderate amount of meaning from would have higher death anxiety.

\section{Specific Aim 3: Examine age differences in death anxiety.}

H7: A linear relation was expected, such that age is negatively related to death anxiety (e.g., Rasmussen \& Brems, 1996; Stevens, Cooper, \& Thomas, 1980; Thorson, 1991). However, a curvilinear relation is possible (Suhail \& Akram, 2002), so it will be examined.

\section{Specific Aim 4: Examine age differences in trait anxiety}

H8: A linear relation was expected, such that age is negatively related to trait anxiety as, although findings have been inconsistent, some have found a linear relation (Jorm, 2000). However, Jorm also indicates that a few studies find an initial rise in anxiety in adulthood, followed by a decline, suggesting that a curvilinear relation is possible. Due to the inconsistencies, both linear and curvilinear relations will be examined.

\section{Specific Aim 5: Develop and test a model predicting death anxiety.}

H9: It was hypothesized that age (a negative relation; Rasmussen \& Brems, 1996;

Thorson, 1991; Wu et a., 2002), gender (females having greater death anxiety; Cotter, 2003; Ens \& Bond, 2007; Pierce et al., 2007), religious doubt (a positive relation), spirituality (a negative relation; Rasmussen and Johnson, 1994), religious beliefs (a negative relation; e.g., Harding et al., 2005; Lundh \& Radon, 1997; Rasmussen \& Johnson, 1994; Roshdieh et al., 1999), organizational religiousness (a negative relation; e.g., Aday, 1985; Long \& Elghameni, 1987), future time perspective (a negative relation; Rappaport et al., 1993), and trait anxiety (a positive relation) would be significant predictors of death anxiety. 


\section{Chapter 4: Method}

\section{Participants}

Data from the current study represent a subset from a larger study (Religiousness and Future Time Perspective among Adults) in which 674 adults participated. Due to an unequal age distribution (over $75 \%$ of the adults were under the age of 35), a subset of younger, middle-aged, and older adults was used. Specifically, data from all of the middle-aged and older adults were used, while data from a subset of younger adults who had provided data for each of the necessary scales were used.

Data from 273 participants (18 to 89 years of age, $M=38.28$ years, $S D=19.03,79.1 \%$ female, 93.8\% Caucasian) were used in current study. The sample consisted of 133 young adults (18 to 35 years of age, $M=20.24$ years, $S D=2.92$, $78.9 \%$ female), 89 middle-aged adults (36 to 59 years of age, $M=49.69$ years, $S D=6.24,78.7 \%$ female), and 51 older adults (60 to 89 years of age, $M=65.41$ years, $S D=5.50,80.4 \%$ female). Younger adults (and six middle-aged adults) were recruited through psychology courses. Middle-aged adults and older adults were recruited using referrals from younger, middle-aged, and older adults (133 middle-aged and older adults participated out of approximately 1700 referrals) and through community outreach (press releases to 30 West Virginia newspapers that resulted in two additional participants).

\section{Materials and Measures}

Below are descriptions of each of the questionnaires and measures used in the current study. For each of the scales, when missing data were encountered, individual mean substitution, where answered items on a scale are used to determine scores for missing items (Widaman, 2005), was used when possible. In the present study, an individual's total scale score was determined based on the items they did answer, as long as $70 \%$ or more of the items in the scale 
had been answered. If greater than $30 \%$ of the items on a scale had not been answered, listwise deletion was used.

Demographic variables. The demographic questionnaire (Appendix AM) included a variety of background and demographic measures, including age in years, gender, ethnicity, highest level of education, marital status, employment status, and religious affiliation.

Spirituality. Spirituality was measured using the 16-item Daily Spiritual Experiences Scale (DSES) of the Brief Multidimensional Measure of Religiousness/Spirituality (BMMRS; Fetzer Institute, 1999). Participants indicated how frequently they have had certain spiritual experiences, such as feeling the presence of a higher power, finding strength in religion/spirituality, being thankful, and finding beauty in the world. Questions 1 through 14 are rated from 1 ("never or almost never") to 6 ("many times a day"), while questions 15 and 16 are rated from 1 ("not at all close") to 4 ("as close as possible"). Thus, the composite scores can range from 16 to 92 . The scores for the present study ranged from 22 to 92 , with $M=61.81$ and $S D=16.91$, and the DSES had a Cronbach's alpha estimate of internal consistency of .95. Other psychometric data for the DSES (and all of the other measures from the BMMRS) are not available, as the studies investigating the different aspects of the psychometrics of the BMMRS are yet to be conducted. It was developed through discussions of a panel of expert researchers and scholars from across the nation (Fetzer Institute, 1999). The body of research investigating religiousness and spirituality, especially as they relate to psychological and physical health, had made it clear that religiousness and spirituality needed to be studied using a multidimensional approach with consistent measures. Thus, they formulated the many scales in the BMMRS by consulting available and frequently used measures of the constructs of interest, and using the aspects that appeared most theoretically and empirically important. Correlations between each of 
the measures used in the study, including the religiousness and spirituality variables, can be found in Appendix A.

Religious meaning. The importance that individuals placed on religion was measured using the 20-item Religious Meaning Scale of the BMMRS (Fetzer Institute, 1999). Participants indicated to what extent they agreed with statements about feeling a purpose in life due to a relationship with their god and their religious beliefs. Answers range from 1 ("strongly disagree”) to 5 (“strongly agree”), meaning composite scores can range from 20 to 100. Scores for the present study covered the entire range, with $M=69.94$ and $S D=20.66$. The Religious Meaning Scale had a Cronbach’s alpha of .98.

Religious beliefs. Religious Beliefs were measured using the seven-item Beliefs Scale of the BMMRS (Fetzer Institute, 1999). Participants indicated whether they held general and specific beliefs, such as a belief in an afterlife, believing that everything happens for a reason, and believing that your god loves you. Answers to question 1 range from 1 ("none”) to 3 (“a great deal”), question 2 is a yes (1) or no (0) question (with “undecided” as an unscored option), and answers to questions 3 through 7 range from 1 (“disagree strongly”) to 5 (“agree strongly”). Thus, composite scores can range from 6 to 29. Scores for the present study covered the entire range, with $M=24.45$ and $S D=5.81$. The Religious Beliefs Scale had a Cronbach’s alpha of .90 .

Organizational religiousness. Organizational Religiousness was measured two ways. The first involved using the eight-item Organizational Religiousness Scale of the BMMRS (Fetzer Institute, 1999). Participants indicated the degree to which they were involved with their religious institution and attend services. Questions 1 and 2 are scored from 1 (“never”) to 9 (“several times a week”). Question 3 is scored from 1 (“do not fit at all”) to 5 ("fit extremely 
well”). Questions 4 through 7 are scored from 1 (“strongly disagree”) to 5 (“strongly agree”). Questions 8a through 8j each have two parts, where the first part is scored 1 (“never”) to 5 (“more than once per service”) and the second part is scored 1 ("not at all important”) to 5 (“extremely important”). Composite scores can range from 27 to 143 . However, missing data on this scale resulted in an inability to use over one quarter of the respondents for the analyses. Therefore, the second measure of organizational religiousness was used for the analyses.

The second measure of organizational religiousness was a five-item scale derived from Kenney, Cromwell, and Vaughan (1977). Participants indicated their frequency of involvement in particular activities associated with their religious community. All five questions were rated on a scale of 1 (“Rarely/Never”) to 4 (“Very Frequently”). Composite scores can range from 5 to 20, and scores in the current investigate covered the entire range, with a $M=10.06$ and $S D=$ 4.44. The five-item scale of organizational religiousness had a Cronbach's alpha of .88.

Future time perspective. Carstensen and Lang's (1996) Future Time Perspective Scale (FTP) was used. It was designed to investigate the degree to which one perceived their future as limited or extensive. Participants indicated how true ten statements were for them on a sevenpoint Likert-style scale ranging from "very untrue” (1) to “very true” (7). Thus, composite scores can range from 7 to 70 . Scores ranged from 17 to 70 in the present study, with $M=51.81$ and $S D$ $=10.73$. The Future Time Perspective Scale had a Cronbach’s alpha of .89 .

Religious doubt. Religious Doubt was measured using a scale developed for use in the current study (Appendix AN). Given that there does not appear to be a "gold standard" for the measurement of religious doubt, researchers have often created their own scale of religious doubt (e.g. Galek et al., 2007; Hunsberger et al., 2002), and psychometric data are often not reported. For the scale developed for the current investigation, participants indicated how true 14 
statements about experiences or feelings may cause doubt were for them, with possible answers ranging from “very untrue” (1) to "very true” (5). Scores can range from 14 to 70, and scores in the investigation covered the entire range, with $M=31.35$ and $S D=12.83$. The Religious Doubt Scale had a Cronbach’s alpha of .92. In the present study, the Religious Doubt Scale was strongly negatively correlated with the measures of religiousness and spirituality (see Table 1 , Appendix A: range of $r=-.569$ to -.673$)$.

Trait anxiety. Trait anxiety was measured using the 20-item Trait Anxiety subscale of the State-Trait Anxiety Inventory for adults (STAI-T). It was designed to investigate how uneasy individuals generally feel. Participants indicate how often they feel particular ways on a four point Likert-type scale ranging from “almost never” (1) to “almost always” (4). Scores can range from 20 to 80 . They ranged from 20 to 69 in the present study, with $M=37.26$ and $S D=10.22$. The Trait Anxiety subscale of the STAI had a Cronbach’s alpha of .93.

Death anxiety. Death anxiety was measured using two different measures, the Death Anxiety Scale-Extended (DAS-E; Templer et al., 2006) and the Death Anxiety Inventory (DAI; Tomás-Sábado \& Gómez-Benito, 2005), which were very highly correlated in the present study (see Table 1, Appendix A: $r=.812$ )

The DAS-E is a 51-item questionnaire that asks participants to indicate whether they believe statements made about death and dying are true (1) or false (0) for them. Included in the questionnaire are statements about general fear of death and specific scenarios involving personal death and witnessing death, as well as statements about pain and suffering. The scale was developed to add to the diversity of content found in the original DAS by adding 36 new statements, reduced from 63 after an item analysis, to the original 15 statements (Templer, 1970). The original DAS had high three-week test-retest reliability (.83) and a $K R-20$ coefficient of .76. 
It was validated by comparing scores on the DAS between state hospital patients who had verbalized concerns about death to nurses or chaplains with scores from control participants, where the state hospital patients scored significantly higher. In previous investigations, the DASE has good internal consistency $(\mathrm{KR}-20=.92)$ and was validated by comparing scores on the DAS and DAS-E for American, Kuwaiti, and Sudanese college students (Templer et al., 2006). Also, the new items correlated strongly with the original items $(r=.64)$. Scores can range from 0 to 51 , and the range was 0 to 48 in the current investigation, with $M=13.33$ and $S D=9.42$. The Death Anxiety Scale-Extended had a KR-20 of .93.

The DAI is a 20-item questionnaire that can be used in a true (1)-false (0) format, which was used in the present study, or six-point Likert-style format ranging from totally agree to totally disagree. Similar to the DAS, the statements include references to the idea of death and to objects and locations associated with death (e.g., coffins and cemeteries). As mentioned earlier, it was originally developed to investigate death anxiety among Spanish-speaking individuals, but has been translated into English. Previous investigations have found that the DAI has a fourweek test-retest correlation of .94, a Cronbach’s alpha of .90, and correlation of .79 with Templer’s DAS (Tomás-Sábado \& Gómez-Benito, 2005). Scores for the DAI could range from 0 to 20, and scores in the present investigation covered the entire range, with $M=5.18$ and $S D=$ 4.08. The $K R-20$ for the DAI in the present investigation was .85. Additionally, in TomásSábado and Gómez-Benito’s investigation, a factor analysis indicated that the statements could be separated into five significant factors: Externally Generated Death Anxiety, Meaning and Acceptance of Death, Thoughts about Death, Life after Death, and Brevity of Life.

Tomás-Sábado, Gómez-Benito, \& Limonero (2005) published a revision of the DAI in which they dropped three items to improve the psychometrics of their measure. This resulted in a 
17-item measure with four significant factors they entitled Externally Generated Death Anxiety, Death Acceptance, Death Finality, and Thoughts about Death. While this did improve the psychometrics of the measure for their study (Cronbach's alpha for the DAI $=.89$, for the Revision $=.92)$, in the present study, the Cronbach's alpha for the 20-item version $(\alpha=.85)$ was better than for the 17-tem version $(\alpha=.83$ ). The analyses reported below were conducted using both the 20- and 17-item versions, with the statistical conclusions remaining the same for every analysis. The results reported below are from the analyses conducted using the 20-item version, as it had the better internal consistency in the present study.

\section{Design and Procedure}

Using SONA, an online data collection system, participants were first presented with an informed consent form. At that point, participants had the option to decline or continue participation, which indicated their consent. After consenting, participants were presented with the above mentioned questionnaires, with the opportunity to decline answering any question they did not wish to answer. The first questionnaire the participants filled out was the Future Time Perspective Scale, followed by the Daily Spiritual Experiences Scale, the Religious Meaning Scale, the Trait Anxiety Subscale of the State-Trait Anxiety Inventory, the Religious Doubts Scale, the Religious Beliefs Scale, the Death Anxiety Scale-Extended, the Organizational Religiousness Scale, the Death Anxiety Inventory, and the demographics questionnaire, respectively. Additionally, at the beginning and end of the online survey, contact information for mental services was provided for those individuals who may have needed it.

To collect the data, two identical surveys were used on SONA: one for the younger adults and one for the middle and older adults. Two surveys were used due to the proprietary nature of the STAI. If only one survey had been used, the fear was that all of the permissions to use the 
STAI would have been used quickly by younger adults. The use of two surveys allowed for confirmation that age comparisons would be possible, rather than having the entire sample consist of younger adults. The survey for the young adults was entitled "Religiousness and Future Time Perspective among Adults,” while the survey for the middle-aged and older adults was entitled "Perspectives on Life and Religiosity.” The word “death” was avoided in the title so as not to cause potential participants to avoid the study. However, to counteract the avoidance of the word in the title, an extensive explanation of the nature and interests of the study, including death anxiety and what the questions would ask, was provided prior to asking participants to consent.

\section{Chapter 5: Results}

The results are organized according to hypotheses and the associated analyses used to test those hypotheses. For the MANOVA and each of the ANOVAs, the post hoc tests that were conducted were the Scheffé, Tukey, and Bonferroni tests, with the statistical conclusions being identical. The Scheffé test is reported because it is the most conservative of the tests and, given the number of analyses conducted for this study, the familywise error rate may have been somewhat high.

\section{Age and Gender Differences in Death Anxiety}

Both gender (hypothesis 1a) and age (1b) differences in death anxiety were anticipated, with females expected to have greater death anxiety than males and each older age group expected to have less death anxiety than the younger age groups. Hypotheses $1 \mathrm{a}$ and $1 \mathrm{~b}$ were tested using a 2 (gender) by 3 (age group) factorial MANOVA with the death anxiety questionnaires (the DAS-E and the DAI) as the dependent variables. The overall analysis generally supported the hypotheses, as young adults had significantly higher death anxiety than 
the other two age groups and females had significantly higher death anxiety than males using both measures.

Concerning the Death Anxiety Scale-Extended (Appendix B: Table 2, Appendix O: Figure 1), a significant main effect for gender $(F(1,267)=8.41, p=.004)$ was found, such that females reported greater death anxiety. Additionally, a significant main effect for age group ( $F$ $(2,267)=10.25, p<.001)$ was found. The Scheffé test indicated that, while young adults had greater death anxiety than middle-aged adults $(p<.001)$ and older adults $(p<.001)$, middle-aged adults and older adults did not significantly differ $(p=.179)$. The age group by gender interaction was not significant $(F(2,267)=1.35, p=.262)$.

Results concerning the Death Anxiety Inventory (Appendix B: Table 2, Appendix P: Figure 2) were very similar. There was a significant main effect for gender $(F(1,267)=6.84, p=$ .009), with females having greater death anxiety. There was also a significant main effect for age group $(F(2,267)=10.74, p<.001)$, with the Scheffé test indicating that young adults had significantly greater death anxiety than middle-aged adults $(p<.001)$ and older adults $(p<.001)$, and that middle-aged adults had significantly greater death anxiety than older adults $(p=.008)$. Like the results with the Death Anxiety Scale-Extended, the age group by gender interaction was not significant $(F(2,267)=1.74, p=.178)$.

\section{Age and Gender Differences in Religious Doubt}

Gender (hypothesis 2a) and age (2b) differences were expected in religious doubt, as males were expected to express more religious doubt, and a main effect for age was expected, such that older adults would express less religious doubt than middle-aged adults, who would express less religious doubt than young adults. A 2 (gender) by 3 (age group) factorial ANOVA was conducted, with scores on the Religious Doubts Scale as the dependent variable, and both 
hypotheses were generally supported (Appendix C: Table 3, Appendix Q: Figure 3). There were significant main effects for gender $(F(1,265)=7.55, p=.006)$, with males expressing greater religious doubt, and age group $(F(2,265)=7.57, p=.001)$. The Scheffé test indicated that, although middle-aged adults and older adults did not significantly differ ( $p=.128)$, young adults reported more religious doubt than middle-aged adults $(p=.026)$ and older adults $(p<.001)$. The age group by gender interaction was not significant $(F(2,265)=0.20, p=.820)$.

\section{Age and Gender Differences in Future Time Perspective}

A 2 (gender) by 3 (age group) factorial ANOVA was used to examine potential gender (hypothesis 3a) and age differences (3b) in future time perspective (using the Future Time Perspective Scale), as males were expected to report greater future time perspective, and a main effect for age was expected, such that older adults would report having a more compressed (shorter) future time perspective than middle-aged adults, who would report having a more compressed future time perspective than young adults. The gender hypothesis was not supported, but the age hypothesis was partially supported (Appendix D: Table R, Appendix R: Figure 4). The age group main effect was significant $(F(2,267)=14.09, p<.001)$. Further examination of the age group main effect (using the Scheffé test) revealed that, while young adults had significantly greater future time perspective than middle-aged adults $(p<.001)$ and older adults $(p<.001)$, the middle-aged and older adults did not significantly differ $(p=.650)$. However, neither the gender main effect $(F(1,267)=0.94, p=.332)$, nor the gender by age group interaction was significant $(F(2,267)=0.05, p=.953)$.

\section{Age and Gender Differences in Trait Anxiety}

Gender (hypothesis 4a) differences were expected in trait anxiety, with females expected to report greater trait anxiety. Similarly, age differences were hypothesized (hypothesis 4b), with 
older adults expected to report lower trait anxiety than middle-aged adults, who would report lower trait anxiety than young adults. A 2 (gender) by 3 (age group) factorial ANOVA was conducted, with scores on the Trait Anxiety subscale of the State-Trait Anxiety Scale as the dependent variable. The age hypothesis was partially supported (Appendix E: Table 5, Appendix S: Figure 5), as the main effect for age group was significant $(F(2,267)=5.20, p=.006)$, and the Scheffé test revealed that young adults had higher trait anxiety than older adults $(p<.001)$, but middle-aged adults did not significantly differ from young adults $(p=.065)$ or older adults $(p$ $=.079)$. The gender hypothesis was not supported $(F(1,267)=0.66, p=.418)$, and the gender by age interaction was not significant $(F(2,267)=0.30, p=.745)$.

\section{Age and Gender Differences in Religiousness and Spirituality}

A 2 (gender) by 3 (age group) factorial MANOVA was used to examine potential gender (hypothesis 5a) and age differences (5b) in religious meaning (using the Religious Meaning Scale), religious beliefs (Religious Beliefs Scale), organizational religiousness (5-item organizational religiousness scale), and spirituality (Daily Spiritual Experiences Scale). Females were expected to report higher levels on each of the religiousness and spirituality variables (religious meaning, religious beliefs, organizational religiousness, and spirituality), while a main effect for age was expected, such that older adults would report higher levels of religiousness and spirituality than middle-aged adults, who would report higher levels of religiousness and spirituality than young adults. The hypotheses were generally supported.

Religious meaning. Concerning religious meaning (Appendix F: Table 6, Appendix T: Figure 6), the main effects for gender $(F(1,263)=12.94, p<.001)$, where females reported higher religious meaning, and age $(F(2,263)=6.66, p=.002)$ were significant. The Scheffé test indicated that young adults reported significantly lower religious meaning than middle-aged 
adults ( $p=.017)$ and older adults $(p<.001)$, but middle-aged and older adults did not significantly differ $(p=.316)$. The interaction was not significant $(F(2,263)=1.37, p=.257)$.

Religious belief. Concerning religious belief (Appendix F: Table 6, Appendix U: Figure 7), the main effects for gender $(F(1,263)=19.44, p<.001)$, where females reported higher levels of religious belief, and age group $(F(2,263)=7.17, p=.001)$ were significant. Further examination of the age group main effect (using the Scheffé test) revealed that young adults reported significantly lower levels of religious belief than middle-aged adults $(p=.006)$ and older adults ( $p=.003$ ), but middle-aged and older adults did not significantly differ $(p=.800)$. The interaction was not significant $(F(2,263)=0.75, p=.475)$.

Organizational religiousness. The results concerning organizational religiousness (Appendix F: Table 6, Appendix V: Figure 8) indicated that the main effects for gender (F $(1,263)=6.66, p=.010)$, with females reporting higher organizational religiousness, and age group $(F(2,263)=7.22, p=.001)$ were significant. The Scheffé test indicated that, like the other religiousness variables, young adults had significantly lower levels of religious belief than middle-aged adults $(p=.001)$ and older adults $(p<.001)$, but middle-aged and older adults did not significantly differ $(p=.518)$. The interaction was not significant $(F(2,263)=1.16, p=.317)$

Spirituality. Finally, concerning spirituality (Appendix F: Table 6, Appendix W: Figure 9), the main effects for gender $(F(1,263)=16.04, p<.001)$, where females reported higher levels of spirituality, and age group $(F(2,263)=7.94, p<.001)$ were significant. Further examination of the age group main effect (using the Scheffé test) revealed that young adults reported significantly lower levels of spirituality than middle-aged adults $(p=.006)$ and older adults $(p<.001)$, but middle-aged and older adults did not significantly differ $(p=.223)$. The interaction was not significant $(F(2,263)=1.28, p=.279)$. 


\section{Differences in Death Anxiety as a Function of Religious Meaning}

Hypothesis 6, that religious meaning would have a curvilinear relation with death anxiety, was examined using a Spearman's rho, an ANOVA framework, and curve estimation. Initially, the data were plotted with religious meaning on the horizontal axis and death anxiety plotted as the dependent variable using both the DAS-E (Appendix X: Figure 10) and the DAI (Appendix Y: Figure 11).

Next, a Spearman's rho was calculated to test for a nonparametric correlation between religious meaning and death anxiety, also using the DAS-E and the DAI. Using Pearson's $r$, religious meaning was not significantly correlated with scores on the DAS-E $(r=-.03, p=.602)$ or with scores on the DAI $(r=-.03, p=.576)$. However, using Spearman's rho, religious meaning had small but significant correlations with scores on the DAS-E $(r h o=-.15, p=.016)$ and with scores on the DAI (rho $=-.12, p=.046)$.

Then, tests of trend were conducted, where One-Way ANOVAs with participants broken into three groups based on religious meaning predicting death anxiety (Appendix G: Table 7) scores using both the DAS-E0 and the DAI. The groups were sample-dependent one-thirds, such that each group, low $(N=91$, range $=20-64, M=46.07, S D=15.59)$, medium $(N=91$, range $=$ 65-80, $M=74.53, S D=4.26)$, and high $(N=86$, range $=81-100, M=90.15, S D=6.04)$, consisting of approximately one-third of the sample. Using the DAS-E, both linear $(F(1,269)=$ $6.29, p=.013)$ and quadratic trends $(F(1,269)=4.41, p=.037)$ were significant, with the graph (Appendix Z: Figure 12) confirming an inverted quadratic trend, such that those who reported the highest and lowest religious meaning were lowest in death anxiety, and those who reported intermediate levels religious meaning scoring highest. Using the DAI, neither the linear ( $F$ $(1,269)=3.57, p=.060)$ nor the quadratic trends $(F(1,269)=3.23, p=.074)$ were significant, 
although the graph (Appendix AA: Figure 13) suggests a similar trend to that found using the DAS-E.

Finally, curve estimations were conducted with religious meaning predicting scores on each of the death anxiety measures. Using the DAS-E (Appendix H: Table 8, Appendix AB: Figure 14), when the models were conducted concurrently, the linear $(\beta=3.19, p=.011)$ and quadratic models $(\beta=-5.51, p=.011)$ were significant, while a cubic model was not significant $(\beta=2.33, p=.142)$. Using the DAI (Appendix H: Table 8, Appendix AC: Figure 15), also when the models were conducted concurrently, none of the three models, linear $(\beta=2.19, p=.082$ ), quadratic $(\beta=-3.37, p=.227)$, and cubic $(\beta=1.15, p=.471)$, were significant.

Overall, results are somewhat mixed concerning the curvilinear relation of religious meaning with death anxiety. When using the DAS-E, the above analyses suggest that there is an inverted quadratic curvilinear relation between religious meaning and death anxiety, with a small linear relation also partially involved. However, when using the DAI, the conclusions aren't as clear. The Spearman’s rho suggests a nonparametric relation, but neither the tests of trend nor the curve estimation could confirm a trend similar to that found when using the DAS-E.

\section{Age Differences in Death Anxiety}

Hypothesis 7, that age would not have a curvilinear relation with death anxiety, was examined using a Spearman's rho, an ANOVA framework, and curve estimation. Initially, the data were plotted with age on the horizontal axis and death anxiety plotted as the dependent variable using both the DAS-E (Appendix AD: Figure 16) and the DAI (Appendix AE: Figure 17).

Next, a Spearman's rho was calculated to test for a nonparametric correlation between age and death anxiety, using both the DAS-E and the DAI. When testing the correlation between 
the death anxiety measures and age, the Pearson's $r$ between age and DAS-E scores $(r=-.39, p<$ $.001)$ and age and scores on the DAI $(r=-.39, p<.001)$ were significant, and were similar to the Spearman's rho between age and DAS-E $(r h o=-.40, p<.001)$ and age and scores on the DAI $(r h o=-.40, p<.001)$.

Then, tests of trend were conducted with age group predicting death anxiety scores using both the DAS-E and the DAI. With the DAS-E (Appendix I: Table 9, Appendix AF: Figure 18), the linear trend was significant $(F(1,270)=34.72, p<.001)$, while the quadratic trend was not $(F(1,270)=1.55, p=.215)$. Essentially identical findings were found using the DAI (Appendix I: Table 9, Appendix AG: Figure 19), as the linear trend was significant $(F(1,270)=43.76, p<$ $.001)$, but the quadratic trend was not $(F(1,270)=0.003, p=.957)$.

Finally, curve estimations were conducted with age predicting scores on the death anxiety measures. With the DAS-E (Appendix J: Table 10, Appendix AH: Figure 20), and with the models conducted concurrently, none of the three models, linear $(\beta=0.30, p=.843)$, quadratic $(\beta=-1.46, p=.616)$, and cubic $(\beta=0.79, p=.585)$, were significant. Similarly, with the DAI (Appendix J: Table 10, Appendix AI: Figure 21) and the models conducted concurrently, the three models, linear $(\beta=0.79, p=.606)$, quadratic $(\beta=-2.40, p=.412)$, and cubic $(\beta=1.26, p=$ .386), were not significant.

Given the strength of the linear relation found when conducting the Pearson's $r$ and the non-significant trend analyses and curve estimations, it appears that the hypothesis (that age would have a curvilinear relation with death anxiety) was not supported.

\section{Age Differences in Trait Anxiety}

Hypothesis 8, that age would not have a curvilinear relation with trait anxiety, was also examined using a Spearman’s rho, an ANOVA framework, and curve estimation. The 
scatterplot, with age on the horizontal axis and scores on the Trait Anxiety subscale of the StateTrait Anxiety Inventory plotted as the dependent variable, can be found in Appendix AJ: Figure 22.

Next, a Spearman's rho was calculated to test for a nonparametric correlation between age and trait anxiety. Using Pearson's $r$, a small-to-moderate relation between age and trait anxiety was found $(r=-.28, p<.001)$. A similar relation was found using Spearman's $r h o$ ( $r h o=$ $-.30, p<.001)$

Then, tests of trend were conducted with age group predicting trait anxiety scores (Appendix K: Table 11, Appendix AK: Figure 23). While the linear trend was significant ( $F$ $(1,264)=19.83, p<.001)$, the quadratic trend was not $(F(1,264)=0.072, p=.788)$.

Finally, a curve estimation was conducted with age predicting trait anxiety scores (Appendix L: Table 12, Appendix AL: Figure 24). With the models conducted concurrently, none of the three models, linear $(\beta=0.70, p=.675)$, quadratic $(\beta=-1.60, p=.613)$, and cubic $(\beta$ $=0.64, p=.683)$, were significant.

Overall, the findings from the above analyses support the hypothesis (that age will not have a curvilinear relation with trait anxiety), as the trend analyses and curve estimations were not significant.

\section{Testing a Model Predicting Death Anxiety}

In order to develop and test a more comprehensive predictive model of death anxiety (hypothesis 9), two hierarchical linear regressions were conducted predicting death anxiety, where one predicted scores on the DAS-E and the other predicting scores on the DAI. The Beta weights were noted after each step. Gender (a negative relation expected, as females were coded as “0” and males were coded as “ 1 ”) and age (an expected negative relation) were entered in the 
first step. Religious doubt (positive) was entered in the second step because it was the primary variable of interest. Future time perspective (negative) and trait anxiety (positive) were entered in the third step. Finally, spirituality (negative), religious meaning (negative), religious beliefs (negative), and organizational religiousness (negative) were entered to examine what specific aspects of religion were related to death anxiety (as well as their relative influence) and to investigate whether they mediated the relations of gender and age with death anxiety. In the analyses, the difference between $R^{2}$ and Adjusted $R^{2}$ never exceeded .025, so only $R^{2}$ values are reported.

Regression predicting the Death Anxiety Scale-Extended. Results from the regression predicting scores on the Death Anxiety Scale-Extend (Appendix M: Table 13) were not quite as expected. The first model was significant $\left(F(2,260)=34.45, p<.001, R^{2}=.209\right)$, and both gender and age were significant predictors. The second model (adding religious doubt as a predictor) was significant $\left(F(3,259)=27.45, p<.001, R^{2}=.241 ; F \Delta(1,259)=10.84, p=.001\right.$, $R^{2} \Delta=.032$ ), with gender, age, and religious doubt being significant predictors. The third model (adding future time perspective and trait anxiety) was significant $\left(F(5,257)=28.23, p<.001, R^{2}\right.$ $\left.=.355 ; F \Delta(2,257)=22.56, p<.001, R^{2} \Delta=.113\right)$. Gender, age, and trait anxiety were significant predictors, while religious doubt and future time perspective were not significant. The fourth and final model (adding the religiousness/spirituality variables) was also significant $(F(9,253)=$ 17.78, $\left.p<.001, R^{2}=.387 ; F \Delta(4,253)=3.40, p=.010, R^{2} \Delta=.033\right)$. The significant predictors were gender, age, religious doubt, trait anxiety, and religious beliefs. The non-significant predictors were future time perspective, spirituality, religious meaning, and organizational religiousness. The results suggest that the age and gender relations with death anxiety are partially mediated by religious doubt, trait anxiety, and religious beliefs, given that the 
standardized beta weights decreased for age and gender from the first to last models, although future time perspective, spirituality, religious meaning, and organizational religiousness were not significant predictors of death anxiety. Additionally, the results suggest that death anxiety is uniquely predicted by religious beliefs and religious doubts, even with the inclusion of important demographic and personality characteristics.

Regression predicting the Death Anxiety Inventory. Results from the regression predicting scores on the Death Anxiety Inventory (Appendix N: Table 14) were almost identical to the results from the regression predicting scores on the Death Anxiety Scale-Extended, as significant predictors are identical in each model and the standardized beta weights are very similar. The first model was significant $\left(F(2,260)=32.79, p<.001, R^{2}=.201\right)$, and both gender and age were significant predictors. In the second model (adding religious doubt; $F(3,259)=$ 26.52, $\left.p<.001, R^{2}=.235 ; F \Delta(1,259)=11.836, p=.001, R^{2} \Delta=.034\right)$, gender, age, and religious doubt were significant predictors. The third model (adding future time perspective and trait anxiety) was significant $\left(F(5,257)=25.55, p<.001, R^{2}=.332 ; F \Delta(2,257)=18.66, p<.001\right.$, $\left.R^{2} \Delta=.097\right)$. Gender, age, and trait anxiety were significant predictors, while religious doubt and future time perspective were not significant. In the fourth model (adding the religiousness/spirituality variables; $F(9,253)=17.34, p<.001, R^{2}=.382 ; F \Delta(4,253)=5.07, p=$ $.001, R^{2} \Delta=.050$ ), the significant predictors were gender, age, religious doubt, trait anxiety, and religious beliefs. The non-significant predictors were future time perspective, spirituality, religious meaning, and organizational religiousness. Once again, the results suggest partial mediation of the relation of age and gender with death anxiety, religious doubt, trait anxiety, and religious beliefs as the significant predictors and future time perspective, spirituality, religious meaning, and organizational religiousness as non-significant predictors. Also, the model 
predicting DAI scores also suggests that religious beliefs and religious doubts uniquely predict death anxiety, even with the inclusion of important demographic and personality characteristics.

Overall, it appears that the age and gender relations with death anxiety were only partially mediated by the other variables in either regression. Instead, the age and gender relations remained, and the variables believed to be potential mediators actually accounted for variance above and beyond age and gender in both regressions, with religious belief, religious doubt, and the demographic and personality variables remaining significant.

\section{Chapter 6: Discussion}

Findings from the current investigation are discussed in terms of theories that may guide interpretation of findings, implications of significant results, and methodological issues in the study of religiousness and death anxiety. First, age differences in the primary variables of interest are discussed.

A theoretical approach to the discussion of age differences in death anxiety, religiousness, and religious doubt is Carstensen’s (1992) Socioemotional Selectivity Theory, although it may be applied in a slightly different context than is typical. The theory suggests that our motivations for social interaction differ depending upon our needs. Specifically, in early adulthood, when our motivations may be more focused upon the gathering of information, individuals will seek social interaction from individuals who can provide that information. Toward older adulthood, when gathering information may be less valuable and attaining emotional support may be of greater interest, individuals will seek social interaction from individuals who provide emotional support and avoid social interaction that is more emotionally negative. 
This approach (that, starting in young adulthood, with age individuals seek that which is emotionally supportive and avoid that which is emotionally negative) may help explain the age differences in death anxiety, religiousness, and religious doubt. Middle-aged and older adults reported less death anxiety, greater religiousness/spirituality, and less religious doubt than younger adults. Thus, they may be emphasizing something that provides emotional comfort, such as religiousness and spirituality, as they been found to be positively associated with several aspects of well-being (e.g., Wink \& Dillon, 2003), while avoiding or minimizing feelings and/or thoughts that may provoke negative emotions, such as death anxiety, which has been found to be negatively associated with psychological well-being (e.g., Rappaport et al., 1993), or religious doubt, which has been associated with poorer physical and mental health (e.g., Krause \& Wulff, 2004; Krause, 2006). Therefore, the approach of Carstensen’s (1992) Socioemotional Selectivity Theory may apply outside of its typical realm to assist in interpretation of age differences in findings.

However, there is one potential caveat that must be considered before assuming that these age differences are developmental in nature. It is quite possible that each of these age differences, and especially those associated with religious belief and religious doubt, are due to cohort differences, rather than developmental differences. Specifically, current cultural situations may influence younger generations to more questioning of religion. Koenig, McGue, and Iacono (2008) investigated religiousness among adolescents (assessing them at 14 and 18 years of age) and young adults (assessing them at 20 and 25 years of age), finding that levels of religiousness had declined significantly in each group from the first assessment to the second, especially concerning religious service attendance. Similarly, Pascarella and Terenzini (1991), when reviewing literature on change in young adults while in college, found that religiousness 
significantly declined from the beginning to the end of the college years, once again, emphasizing that the primary change was in religious attendance. Additionally, the Pew Research Forum (2010) found that each successive generation has reported lower levels of religiousness in young adulthood than each previous generation. However, they also found that, as those previous generations age, they have become more religious.

The findings showing that younger adults were less religious than older individuals, now and when those older individuals were younger, may suggest that experiences that younger generations have may differ from those of older generations. Perhaps the college experience, more available for young adults now than for previous generations in young adulthood, is influencing young adults' religiousness. It may foster critical thinking, an idea supported by Pascarella and Terenzini's (1991) review, which may lead to more critical review of religion, more doubts, and less religiousness. Perhaps the greater availability of information about diverse viewpoints, through resources such as the internet or interaction with individuals from diverse backgrounds (King \& Furrow, 2004), leads young adults to think about views other than those with which they were raised, possibly leading them to question those views more than older generations. Thus, considering possibilities like these and the cross-sectional nature of the data in the current investigation, both theoretical and cohort differences should be considered.

Concerning other findings from this study, each of the above mentioned relations played a role in the primary goal of this current investigation, which was to test whether several variables (religious doubt, future time perspective, trait anxiety, spirituality, religious meaning, religious beliefs, and organizational religiousness) mediated the relations of age and gender with death anxiety. While results indicate that those variables only partially mediate the relations, they 
do still provide interesting findings regarding which variables are significant predictors of death anxiety.

Specifically, a personality variable, trait anxiety, was found to be a relatively strong, significant predictor of death anxiety. It had the strongest standardized beta with the DAS-E $(\beta=$ $0.33)$ and tied for second strongest (along with age) with DAI $(\beta=0.30)$. It follows logically that those who are generally uneasy will also experience uneasiness in reference to their mortality. Also, a few of the items in the Trait subscale of the STAI generally ask respondents to report if they are upset about how their life is going. Being dissatisfied with life (possibly feeling as if you are not living up to expectations) may invoke anxiety about passing away unaccomplished, after what they may perceive as a subpar life. Finally, trait anxiety may be a general expression of feelings from a specific anxiety. In that vein, if someone experiences significant death anxiety, it may also mean expression of a general, or trait, anxiety.

Most interestingly, two variables, religious belief and religious doubt, were unique predictors of death anxiety, even after the inclusion of the two demographic variables (age and gender) and the personality variable (trait anxiety). The positive relation between religious doubt and death anxiety suggests that being less certain of religious beliefs or of dedication to religious practices may result in greater death anxiety, whereas being certain may reduce death anxiety. Questioning core beliefs and cultural practices, especially those concerned with morality and mortality, like religion, may involve an existential crisis, which could cause anxiety. Conversely, awareness of mortality, an existential crisis in its own right, might provoke individuals to question core beliefs, such as religion.

Religious beliefs significance in predicting death anxiety may involve its ability to provide purpose and feelings of immortality. Researchers who have found somewhat similar 
findings (that religious beliefs are negatively related to death anxiety) have discussed this in terms of Terror Management Theory (TMT; Greenburg et al., 1986). TMT posits that humans are uniquely able to contemplate our own mortality, and this ability can lead to extreme emotional distress. However, we can manage the turmoil associated with awareness of the cessation of life using culturally-provided worldviews that offer purpose for life and feelings of immortality. From this point of view, religious beliefs are some of the relatively few worldviews that may be able to provide these necessities (Vail et al., 2010). In fact, religious texts and leaders often discuss those topics in great detail, providing guidance to religious followers. Thus, the moderately strong, negative relation between religious beliefs and death anxiety found in this study is of little surprise. Specifically, individuals who believe that their bodily life is not the end of their existence may be significantly less worried about the cessation of their bodily life. This is generally what has been found in numerous studies (e.g., Harding et al., 2005; Ochsmann, 1984; Templer \& Ruff, 1975; Thorson, 1991). Indirectly TMT may also explain the age difference in death anxiety discussed above. In the present study, as in other studies, older adults experienced less death anxiety than younger adults, and older adults reported higher levels of religiousness. It is possible that the higher levels of religiousness for older adults are the cause of the lower levels of death anxiety amongst older adults.

Terror Management Theory could also be used to interpret the positive relation between religious doubt and death anxiety. As mentioned above, from this perspective, culturallyprovided worldviews protect us from the uneasiness associated with the knowledge of our mortality. If we once again consider religious belief as a worldview that offers that protection, experiencing doubts about that worldview may threaten the support and buffering we receive from that worldview, and might even pull the pillars out from under that worldview, bringing the 
turmoil crashing down. Thus, experiencing religious doubt may result in increased death anxiety. Also, given that the causal directionality of the relation between religious doubt and death anxiety is indeterminable from the data in this study, it is quite possible that high levels of death anxiety could overwhelm a worldview like religion, and thus result in questioning of that worldview, which would still be consistent with TMT.

A final finding to consider from this study involved simultaneously investigating a hypothesis developed long ago and emphasizing multiple methodological concerns that should be addressed in future studies in various areas of research. The finding of interest here concerns testing the hypothesis that there would be a curvilinear (quadratic) relation between religious meaning and death anxiety, such that those lowest and highest in religious meaning would have the lowest death anxiety, and those who reported moderate religious meaning would have the highest death anxiety. Using the Death Anxiety Scale-Extended, results from a Spearman's rho, a one-way ANOVA with tests of trend, and a curve estimation take together suggest that there is indeed an inverted quadratic curvilinear relation between religious meaning and death anxiety, with those lowest and highest in religious meaning having the lowest death anxiety. Terror Management Theory has been discussed above to explain why those highest in religiousness may have lower death anxiety (the worldview may buffer individuals against the turmoil associated with awareness of one's own death). However, this seems like it would suggest that those who don't embrace that worldview would experience greater death anxiety, contrary to the findings from testing this hypothesis.

On the contrary, religion is likely not the only possible worldview that could provide a buffer against the distress of mortality salience. Perhaps non-religious worldviews, such as secular humanism, could provide the same protection. Secular humanism is a worldview that, 
while rejecting religious dogma and ideas of the supernatural, still discusses purpose for life and immortality (Council for Secular Humanism, 1980), although in very different sense than religion. Specifically, some of the Council for Secular Humanism’s basic tenets emphasize searching for truth through reason with evidence and building a better world for people of all faiths and ideas, and followers of those tenets may view the longer lasting social contributions they make during life as a version of immortality. Thus, from the perspective of Terror Management Theory, Secular Humanism may fit the definition of a worldview that can protect individuals from the anxieties of mortality, just as religion does. Following from that, the findings from the curvilinear relation between religious meaning and death anxiety actually suggest that individuals who have made a commitment, whether for or against religion, have the least death anxiety, whereas those without that firm commitment have the most.

The methodological concerns raised from the testing of this hypothesis are twofold. First, it emphasizes the need to test whether relations between variables are nonlinear. In research concerning importance and strength of religiousness and death anxiety, research has found mixed results. Some found no linear relation (e.g., Templer \& Dotson, 1970), others found a negative association (e.g., Alvarado et al., 1995), still others found a positive relation (e.g., Thorson, 1991), and yet others found (Wink \& Scott), or concluded after a review (Leming, 1980), that there was a non-linear relation. The inconsistencies concerning linear relations might be explained by non-linear relations, and testing for non-linear relations is sadly not necessarily commonplace. Many of our available statistical procedures assume or are dependent upon linear relations. However, non-linear relations still exist and are important, as evidenced by the curvilinear relation found in this study between religious meaning and death anxiety. Statistical procedures exist to test for such relations, such as tests of trend and curve estimations, and 
should be used to do so, especially when linear relations are not significant between variables believed to be related.

The second methodological concern from the testing of this hypothesis actually attacks conclusions concerning the above mentioned curvilinear relation. In the current study, the curvilinear relation was found between religious meaning and death anxiety, as measured by the Death Anxiety Scale-Extended (DAS-E; Templer et al., 2006). However, the findings could not be replicated with the use of the Death Anxiety Inventory (DAI; Tomás-Sábado \& GómezBenito, 2005). Using the DAI, the Spearman's rho was significant ( $r h o=-.121, p=.046$ ), but the tests of trend and the curve estimation did not find significant curvilinear relations. While you could argue that the two measures differ slightly, as the DAS-E generally makes statements that are specific to personal death (e.g., I fear dying a painful death.) and scenarios about personal death (e.g., I fear drowning.) and the DAI includes statements about imagery associated with death (e.g., Coffins make me nervous.), which could explain the different findings, the two are highly correlated $(r=.812)$ and are clearly concerned with thoughts about death. Thus, given that the finding could not be replicated with another measure of death anxiety, the curvilinear relation should be considered carefully and investigated further. This emphasizes that we should be using multiple measures of our variables to be more certain that our conclusions are indeed correct and that we should be paying close attention to convergent validity.

One last methodological concern that the present study emphasizes is the need for multidimensional measurement of religiousness and spirituality. Researchers have emphasized this of late (e.g., Fetzer Institute, 1999; McFadden, Brennan, \& Patrick, 2003), and findings from the current study support this approach. Although the four aspects of religiousness and spirituality that were measured in this study (religious meaning, religious beliefs, organizational 
religiousness, and daily spiritual experiences), where relatively highly related (correlations ranging from .589 to .856$)$, their relations with death anxiety varied. Religious belief was a significant predictor of death anxiety in the regressions, but organizational religiousness (which has been the most frequently used approach to measuring religiousness), spirituality, and religious meaning were not significant predictors. However, using the DAS-E, but not the DAI, religious meaning was curvilinearly related to death anxiety. Thus, a multidimensional approach to religiousness and spirituality is warranted.

As with any study, there are limitations to the findings. The first limitation concerns the sample. The young adults were a convenience sample composed of undergraduates. The middle and older adults were recruited primarily through referrals from the undergraduates and middleaged and older adults who had participated; however, less than 10\% (133 out of approximately 1700) of those who received invitations to participate actually participated. Thus, it is highly unlikely that this sample is representative of the general population.

Second, the mode of participation (online survey) may have skewed the sample and the findings. While most young adults and middle adults are internet savvy, only about 38\% of older adults use the internet (Pew Internet \& American Life Project, 2009). The use of an online survey immediately excluded all individuals who were not internet users. It is possible that, especially among older adults, internet users and non-users might significantly differ on the variables of interest.

Third, the study was cross-sectional. Thus, as mentioned above, differences found between age groups may be due to developmental changes or cohort differences, making interpretation of findings difficult. Longitudinal data could potentially allow for a better understanding of developmental trends in religiousness and death anxiety, and it might allow us 
to determine if trends seen amongst younger generations (such as lower religiousness among young adults) are cohort effects, such that each generation will express less religiousness, or part of a developmental trend, such that religiousness is lowest in young adulthood, but will increase with age, as suggested by the Pew Research Forum (2010).

Fourth, the correlational nature of the findings makes determination of causal relations and direction difficult as well. As mentioned in the discussion of the relation between religious doubt and death anxiety, it is possible that feelings of doubt about religion make individuals experience more death anxiety, and it is also possible that feeling death anxiety makes individuals doubt religious beliefs. Once again, longitudinal research may help answer which, if either, is true. Longitudinal research may allow researchers to recognize which came first, and an understanding of temporal order is one of the issues needed in order to establish causation between variables (Baltes, Reese, \& Nessleroade, 1988). Also, it is important to keep in mind that correlations between two variables may actually be caused by their relation to a third variable.

Terror Management Theory (TMT; Greenburg et al., 1986) posits that death anxiety may provoke religious belief, and experimental research suggests that this may be true (e.g., Vail et al., 2010). However, recall that in death anxiety-risk-taking research, preexisting death anxiety and provoked death anxiety result in contrasting outcomes. Thus, the experimentally-induced death anxiety may not provide much insight into trend in developing death anxiety. Thus, it is quite possible that increases in religious belief with age precede declines death anxiety, with specific beliefs like belief in an afterlife, which research already suggests is related to lower death anxiety (e.g., Harding et al., 2005; Ochsmann, 1984; Templer \& Ruff, 1975; Thorson, 1991), possibly making death anxiety less relevant. 
Despite the limitations of this correlational, cross-sectional research, there are important findings involved. Identification of cohort differences can be just as valuable as identification of developmental changes. Cohort differences may suggest desensitization to death with experience. Additionally, correlational research helps identify predictors, which may be of particular importance in death anxiety research, as research has found relations between death anxiety and negative outcomes, like risk-taking behavior and poorer psychological and physical health.

Fifth, no correction was made for the non-independence of data. Given that referrals were used to recruit middle-aged and older adults, it is possible that non-independence may have influenced the data, perhaps causing the age groups to be more similar than independent samples would have been. However, only approximately half of the middle-aged and older adults were recruited through referrals. Thus, effects caused by the non-independence of data, if there were any, were likely to be small.

A final limitation involves the relative lack of findings that suggest significant differences between middle-aged and older adults. The only measure on which the Scheffé indicated a significant difference between middle and older adults was the Death Anxiety Inventory. In previous studies investigating age differences in death anxiety, researchers have consistently demonstrated that older adults have significantly less death anxiety than younger adults (e.g., Rasmussen \& Brems, 1996; Thorson, 1991). In fact, researchers have found that the oldest old have significantly less death anxiety than those considered the youngest old (Bengston et al., 1977; Wu et al., 2002). Thus, age differences were likely to be found between middle and older adults using both measures of death anxiety, rather than just one. The ages used for the age groups were relatively typical for cross-sectional research. Sixty years of age is often used as the 
differentiating age between middle-aged and older adults (e.g., Galt \& Hayslip, 1998), and the developmental tasks of 36- to 59-year-olds is generally seen as differing from the tasks of those 60 years of age and older. Larger samples of middle-aged and older adults may allow for a more in-depth exploration of within- and between-groups differences.

Future research should focus on a few specific directions. First, given that Tomás-Sábado and Gómez-Benito (2005) argue that their measure of death anxiety, the Death Anxiety Inventory, consists of five factors, a multidimensional approach to the study of religiousness and death anxiety should be taken. Perhaps the multiple facets of religiousness relate differently to the separate factors involved in death anxiety.

Second, research investigating religiousness and death anxiety should consider how the relations may vary with age. Given that levels of both religiousness and death anxiety vary from one age group to the next, it is possible that the specific aspects of religiousness that are related to death anxiety might also vary with age. Both Koenig et al. (2008) and Pascarella and Terenzini (1991) note that, while there appear to be general declines in religiousness over time among young adults, the declines are greatest in religious service attendance, an aspect of organizational religiousness. These differing rates of change in religiousness might lead to different aspects of religiousness being more important at different ages. Perhaps organizational religiousness is an important predictor of death anxiety among older adults but not young adults, as older adults are more likely to attend religious services than young adults.

Finally, the construct of religious doubt, and its relation with death anxiety, needs to be further examined. Measures of religious doubt should be investigated more thoroughly and subjected to a full psychometric battery. The lack of consistent measurement of religious doubt could hamper our understanding of the construct and its implications. Additionally, the 
implications of religious doubt should be further examined. While one group of researchers have consistently studied the relations between religious doubt and subjective well-being (Galek et al., 2007; Krause, 2006; Krause et al., 1999; Krause \& Wulff, 2004), this relation, as well as the relation between physical health and religious doubt, should be further examined. Furthermore, research suggests that religiousness is related to prosocial behavior (e.g., Saroglou, Pichon, Trompette, Verschuren, \& Dernelle, 2005); the impact of religious doubt on these types of behaviors should be investigated. 


\section{References}

Aday, R. H. (1985). Belief in afterlife and death anxiety: Correlates and comparisons. Omega: Journal of Death \& Dying, 15, 67-75.

Allport, G. W., \& Ross, J. M. (1967). Personal religious orientation and prejudice. Journal of Personality of Social Psychology, 5, 432-443.

Alvarado, K. A., Templer, D. I., Bresler, C., \& Thomas-Dobson, S. (1995). The relationship of religious variables to death depression and death anxiety. Journal of Clinical Psychology, $51,202-204$.

Baltes, P. B., Reese, H. W., \& Nessleroade, J.R. (1988). Life-span developmental psychology: Introduction to research methods. Hillsdale, NJ: Lawrence Erlbaum Associates.

Beck, J. R. (1981). Treatment of spiritual doubt among obsessing evangelicals. Journal of Psychology and Theology, 9, 224-231.

Bengston, V. L., Cuellar, J., \& Ragan, P. K. (1977). Stratum contrasts and similarities in attitudes toward death. Journal of Gerontology, 32, 76-88.

Berman, A. L., \& Hays, J. E. (1973). Relation between death anxiety, belief in afterlife, and locus of control. Journal of Consulting and Clinical Psychology, 41, 318.

Carstensen, L.L. (1992). Social and emotional patterns in adulthood: Support for socioemotional selectivity theory. Psychology \& Aging, 7, 331-338.

Carstensen, L.L., Isaacowitz, D.M., \& Charles, S.T. (1999). Taking time seriously: A theory of socioemotional selectivity. American Psychologist, 54, 165-181.

Cohen, A. B., Pierce, J. D., Chambers, J. A., Meade, R. M., Gorvine, B. J., \& Koenig, H. G. (2005). Intrinsic and extrinsic religiosity, belief in afterlife, death anxiety, \& life 
satisfaction in young Catholics and Protestants. Journal of Research in Personality, 39, 307-324.

Cotter, R. P. (2003). High risk behaviors in adolescence and their relationship to death anxiety and death personifications. Omega: Journal of Death \& Dying, 47, 119-137.

Council for Secular Humanism. (1980). A secular humanist declaration. Retrieved April 15, 2010, from http://www.secularhumanism.org/index.php?section=main\&page=declaration

D’Attilio, J. P., \& Campbell, B. (1990). Relationship between death anxiety and suicide potential in an adolescent population. Psychological Reports, 67, 975-978.

De Montaigne, M. S., \& Coste, P. (1685). That we are not to judge of man’s happiness before his death. In M. S. de Montaigne, P. Coste, \& C. Cotton (Eds.), The essays of Michael Seigneur de Montaigne (8th ed.), in 3 volumes, Vol 1 (pp. 65-69). London, England: J. Pote, E. Ballard, C. Bathurst, T. Davies, T. Payne, J. F. Rivington, C. Rivington, S. Crowder, \& T. Longman.

Devins, G. M. (1979). Death anxiety and voluntary passive euthanasia: Influences of proximity to death and experiences with death in important other persons. Journal of Consulting and Clinical Psychology, 47, 301-309.

Ens, C., \& Bond, J. B. (2007). Death anxiety in adolescents: The contributions of bereavement and religiosity. Omega: Journal of Death \& Dying, 55, 169-184.

Feingold, A. (1994). Gender differences in personality: A meta-analysis. Psychological Bulletin, 116, 429-456.

Ford, G. G., Ewing, J. J., Ford, A. M., Ferguson, N. L., \& Sherman, W. Y. (2004). Death anxiety and sexual risk-taking: Different manifestations of the process of defense. Current Psychology, 23, 147-160. 
Fortner, B. V., \& Neimeyer, R. A. (1999). Death anxiety in older adults: A quantitative review. Death Studies, 23, 387-411.

Furrow, J. L., King, P. E., \& White, K. (2004). Religion and positive youth development: Identity, meaning, and prosocial concerns. Applied Developmental Science, 8, 17-26.

Galek, K., Krause, N., Ellison, C. G., Kudler, T., \& Flannelly, K. J. (2007). Religious doubt and mental health across the lifespan. Journal of Adult Development, 14, 16-25.

Galt, C.P. \& Hayslip, B. (1998). Age differences in levels of overt and covert death anxiety. Omega: Journal of Death and Dying, 37, 187-202.

Gauthier, K. J., Christopher, A. N., Walter, M. I., Mourad, R., \& Marek, P. (2006). Religiosity, religious doubt, and the need for cognition: Their interactive relationship with life satisfaction. Journal of Happiness Studies, 7, 139-154.

Gibbs, H. W., \& Achterberg-Lawlis, J. (1978). Spiritual values and death anxiety: Implications for counseling with terminal cancer patients. Journal of Counseling Psychology, 25, 563569.

Gjesme, T. (1979). Future time orientation as a function of achievement motives, ability, delay of gratification, and sex. The Journal of Psychology, 101, 173-188.

Greenberg, J., Pyszczynski, T., \& Solomon, S. (1986). The causes and consequences of the need for self-esteem: A terror management theory. In R. F. Baumeister (Ed.), Public self and private self (pp. 189-212). New York, NY: Springer.

Harding, S. R., Flannelly, K. J., Weaver, A. J., \& Costa, K. G. (2005). The influence of religion on death anxiety and death acceptance. Mental Health, Religion, \& Culture, 8, 253-261.

Hayslip, B., Luhr, D.D., \& Beyerlein, M.M. (1991-1992). Levels of death anxiety in terminally ill men: A pilot study. Omega: Journal of Death and Dying, 24, 13-19. 
Hayslip, B., Servaty, H.L., Christman, T., \& Mumy, E. (1997). Levels of death anxiety in terminally ill persons: A cross validation and extension. Omega: Journal of Death and Dying, 34, 203-217.

Hecht, J. M. (2003). Doubt: A history. San Francisco, CA: Harper San Francisco.

Hunsberger, B., Alisat, S., Pancer, S. M., \& Pratt, M. (1997). Religious fundamentalism and religious doubts: Content, connections, and complexity of thinking. The International Journal for the Psychology of Religion, 6, 201-220.

Hunsberger, B., \& Brown, L.B. (1984). Religious socialization, apostasy, and the impact of family background. Journal for the Scientific Study of Religion, 23, 239-251.

Hunsberger, B., Pratt, M., \& Pancer, S. M. (2002). A longitudinal study of religious doubts in high school and beyond: Relationships, stability, and searching for answers. Journal of the Scientific Study of Religion, 41, 255-266.

Jacobs, J. (1987). Deconversion from religious movements: An analysis of charismatic bonding and spiritual commitment. Journal for the Scientific Study of Religion, 26, 294-308.

John E. Fetzer Institute. (1999). Multidimensional measurement of religiousness/spirituality for use in health research: A report of the Fetzer Institute/National Institute on Aging Working Group. Retrieved January 27, 2009 from http://www.fetzer.org/pdf/total_fetzer_book.pdf

Jorm, A.F. (2000). Does old age reduce the risk of anxiety and depression? A review of epidemiological studies across the adult life span. Psychological Medicine: A Journal of Research in Psychiatry and the Allied Sciences, 30, 11-22.

Kasper, F.E., \& Vesper, J.J. (1976). Death anxiety in a risk-taking group. Essence: Issues in the Study of Aging, Dying, and Death, 1, 95-97. 
Kenney, B. P., Cromwell, R. E., \& Vaughan, C. E. (1977). Identifying the socio-contextual forms of religiosity among urban ethnic minority group members. Journal for the Scientific Study of Religion, 16, 237-244.

King, P. E., \& Furrow, J. L. (2004). Religion as a resource for positive youth development: Religion, social capital, and moral outcomes. Developmental Psychology, 40, 703-713.

Kirkpatrick, L.A. \& Wood, R.W. (1990). Intrinsic-extrinsic religious orientation: The boon or bane of contemporary psychology of religion. Journal for the Scientific Study of Religion, 29, 442-462.

Koenig, L. B., McGue, M., \& Iacono, W. G. (2008). Stability and change in religiousness during emerging adulthood. Developmental Psychology, 44, 532-543.

Krause, N. (2006). Religious doubt and psychosocial well-being: A longitudinal investigation. Review of Religious Research, 47, 287-302.

Krause, N., Ingersoll-Dayton, B., Ellison, C. G., \& Wulff, K. M. (1999). Aging, religious doubt, and psychological well-being. The Gerontologist, 39, 525-533.

Krause, N., \& Wulff, K. M. (2004). Religious doubt and health: Exploring the potential dark side of religion. Sociology of Religion, 65, 35-56.

Lang, F.R., \& Carstensen, L. L. (2002). Time counts: Future time perspective, goals, and social relationships. Psychology and Aging, 17, 125-139.

Leming, M.R. (1980). Religion and death: A test of Homan's thesis. Omega: Journal of Death \& Dying, 10, 347-364.

Lester, D. (2007). What do death anxiety scales measure?. Psychological Reports, 101, 754.

Lester, D., \& Abdel-Khalek, A. (2003). The Collett-Lester Fear of Death Scale: A correction. Death Studies, 27, 81-85. 
Levin, J.S. \& Taylor, R.J. (1993). Gender and age differences in religiosity among Black Americans. The Gerontologist, 33, 16-23.

Long, D.D., \& Elghanemi, S. (1987). Religious correlates of fear of death among Saudi Arabians. Death Studies, 11, 89-97.

Lundh, L. \& Radon, V. (1997). Death anxiety as a function of belief in afterlife: A comparison between a questionnaire measure and a Stroop measure of death anxiety. Personality and Individual Differences, 25, 487-494.

McDonald, G.W. (1976). Sex, religion, and risk-taking behavior as correlates of death anxiety. Omega: Journal of Death \& Dying, 7, 35-44.

McFadden, S. H., Brennan, M., \& Patrick, J. H. (Eds.) (2003). New directions in the study of late life religiousness and spirituality. New York, NY: Routledge.

Moreno, R. P., De La Fuente Solana, E. I., Rico, M. A., \& Fernández, L. M. L. (2009). Death anxiety in institutionalized and non-institutionalized elderly people in Spain. Omega: Journal of Death \& Dying, 58, 61-76.

Naidu, R. K., \& Sinha, A. (1992). Metaphysical beliefs as predictors of death anxiety. Omega: Journal of Death \& Dying, 25, 95-107.

Naragon-Gainey, K. (2010). Meta-analysis of the relations of anxiety sensitivity to the depressive and anxiety disorders. Psychological Bulletin, 136, 128-150.

Nipkow, K. E., \& Schweitzer, F. (1991). Adolescents' justifications for faith or doubt in God: A study of fulfilled and unfulfilled expectations. New Directions for Child Development, $52,91-100$.

Ochsmann, R. (1984). Belief in afterlife as a moderator of fear of death?. European Journal of Social Psychology, 14, 53-67. 
Padawer, E. A., Jacobs-Lawson, J. M., Hershey, D. A., \& Thomas, D. G. (2007). Demographic indicators as predictors of future time perspective. Current Psychology, 26, 102-108.

Pascarella, E.T., \& Terenzini, P.T. (1991). How college makes a difference: A summary. In E.T. Pascarella \& P.T. Terenzini (Eds.), How college affects students: Findings and insights from twenty years of research (pp. 556-635). San Francisco, CA: Jossey-Bass.

Pew Internet \& American Life Project (2009). Four in ten seniors go online. Retrieved April 20, 2010 from http://www.pewinternet.org/Commentary/2010/January/38-of-adults-age-65go-online.aspx

Pew Research Forum. (2010). Religion among millennials: Less religiously active than older Americans, but fairly traditional in other ways. Retrieved April 20, 2010 from http://pewforum.org/docs/?DocID=510

Pierce, J. D., Cohen, A. B., Chambers, J. A., \& Meade, R. M. (2007). Gender differences in death anxiety and religious orientation among US high school and college students. Mental Health, Religion, \& Culture, 10, 143-150.

Pratt, M. W., Hunsberger, B., Pancer, S. M., \& Roth, D. (1992). Reflections on religion: Aging, belief orthodoxy, and interpersonal conflict in the complexity of adult thinking about religious issues. Journal for the Scientific Study of Religion, 31, 514-522.

Rappaport, E. (1978). The effects of dogmatism and anxiety on changes in religious identification. The Journal of Social Psychology, 104, 141-142.

Rappaport, H., Fossler, R. J., Bross, L. S., \& Gilden, D. (1993). Future time, death anxiety, and life purpose among older adults. Death Studies, 17, 369-379.

Rasmussen, C. A., \& Brems, C. (1996). The relationship of death anxiety with age and psychosocial maturity. The Journal of Psychology, 130, 141-144. 
Rasmussen, C. A. \& Johnson, M. E. (1994). Spirituality and religiosity: Relative relationships to death anxiety. Omega: Journal of Death \& Dying, 29, 313-318.

Roff, L. R., Butkeviciene, R., \& Klemmack, D. L. (2002). Death anxiety and religiosity among Lithuanian heath and social service professionals. Death Studies, 26, 731-742.

Roshdieh, S., Templer, D. I., Cannon, W. G., \& Canfield, M. (1999). The relationships of death anxiety and death depression to religion and civilian war-related experiences in Iranians. Omega: Journal of Death \& Dying, 38, 201-210.

Saroglou, V., Pichon, I., Trompette, L., Verschuren, M., \& Dernelle, R. (2005). Prosocial behavior and religion: New evidence based on projective measures and peer ratings. Journal for the Scientific Study of Religion, 44, 323-348.

Spielberger, C.D., Gorsuch, R.L., \& Lushene, R.E. (1970). Manual for the State-Trait Anxiety Inventory. Palo Alto, CA: Consulting Psychologists Press.

Spielberger, C.D., Gorsuch, R.L., Lushene, R.E., Vagg, P.R., \& Jacobs, G.A. (1983). State-Trait Anxiety Inventory sample set: Manual, test booklet, and scoring key. Palo Alto, CA: Consulting Psychologists Press.

Stevens, S. J., Cooper, P. E., \& Thomas, L. E. (1980). Age norms for Templer's Death Anxiety Scale. Psychological Reports, 46, 205-206.

Suhail, K., \& Akram, S. (2002). Correlates of death anxiety in Pakistan. Death Studies, 26, 3950.

Templer, D. I. (1970). The construction and validation of a death anxiety scale. Journal of General Psychology, 82, 165-177. 
Templer, D. I., Awadalla, A., Al-Fayez, G., Frazee, J., Bassman, L., Connelly, H. J., et al. (2006). Construction of a Death Anxiety Scale-Extended. Omega: Journal of Death \& Dying, 53, 209-226.

Templer, D. I., \& Dotson, E. (1970). Religious correlates of death anxiety. Psychological Reports, 26, 895-897.

Templer, D. I. \& Ruff, C. F. (1975). The relationship between death anxiety and religion in psychiatric patients. Journal of Thanatology, 3, 165-168.

Thorson, J. A. (1991). Afterlife constructs, death anxiety, and life reviewing: The importance of religion as a moderating variable. Journal of Psychology and Theology, 19, 278-284.

Thorson, J. A., Powell, F. C., Abdel-Khalek, A. M., \& Beshai, J. A. (1997). Constructions of religiosity and death anxiety in two cultures: The United States and Kuwait. Journal of Psychology \& Theology, 25, 374-383.

Tismer, K. G. (1985). Sex and age differences in personal and global future time perspective: A replication. Perceptual and Motor Skills, 61, 1007-1010.

Tomás-Sábado, J., \& Gómez-Benito, J. (2005). Construction and validation of the Death Anxiety Inventory (DAI). European Journal of Psychological Assessment, 21, 108-114.

Tomás-Sábado, J., Gómez-Benito, J., \& Limonero, J. T. (2005). The Death Anxiety Inventory: A revision. Psychological Reports, 97, 793-796.

United States Department of Transportation. (2007). Fatality Analysis Reporting System (FARS): Fatal Crashes 1994 - 2007 - State : USA. Retrieved March 6, 2009 from http://www-fars.nhtsa.dot.gov/Trends/TrendsGeneral.aspx 
Vail, K.E., Rothschild, Z.K., Weise, D.R., Solomon, S., Pyszczynski, T., \& Greenburg, J. (2010). A terror management analysis of the psychological functions of religion. Personality and Social Psychology Review, 14 (1), 84-94.

von Wright, J. M., \& von Wright, M. R. (1977). Sex differences in personal and global future time perspective. Perceptual and Motor Skills, 44, 30.

Widaman, K. F. (2005). Missing data: What to do with or without them. In Monographs of the Society for Research in Child Development, 71 (3, Serial No. 285).

Wink, P. (2006). Who is afraid of death? Religiousness, spirituality, and death anxiety in late adulthood. Journal of Religion, Spirituality, \& Aging, 18, 93-110.

Wink, P., \& Dillon, M. (2003). Religiousness, spirituality, and psychosocial functioning in late adulthood: Findings from a longitudinal study. Psychology \& Aging, 18, 916-924.

Wink, P., \& Scott, J. (2005). Does religiousness buffer against the fear of death and dying in late adulthood? Findings from a longitudinal study. Journals of Gerontology: Series B: Psychological Sciences and Social Sciences, 60B, 207-214.

Wohlwill, J. F. (1970). The age variable in psychological research. Psychological Review, 77, 49-64.

Wu, A. M. S., Tang, C. S. K., \& Kwok, T. C. Y. (2002). Death anxiety among Chinese elderly people in Hong Kong. Journal of Aging \& Health, 14, 42-56.

Young, M., \& Daniels, S. (1980). Born again status as a factor in death anxiety. Psychological Reports, 47, 367-370.

Young, M., \& Daniels, S. (1981). Religious correlates of death anxiety among high school students in the rural South. Death Education, 5, 223-233. 
Religion and Death Anxiety 62

Zelan, J. (1968). Religious apostasy, higher education, and occupational choice. Sociology of Education, 41, 370-379. 
Appendix A: Table 1

Correlation Matrix for Variables in current study.

\begin{tabular}{|c|c|c|c|c|c|c|c|c|c|c|c|c|}
\hline & Variable & 1 & 2 & 3 & 4 & 5 & 6 & 7 & 8 & 9 & 10 & 11 \\
\hline 1 & Age & - & -.011 & $-.280 * *$ & $-.386^{* *}$ & $-.390 * *$ & $-.267 * *$ & $.283^{* *}$ & $.221^{* *}$ & $.242^{* *}$ & $.280 * *$ & $-.371 * *$ \\
\hline 2 & Gender & & - & -.067 & $-.190 * *$ & $-.207 * *$ & $.178^{* *}$ & $-.170 * *$ & $-.305^{* *}$ & $-.226 * *$ & $-.263 * *$ & -.052 \\
\hline 3 & $\begin{array}{l}\text { Trait } \\
\text { Anxiety }\end{array}$ & & & - & $.438 * *$ & $.451^{* *}$ & $.323^{* *}$ & $-.226 * *$ & $-.132 *$ & -.107 & $-.203^{* *}$ & $-.176^{* *}$ \\
\hline 4 & DAI & & & & - & $.812^{* *}$ & $.250^{* *}$ & $-.152 *$ & .033 & -.034 & $-.121^{* *}$ & .015 \\
\hline 5 & DAS-E & & & & & - & $.245^{* *}$ & $-.128^{*}$ & .013 & -.032 & -.104 & .014 \\
\hline 6 & $\begin{array}{l}\text { Religious } \\
\text { Doubt }\end{array}$ & & & & & & - & $-.569 * *$ & $-.657^{* *}$ & $-.612^{* *}$ & $-.673^{* *}$ & -.039 \\
\hline 7 & $\begin{array}{l}\text { Org. } \\
\text { Relig. }\end{array}$ & & & & & & & - & $.589 * *$ & $.670 * *$ & $.665^{* *}$ & -.029 \\
\hline 8 & $\begin{array}{l}\text { Religious } \\
\text { Beliefs }\end{array}$ & & & & & & & & - & $.856 * *$ & $.795 * *$ & .015 \\
\hline 9 & $\begin{array}{l}\text { Religious } \\
\text { Meaning }\end{array}$ & & & & & & & & & - & $.836^{* *}$ & .017 \\
\hline 10 & DSES & & & & & & & & & & - & .077 \\
\hline 11 & FTP & & & & & & & & & & & - \\
\hline
\end{tabular}

Note.

Gender coded as Female $=0$, Male $=1$.

DAI: Death Anxiety Inventory

DAS-E: Death Anxiety Scale-Extended

Org. Relig.: Organizational Religiousness

DSES: Daily Spiritual Experiences

FTP: Future Time Perspective

$* p<.05$

$* * p<.01$ 
Appendix B: Table 2

2 (gender) by 3 (age group) Multiple Analysis of Variance predicting scores on the Death Anxiety Scale-Extended and the Death Anxiety Inventory.

\begin{tabular}{lcccc}
\hline \multicolumn{1}{c}{ Source } & $d f$ & $F$ & $\eta^{2}$ & $p$ \\
\hline Gender & \multicolumn{3}{c}{ Death Anxiety Scale-Extended } \\
Age Group & 1 & 8.41 & .031 & .004 \\
Gender*Age Group & 2 & 10.25 & .071 & .001 \\
Error & 2 & 1.35 & .010 & .262 \\
\hline \multicolumn{3}{c}{ Death Anxiety Inventory } \\
Gender & 267 & 6.84 & .025 & .009 \\
Age Group & 1 & 10.74 & .074 & .001 \\
Gender*Age Group & 2 & 1.74 & .013 & .178 \\
Error & 2 & $(13.60)$ & & \\
\hline
\end{tabular}

Note. Values enclosed in parentheses represent mean square error. 
Appendix C: Table 3

2 (gender) by 3 (age group) Analysis of Variance predicting Religious Doubt scores.

\begin{tabular}{lcccc}
\hline \multicolumn{1}{c}{ Source } & $d f$ & $F$ & $\eta^{2}$ & $p$ \\
\hline Gender & 1 & 7.55 & .028 & .006 \\
Age Group & 2 & 7.57 & .054 & .001 \\
Gender*Age Group & 2 & 0.20 & .001 & .820 \\
Error & 265 & $(150.19)$ & & \\
\hline
\end{tabular}

Note. Values enclosed in parentheses represent mean square error. 
Appendix D: Table 4

2 (gender) by 3 (age group) Analysis of Variance predicting Future Time Perspective scores.

\begin{tabular}{lcccc}
\hline \multicolumn{1}{c}{ Source } & $d f$ & $F$ & $\eta^{2}$ & $p$ \\
\hline Gender & 1 & 0.94 & .004 & .332 \\
Age Group & 2 & 14.09 & .095 & $<.001$ \\
Gender*Age Group & 2 & 0.05 & .000 & .820 \\
Error & 267 & $(100.99)$ & & \\
\hline
\end{tabular}

Note. Values enclosed in parentheses represent mean square error. 
Appendix E: Table 5

2 (gender) by 3 (age group) Analysis of Variance predicting Trait Anxiety scores.

\begin{tabular}{lcccc}
\hline \multicolumn{1}{c}{ Source } & $d f$ & $F$ & $\eta^{2}$ & $p$ \\
\hline Gender & 1 & 0.66 & .003 & .418 \\
Age Group & 2 & 5.20 & .038 & .006 \\
Gender*Age Group & 2 & 0.30 & .002 & .745 \\
Error & 261 & $(97.90)$ & &
\end{tabular}

Note. Values enclosed in parentheses represent mean square error. 
Appendix F: Table 6

2 (gender) by 3 (age group) Multiple Analysis of Variance predicting Religious Meaning, Religious Belief, Organizational Religiousness, and Daily Spiritual Experience scores.

\begin{tabular}{|c|c|c|c|c|}
\hline Source & $d f$ & $F$ & $\eta^{2}$ & $p$ \\
\hline \multicolumn{5}{|c|}{ Religious Meaning } \\
\hline Gender & 1 & 12.94 & .047 & $<.001$ \\
\hline Age Group & 2 & 6.66 & .048 & .002 \\
\hline Gender*Age Group & 2 & 1.37 & .010 & .257 \\
\hline Error & 263 & $(381.16)$ & & \\
\hline \multicolumn{5}{|c|}{ Religious Belief } \\
\hline Gender & 1 & 19.44 & .069 & $<.001$ \\
\hline Age Group & 2 & 7.17 & .052 & .001 \\
\hline Gender*Age Group & 2 & 0.75 & .006 & .475 \\
\hline Error & 263 & $(29.54)$ & & \\
\hline \multicolumn{5}{|c|}{ Organizational Religiousness } \\
\hline Gender & 1 & 6.66 & .025 & .010 \\
\hline Age Group & 2 & 7.22 & .052 & .001 \\
\hline Gender*Age Group & 2 & 1.16 & .009 & .317 \\
\hline Error & 263 & $(17.69)$ & & \\
\hline \multicolumn{5}{|c|}{ Daily Spiritual Experiences } \\
\hline Gender & 1 & 16.04 & .057 & $<.001$ \\
\hline Age Group & 2 & 7.94 & .057 & $<.001$ \\
\hline Gender*Age Group & 2 & 1.28 & .010 & .279 \\
\hline Error & 263 & $(252.75)$ & & \\
\hline
\end{tabular}

Note. Values enclosed in parentheses represent mean square error. 
Appendix G: Table 7

Tests of Trend from One-Way ANOVAs with Religious Meaning Groups predicting Death Anxiety Scale-Extended scores and Death Anxiety Inventory scores.

\begin{tabular}{lccc}
\hline \multicolumn{1}{c}{ Source } & $d f$ & $F$ & $p$ \\
\hline Linear & Death Anxiety & Scale-Extended & \\
Quadratic & 1 & 6.29 & .013 \\
Error & 1 & 4.41 & .037 \\
\hline & 269 & $(86.04)$ & \\
Linear & \multicolumn{1}{c}{ Death Anxiety } & Inventory & \\
Quadratic & 1 & 3.57 & .060 \\
Error & 1 & 3.23 & .074 \\
\hline
\end{tabular}

Note. Values enclosed in parentheses represent mean square error. 
Appendix H: Table 8

Curve Estimations with Religious Meaning predicting Death Anxiety Scale-Extended scores and Death Anxiety Inventory scores.

\begin{tabular}{|c|c|c|c|c|c|}
\hline Variable & Beta & SE Beta & $\beta$ & $t$ & $p$ \\
\hline \multicolumn{6}{|c|}{ Death Anxiety Scale-Extended* } \\
\hline Linear & 1.45 & 0.57 & 3.19 & 2.56 & .011 \\
\hline Quadratic & -0.02 & 0.10 & -5.51 & -2.00 & .047 \\
\hline Cubic & 0.00008 & 0.00 & 2.33 & 1.47 & .142 \\
\hline \multicolumn{6}{|c|}{ Death Anxiety Inventory** } \\
\hline Linear & 0.43 & 0.25 & 2.19 & 1.75 & .082 \\
\hline Quadratic & -0.01 & 0.004 & -3.37 & -1.21 & .227 \\
\hline Cubic & 0.00002 & 0.00 & 1.15 & 0.72 & .471 \\
\hline
\end{tabular}

Note.

$* R^{2}=.092$, Adjusted $R^{2}=.082, F(3,268)=9.05, p<.001$.

$* * R^{2}=.076$, Adjusted $R^{2}=.066, F(3,268)=7.38, p<.001$. 


\section{Appendix I: Table 9}

Tests of Trend from One-Way ANOVAs with Age Groups predicting Death Anxiety ScaleExtended scores and Death Anxiety Inventory scores.

\begin{tabular}{lccc}
\hline \multicolumn{1}{c}{ Source } & $d f$ & $F$ & $p$ \\
\hline Linear & Death Anxiety & Scale-Extended & \\
Quadratic & 1 & 34.72 & .001 \\
Error & 1 & 1.55 & .215 \\
\hline & 270 & $(76.99)$ & \\
Linear & \multicolumn{1}{c}{ Death Anxiety Inventory } & \\
Quadratic & 1 & 43.76 & .001 \\
Error & 1 & 0.003 & \\
\hline
\end{tabular}

Note. Values enclosed in parentheses represent mean square error. 


\section{Appendix J: Table 10}

Curve Estimations with Age predicting Death Anxiety Scale-Extended scores and Death Anxiety Inventory scores.

\begin{tabular}{|c|c|c|c|c|c|}
\hline Variable & Beta & SE Beta & $\beta$ & $t$ & $p$ \\
\hline \multicolumn{6}{|c|}{ Death Anxiety Scale-Extended* } \\
\hline Linear & 0.15 & 0.76 & 0.30 & 0.20 & .843 \\
\hline Quadratic & -0.01 & 0.02 & -1.46 & -0.50 & .616 \\
\hline Cubic & 0.00007 & 0.00 & 0.79 & 0.55 & .585 \\
\hline \multicolumn{6}{|c|}{ Death Anxiety Inventory** } \\
\hline Linear & 0.17 & 0.33 & 0.79 & 0.52 & .606 \\
\hline Quadratic & -0.01 & 0.01 & -2.40 & -0.82 & .412 \\
\hline Cubic & 0.00004 & 0.00 & 1.26 & 0.87 & .386 \\
\hline
\end{tabular}

Note.

$* R^{2}=.154$, Adjusted $R^{2}=.144, F(3,269)=16.28, p<.001$.

** $R^{2}=.152$, Adjusted $R^{2}=.142, F(3,269)=16.05, p<.001$. 


\section{Appendix K: Table 11}

Tests of Trend from One-Way ANOVAs with Age Groups predicting Trait Anxiety scores.

\begin{tabular}{lccc}
\hline \multicolumn{1}{c}{ Source } & $d f$ & $F$ & $p$ \\
\hline Linear & 1 & 19.83 & $<.001$ \\
Quadratic & 1 & 0.07 & .788 \\
Error & 264 & $(97.52)$ & \\
\hline
\end{tabular}

Note. Values enclosed in parentheses represent mean square error. 
Appendix L: Table 12

Curve Estimations with Age predicting Trait Anxiety scores.

\begin{tabular}{lccccc}
\hline \multicolumn{1}{c}{ Variable } & Beta & SE Beta & $\beta$ & $t$ & $p$ \\
\hline Linear & 0.37 & 0.88 & 0.70 & 0.42 & .675 \\
Quadratic & -0.01 & 0.02 & -1.60 & -0.51 & .613 \\
Cubic & 0.00006 & 0.00 & 0.64 & 0.41 & .683 \\
\hline
\end{tabular}

Note.

$R^{2}=.082$, Adjusted $R^{2}=.071, F(3,263)=7.80, p<.001$. 


\section{Appendix M: Table 13}

Hierarchical Regression predicting Death Anxiety Scale-Extended scores.

\begin{tabular}{|c|c|c|c|c|c|c|}
\hline & Variable & Beta & SE Beta & $\beta$ & $t$ & $p$ \\
\hline \multicolumn{7}{|l|}{ Step 1} \\
\hline & Age & -0.20 & 0.03 & -0.41 & -7.34 & $<.001$ \\
\hline & Gender & -5.04 & 1.28 & -0.22 & -3.95 & $<.001$ \\
\hline \multicolumn{7}{|l|}{ Step 2} \\
\hline & Age & -0.17 & 0.03 & -0.35 & -6.25 & $<.001$ \\
\hline & Gender & -5.79 & 1.27 & -0.25 & -4.56 & $<.001$ \\
\hline & Religious Doubt & 0.14 & 0.04 & 0.19 & 3.29 & .001 \\
\hline \multicolumn{7}{|l|}{ Step 3} \\
\hline & Age & -0.14 & 0.03 & -0.29 & -4.89 & $<.001$ \\
\hline & Gender & -4.88 & 1.19 & -0.21 & -4.09 & $<.001$ \\
\hline & Religious Doubt & 0.06 & 0.04 & 0.09 & 1.55 & .123 \\
\hline & Future Time Perspective & -0.04 & 0.05 & -0.05 & -0.80 & .426 \\
\hline & Trait Anxiety & 0.33 & 0.05 & 0.35 & 6.19 & $<.001$ \\
\hline \multicolumn{7}{|l|}{ Step 4} \\
\hline & Age & -0.15 & 0.03 & -0.31 & -5.18 & $<.001$ \\
\hline & Gender & -3.76 & 1.21 & -0.16 & -3.10 & .002 \\
\hline & Religious Doubt & 0.17 & 0.05 & 0.24 & 3.27 & .001 \\
\hline & Future Time Perspective & -0.05 & 0.05 & -0.06 & -0.99 & .324 \\
\hline & Trait Anxiety & 0.32 & 0.05 & 0.33 & 5.85 & $<.001$ \\
\hline & Daily Spiritual Experiences & 0.02 & 0.06 & 0.04 & 0.42 & .675 \\
\hline & Religious Meaning & -0.02 & 0.05 & -0.03 & -0.29 & .774 \\
\hline & Religious Beliefs & 0.42 & 0.17 & 0.26 & 2.50 & .013 \\
\hline & Organizational Religiousness & -0.07 & 0.15 & -0.03 & -0.45 & .653 \\
\hline
\end{tabular}

Note.

Gender coded as Female $=0$, Male $=1$.

Step 1: $R^{2}=.209$, Adjusted $R^{2}=.203, F(2,260)=34.45, M S E=70.57, p<.001$.

Step 2: $R^{2}=.241$, Adjusted $R^{2}=.232, F(3,259)=27.45, M S E=68.00, p<.001 ; R^{2} \Delta=.032, F \Delta$ $(1,259)=10.84, p=.001$.

Step 3: $R^{2}=.355$, Adjusted $R^{2}=.342, F(5,257)=28.23, M S E=58.29, p<.001 ; R^{2} \Delta=.113, F \Delta$ $(2,257)=22.56, p<.001$.

Step 4: $R^{2}=.387$, Adjusted $R^{2}=.366, F(9,253)=17.78, M S E=56.19, p<.001 ; R^{2} \Delta=.033, F \Delta$ $(4,253)=3.40, p=.010$. 
Appendix N: Table 14

Hierarchical Regression predicting Death Anxiety Inventory scores.

\begin{tabular}{|c|c|c|c|c|c|c|}
\hline & Variable & Beta & SE Beta & $\beta$ & $t$ & $p$ \\
\hline \multicolumn{7}{|l|}{ Step 1} \\
\hline & Age & -0.09 & 0.01 & -0.40 & -7.18 & $<.001$ \\
\hline & Gender & -2.11 & 0.55 & -0.21 & -3.81 & $<.001$ \\
\hline \multicolumn{7}{|l|}{ Step 2} \\
\hline & Age & -0.07 & 0.01 & -0.35 & -6.08 & $<.001$ \\
\hline & Gender & -2.45 & 0.55 & -0.25 & -4.43 & $<.001$ \\
\hline & Religious Doubt & 0.06 & 0.02 & 0.19 & 3.37 & .001 \\
\hline \multicolumn{7}{|l|}{ Step 3} \\
\hline & Age & -0.06 & 0.01 & -0.29 & -4.85 & $<.001$ \\
\hline & Gender & -2.09 & 0.53 & -0.21 & -3.99 & $<.001$ \\
\hline & Religious Doubt & 0.03 & 0.02 & 0.10 & 1.75 & .081 \\
\hline & Future Time Perspective & -0.02 & 0.02 & -0.05 & -0.94 & .348 \\
\hline & Trait Anxiety & 0.13 & 0.02 & 0.32 & 5.54 & $<.001$ \\
\hline \multicolumn{7}{|l|}{ Step 4} \\
\hline & Age & -0.06 & 0.01 & -0.30 & -5.04 & $<.001$ \\
\hline & Gender & -1.54 & 0.53 & -0.15 & -2.93 & .004 \\
\hline & Religious Doubt & 0.08 & 0.02 & 0.25 & 3.43 & .001 \\
\hline & Future Time Perspective & -0.02 & 0.02 & -0.06 & -1.05 & .295 \\
\hline & Trait Anxiety & 0.12 & 0.02 & 0.30 & 5.21 & $<.001$ \\
\hline & Daily Spiritual Experiences & -0.004 & 0.03 & -0.02 & -0.15 & .884 \\
\hline & Religious Meaning & -0.01 & 0.02 & -0.07 & -0.58 & .560 \\
\hline & Religious Beliefs & 0.26 & 0.07 & 0.38 & 3.61 & $<.001$ \\
\hline & Organizational Religiousness & -0.06 & 0.07 & -0.07 & -0.88 & .379 \\
\hline
\end{tabular}

Note.

Gender coded as Female $=0$, Male $=1$.

Step 1: $R^{2}=.201$, Adjusted $R^{2}=.195, F(2,260)=32.79, M S E=13.35, p<.001$.

Step 2: $R^{2}=.235$, Adjusted $R^{2}=.226, F(3,259)=26.52, M S E=12.84, p<.001 ; R^{2} \Delta=.034, F \Delta$ $(1,259)=11.836, p=.001$.

Step 3: $R^{2}=.332$, Adjusted $R^{2}=.319, F(5,257)=25.55, M S E=11.30, p<.001 ; R^{2} \Delta=.097, F \Delta$ $(2,257)=18.66, p<.001$.

Step 4: $R^{2}=.382$, Adjusted $R^{2}=.360, F(9,253)=17.34, M S E=10.62, p<.001 ; R^{2} \Delta=.050, F \Delta$ $(4,253)=5.07, p=.001$. 


\section{Appendix O: Figure 1}

Graph of 2 (gender) by 3 (age group) Multiple Analysis of Variance predicting scores on the Death Anxiety Scale-Extended and the Death Anxiety Inventory: Death Anxiety Scale-Extended.

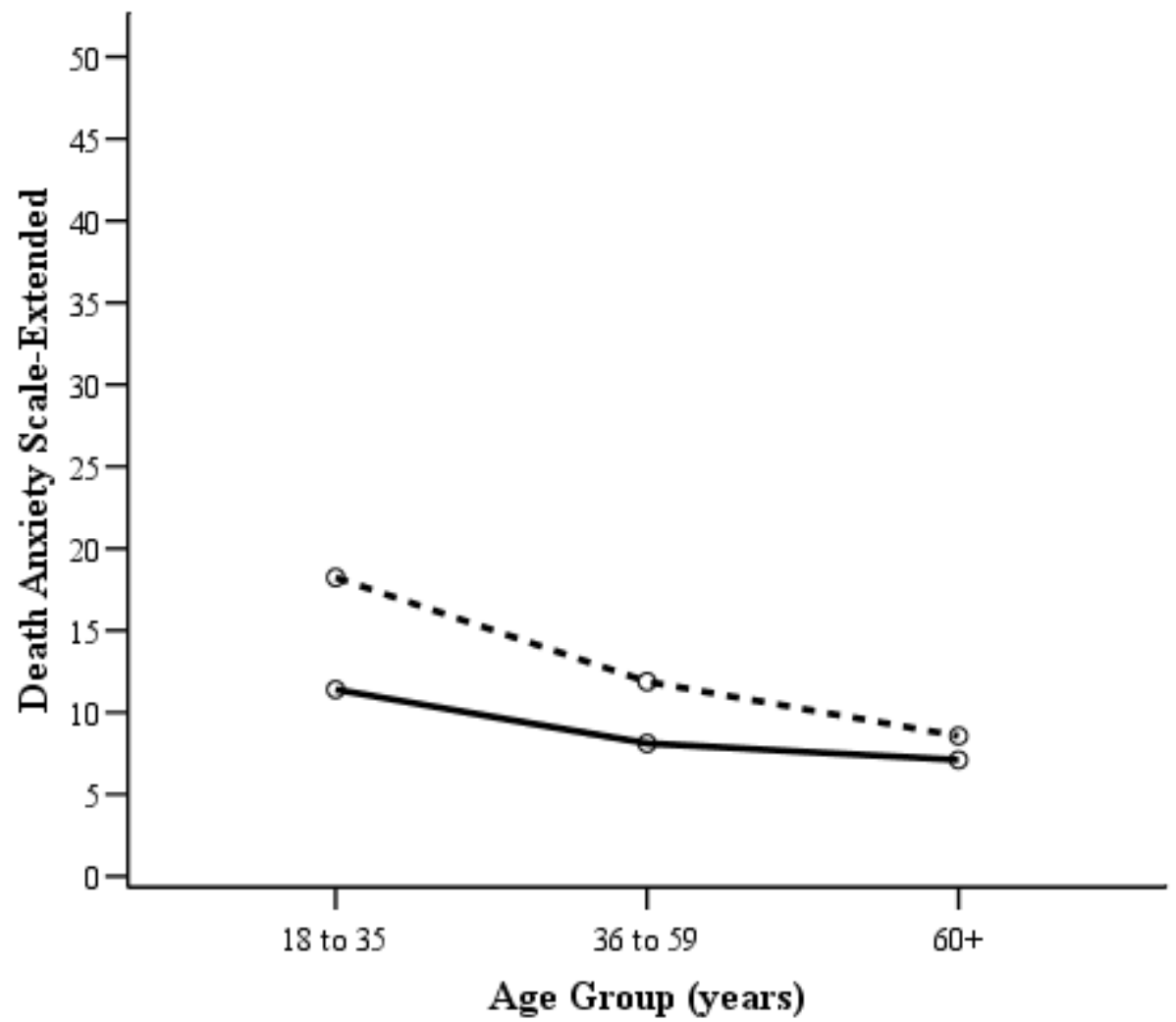

Gender

- - Female

- Male 
Appendix P: Figure 2

Graph of 2 (gender) by 3 (age group) Multiple Analysis of Variance predicting scores on the Death Anxiety Scale-Extended and the Death Anxiety Inventory: Death Anxiety Inventory.

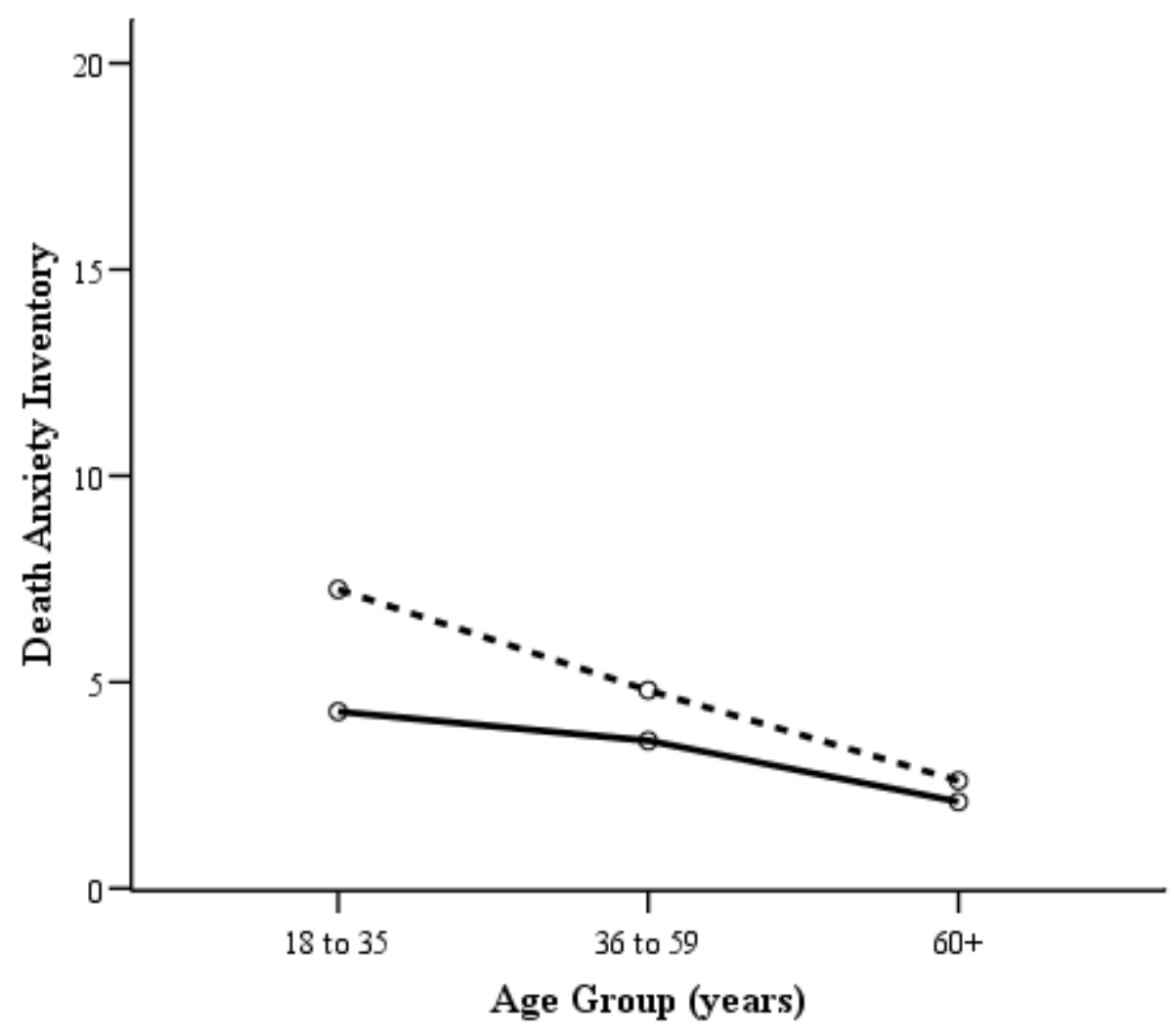

Gender

- - -Female

- Male 
Appendix Q: Figure 3

Graph of 2 (gender) by 3 (age group) Analysis of Variance predicting Religious Doubt scores.

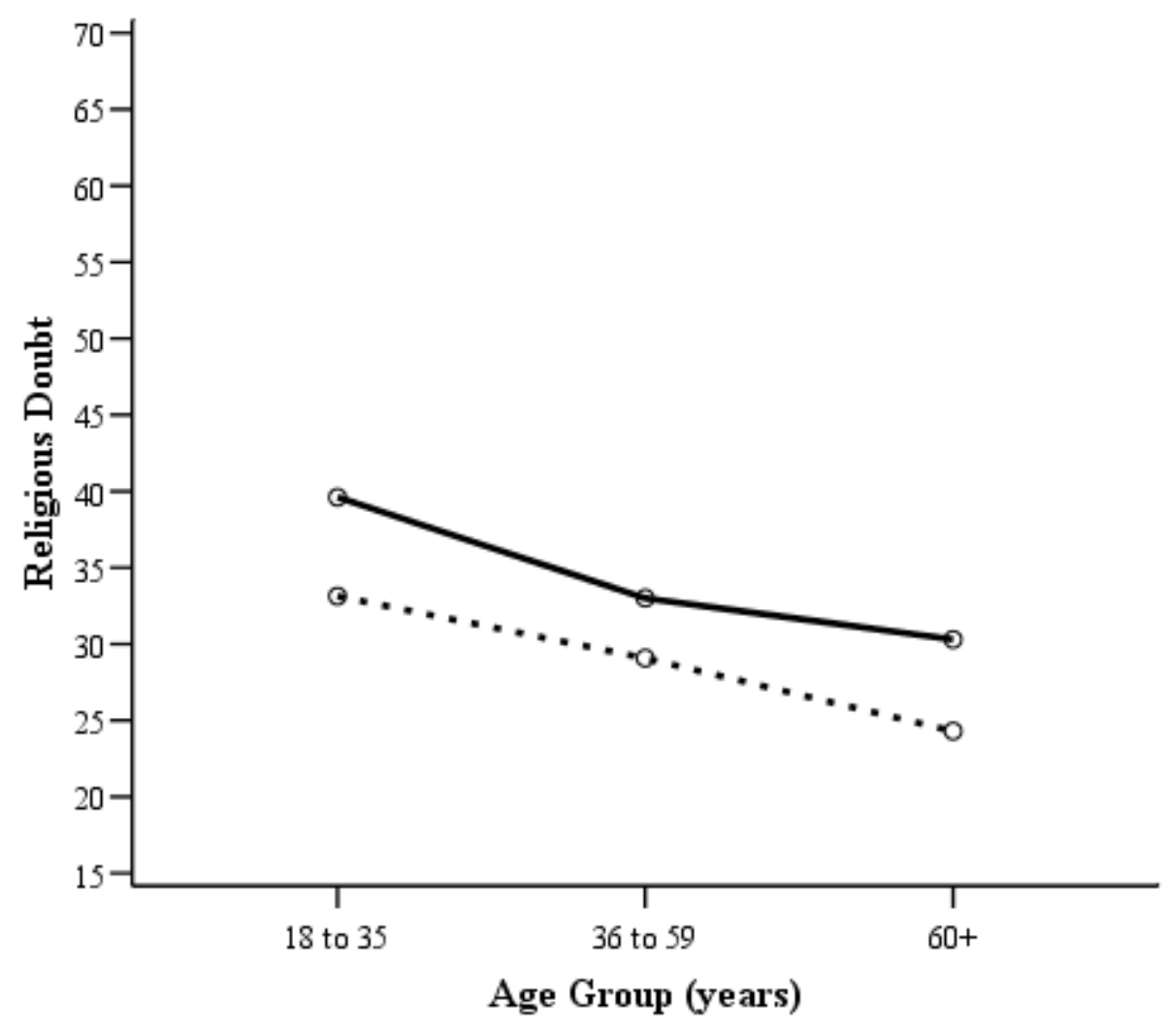

Gender

-. Female

- Male 
Appendix R: Figure 4

Graph of 2 (gender) by 3 (age group) Analysis of Variance predicting Future Time Perspective scores.

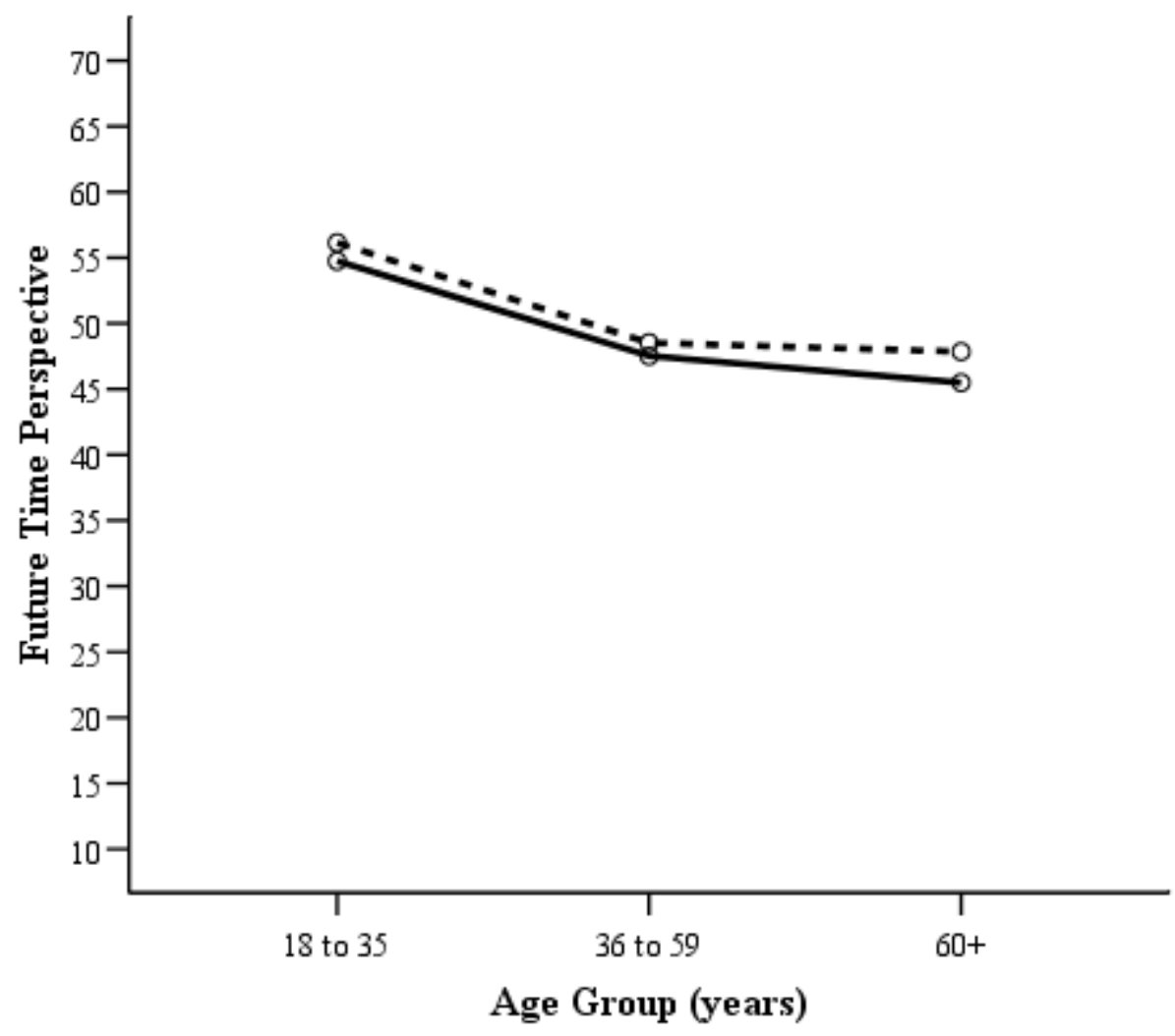

Gender

- - Female

- Male 


\section{Appendix S: Figure 5}

Graph of 2 (gender) by 3 (age group) Multiple Analysis of Variance predicting Trait Anxiety scores.

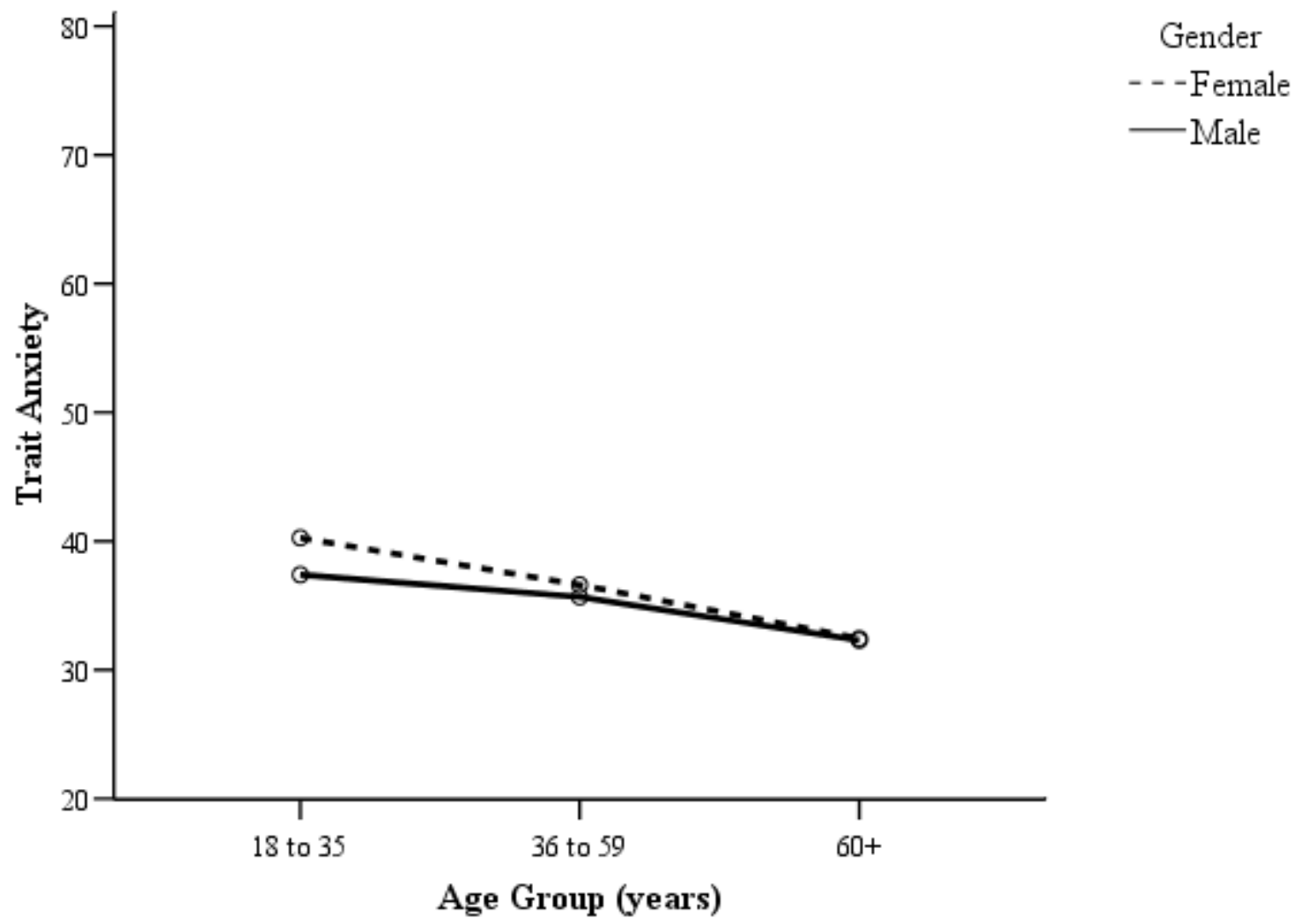


Appendix T: Figure 6

Graph of 2 (gender) by 3 (age group) Multiple Analysis of Variance predicting Religious Meaning scores.

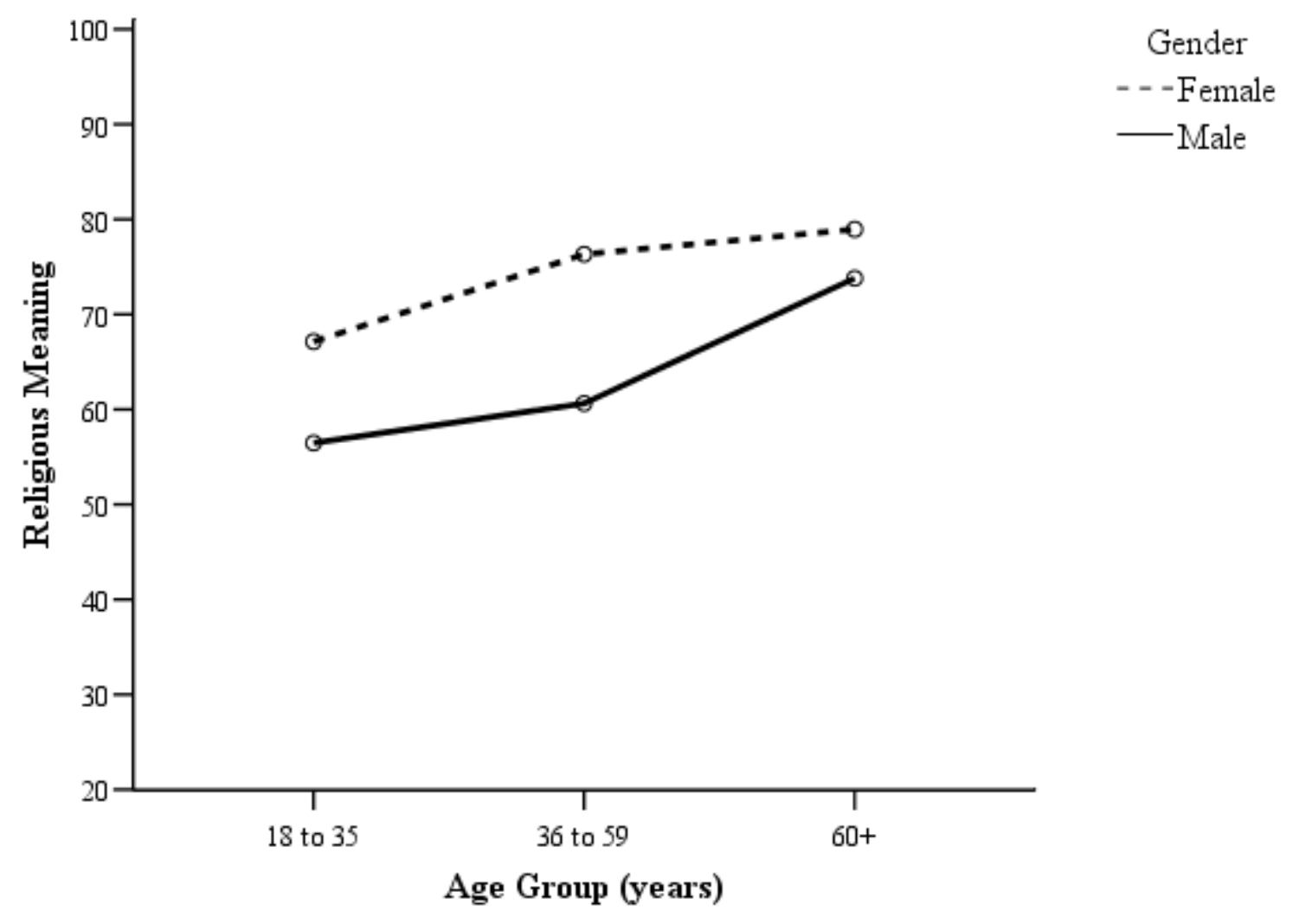


Appendix U: Figure 7

Graph of 2 (gender) by 3 (age group) Multiple Analysis of Variance predicting Religious Beliefs scores.

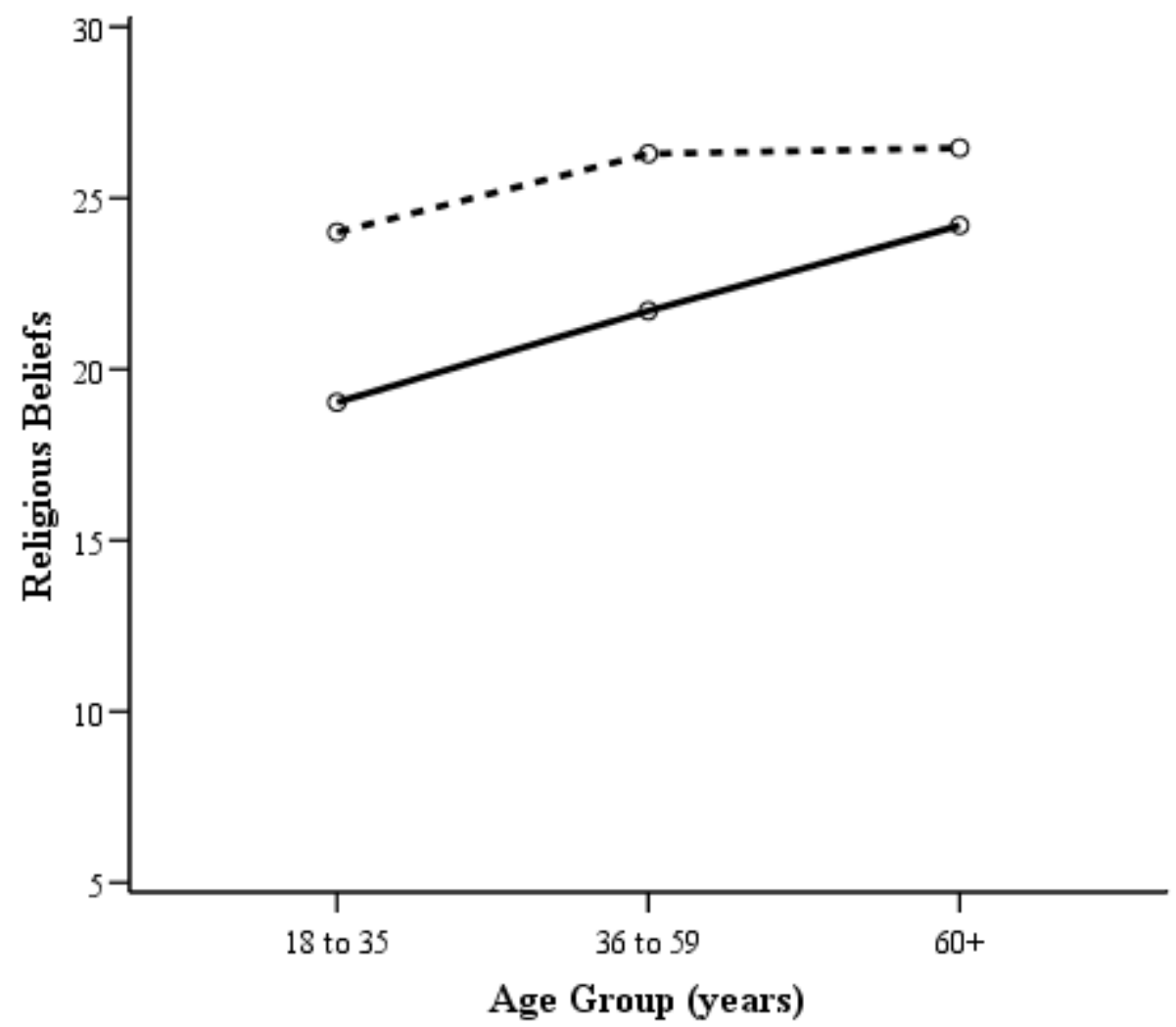

Gender

- - -Female

- Male 
Appendix V: Figure 8

Graph of 2 (gender) by 3 (age group) Multiple Analysis of Variance predicting Organizational Religiousness scores.

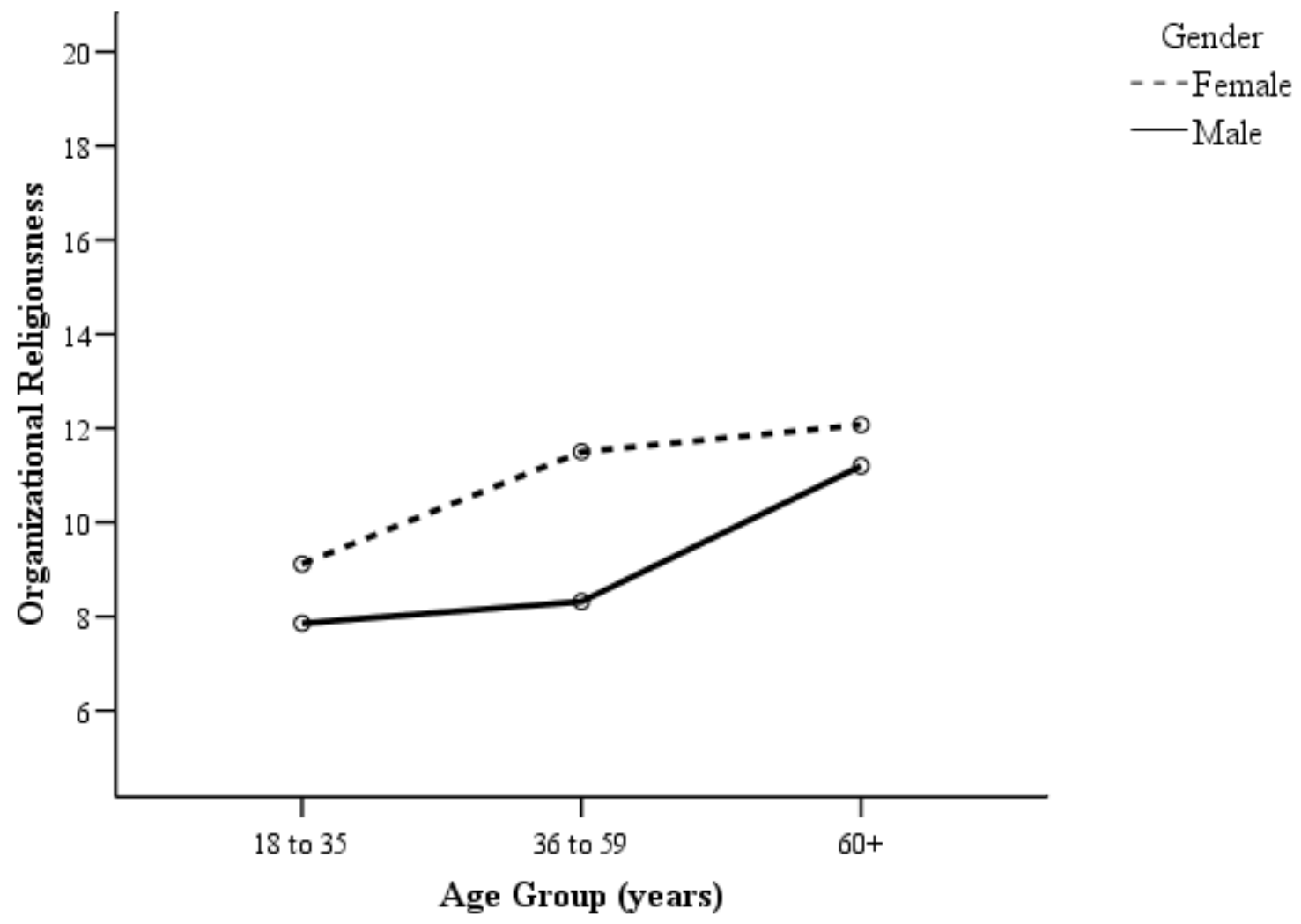


Appendix W: Figure 9

Graph of 2 (gender) by 3 (age group) Analysis of Variance predicting Daily Spiritual Experience scores.

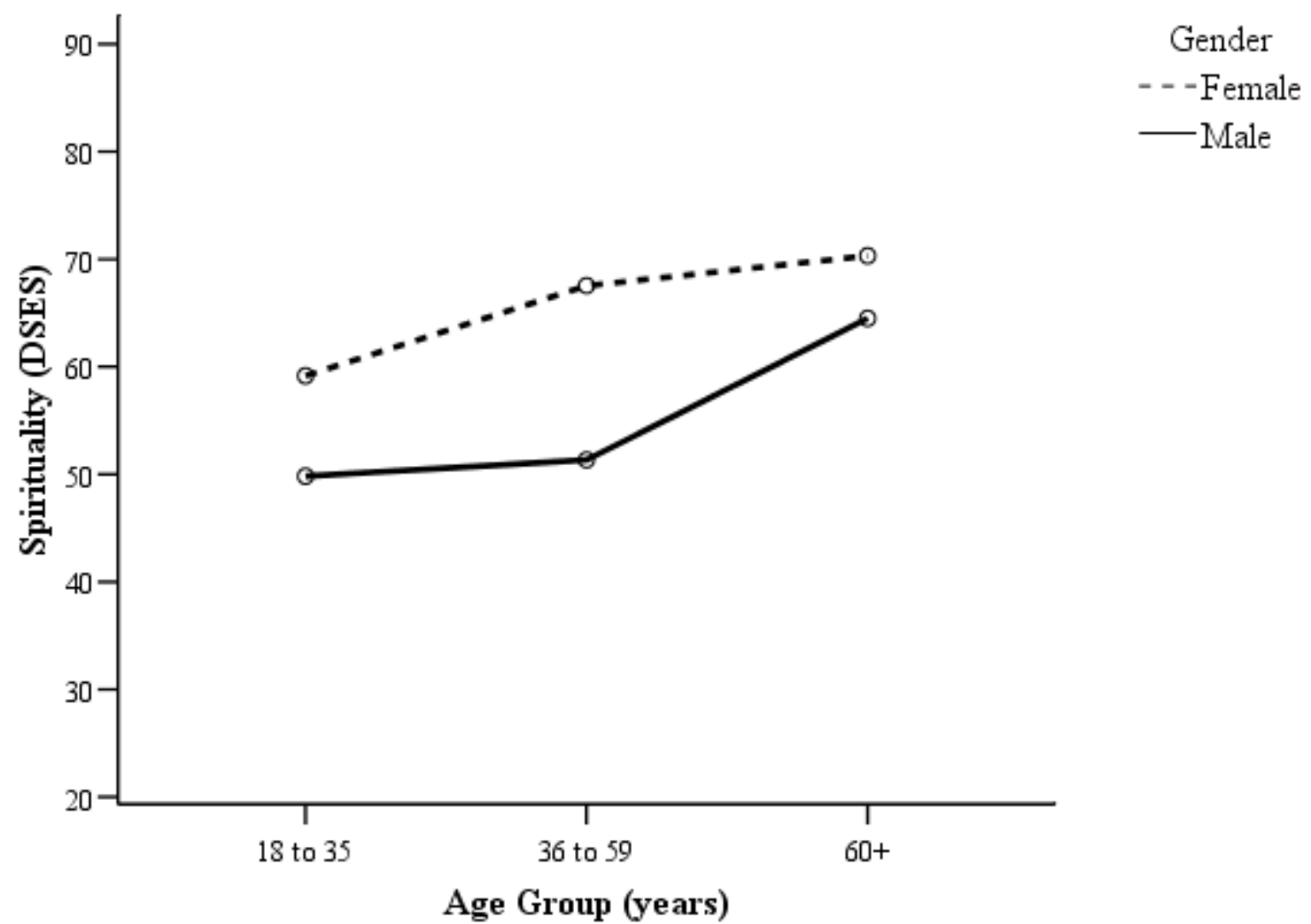


Appendix X: Figure 10

Scatterplot of Religious Meaning (X) and Death Anxiety Scale-Extended (Y).

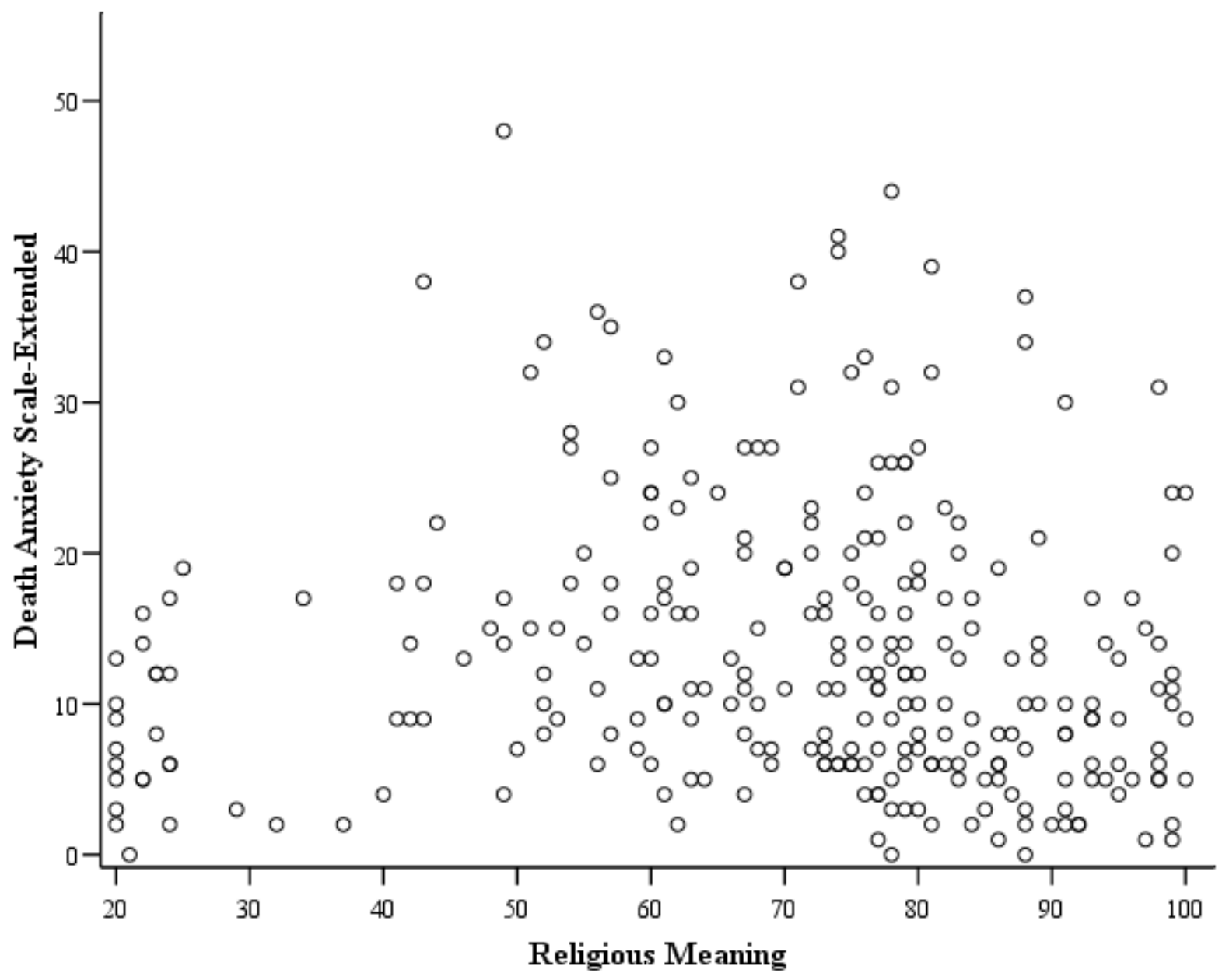


Appendix Y: Figure 11

Scatterplot of Religious Meaning (X) and Death Anxiety Inventory (Y).

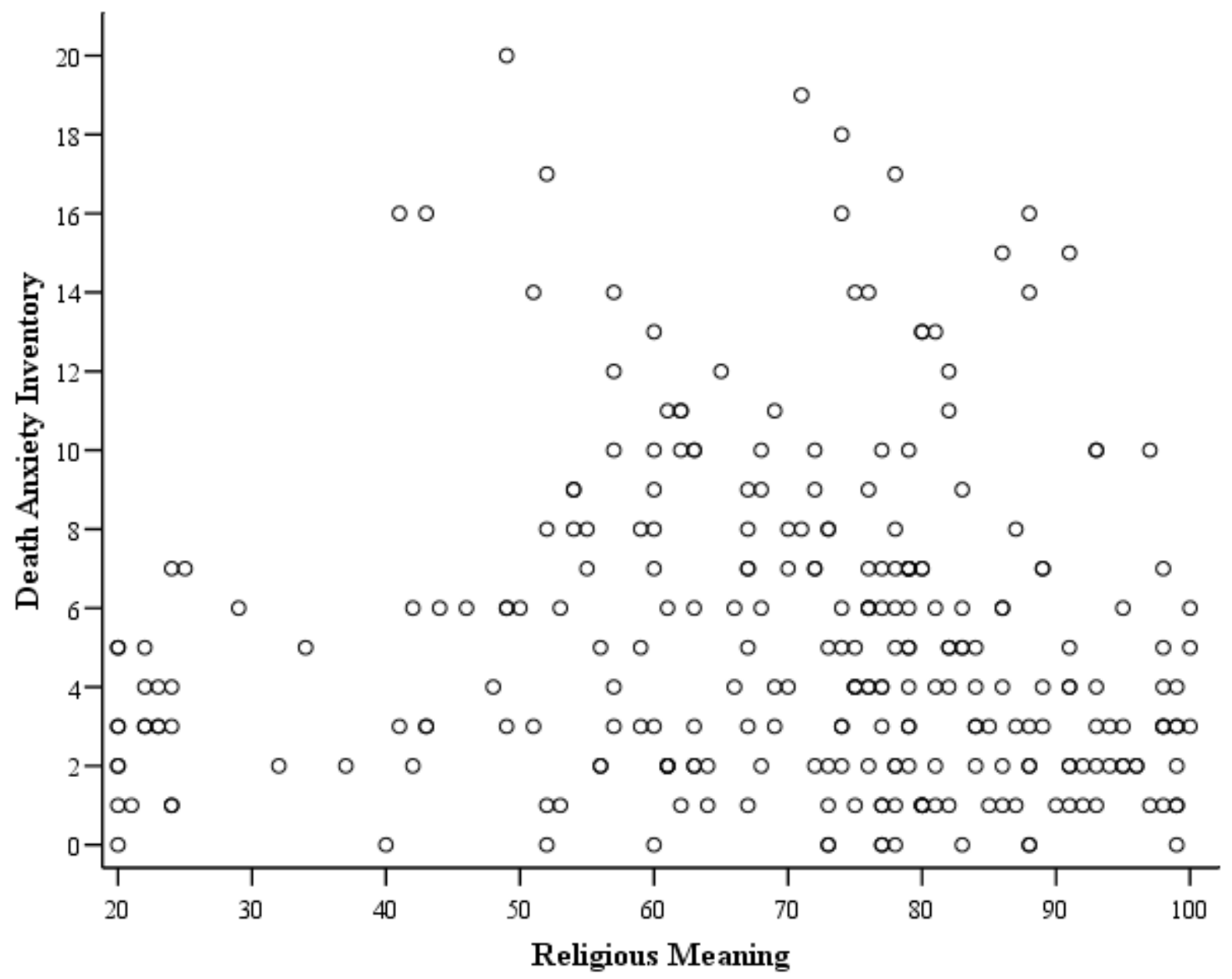


Appendix Z: Figure 12

Graph of Means from Tests of Trend from One-Way ANOVA with Religious Meaning Groups predicting Death Anxiety Scale-Extended scores.

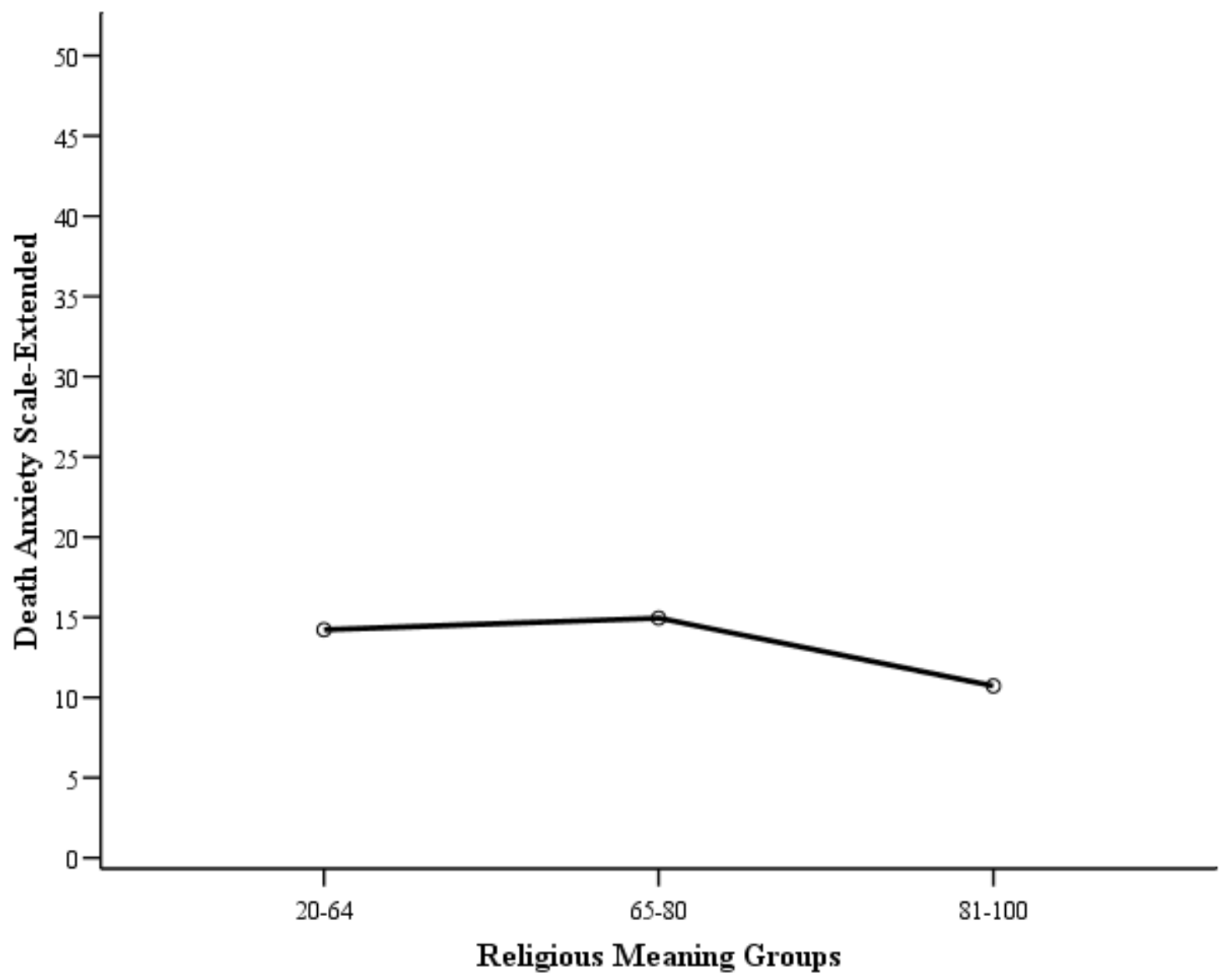


Appendix AA: Figure 13

Graph of Means from Tests of Trend from One-Way ANOVA with Religious Meaning Groups predicting Death Anxiety Inventory scores.

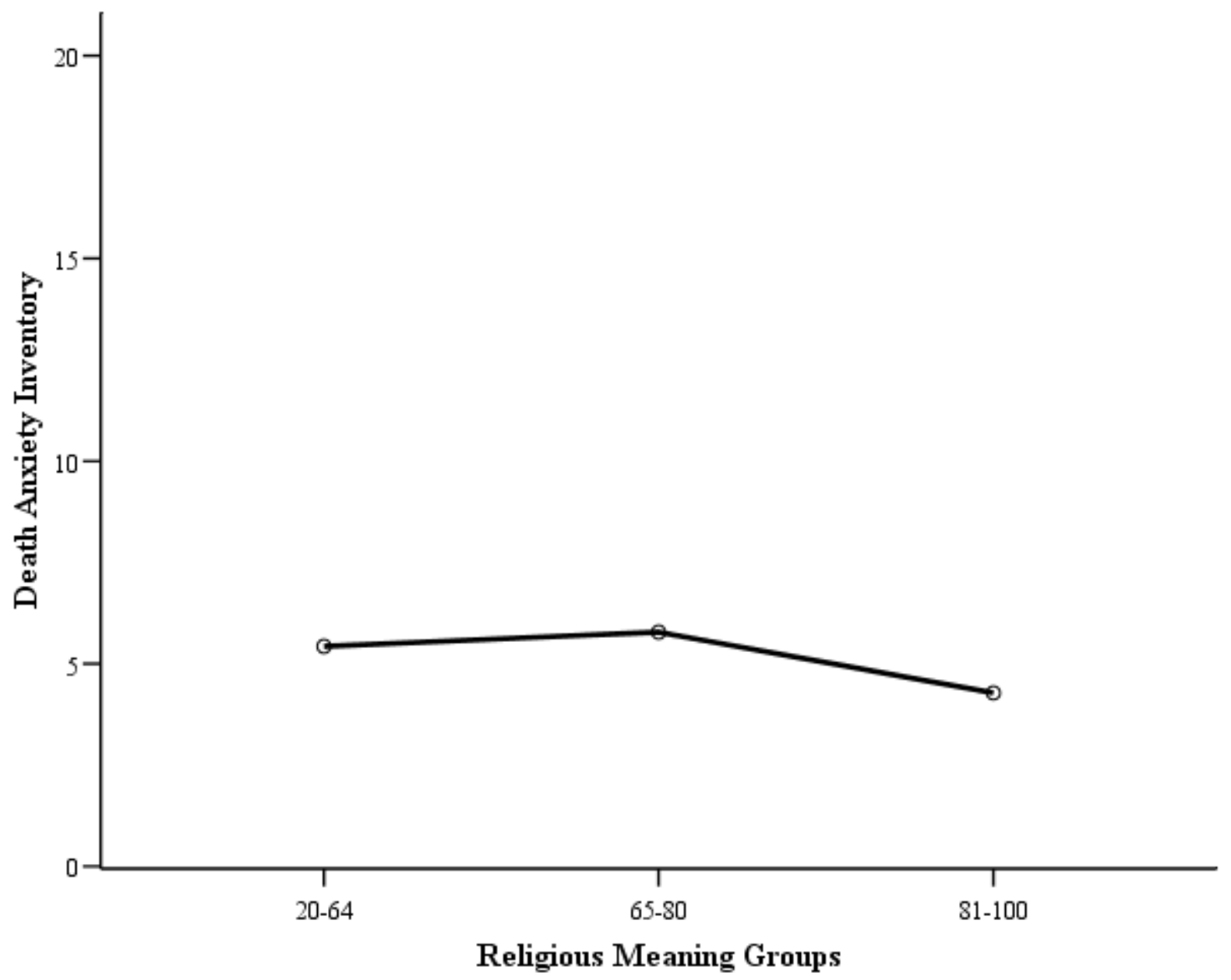


Appendix AB: Figure 14

Graph of Curve Estimation with Religious Meaning predicting Death Anxiety Scale-Extended scores.

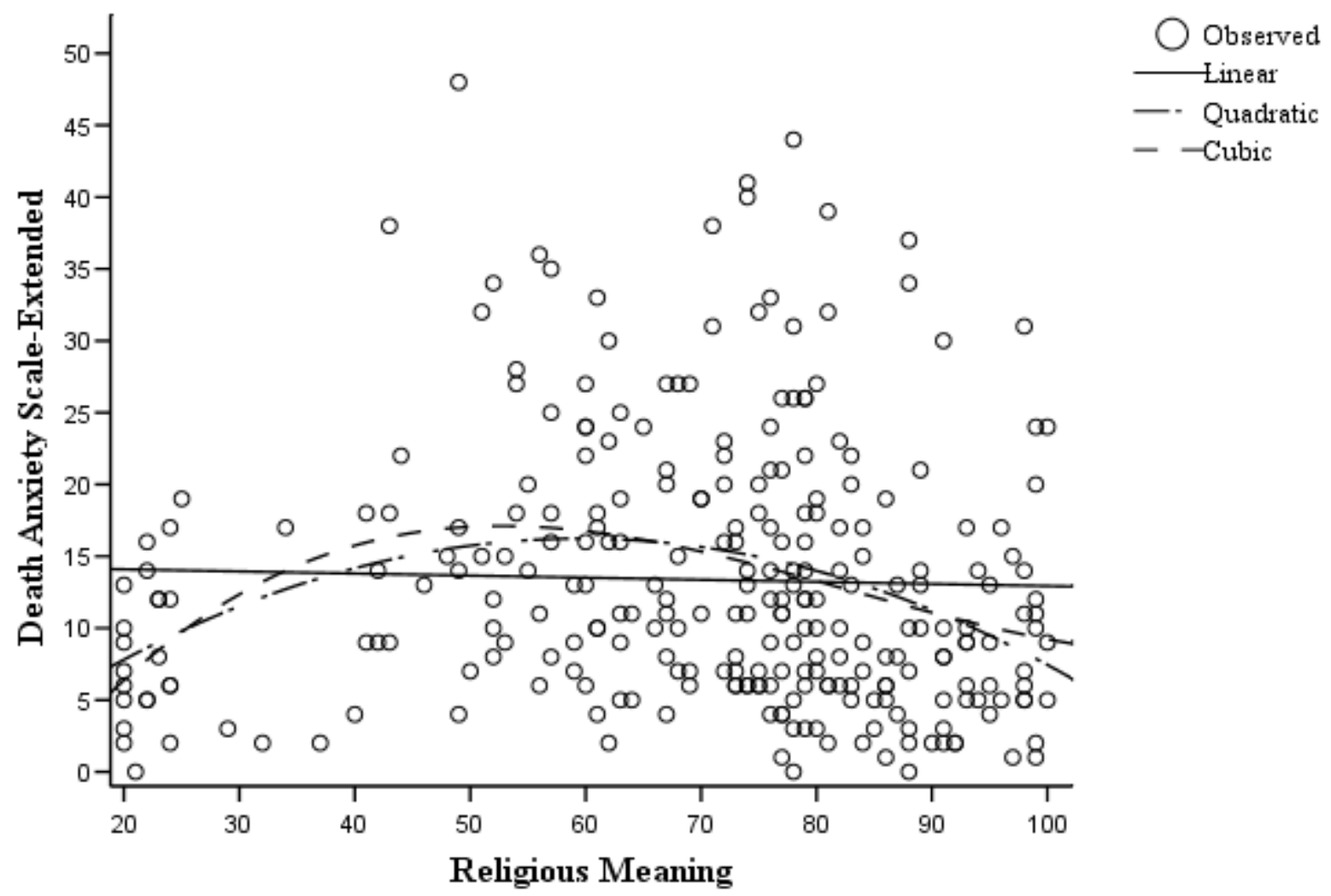


Appendix AC: Figure 15

Graph of Curve Estimation with Religious Meaning predicting Death Anxiety Inventory scores.

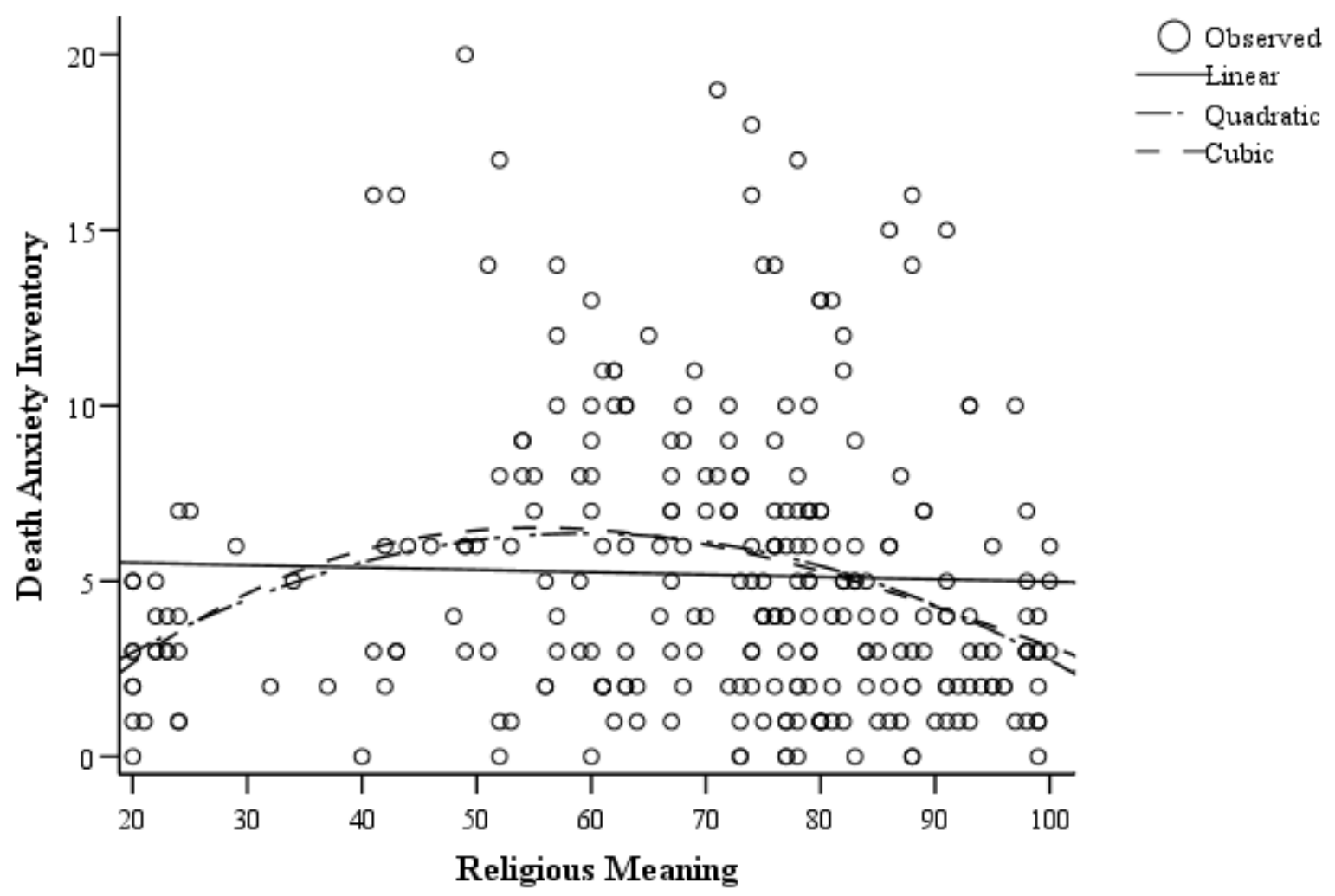




\section{Appendix AD: Figure 16}

Scatterplot of Age (X) and Death Anxiety Scale-Extended (Y).

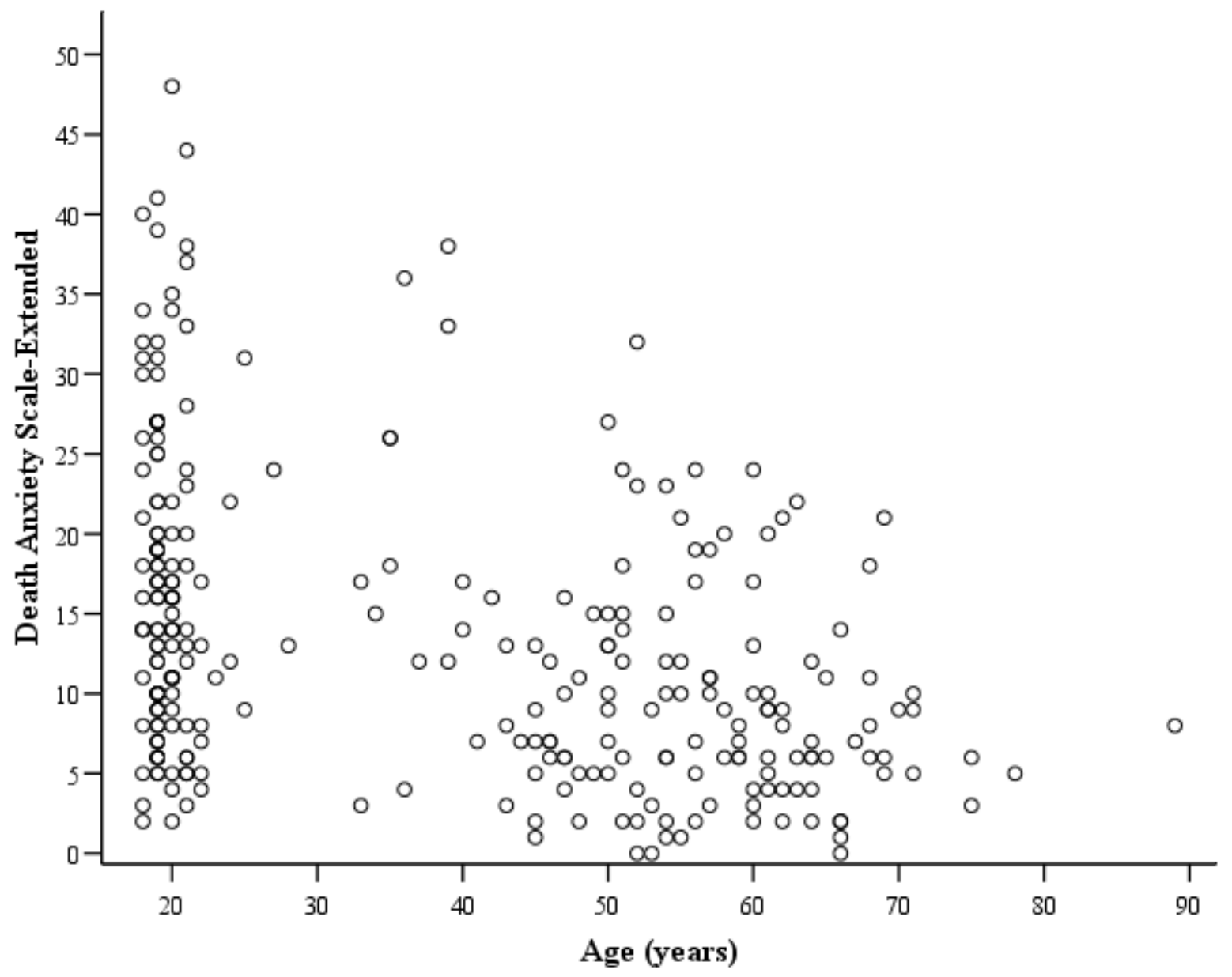


Appendix AE: Figure 17

Scatterplot of Age $(X)$ and Death Anxiety Inventory $(Y)$.

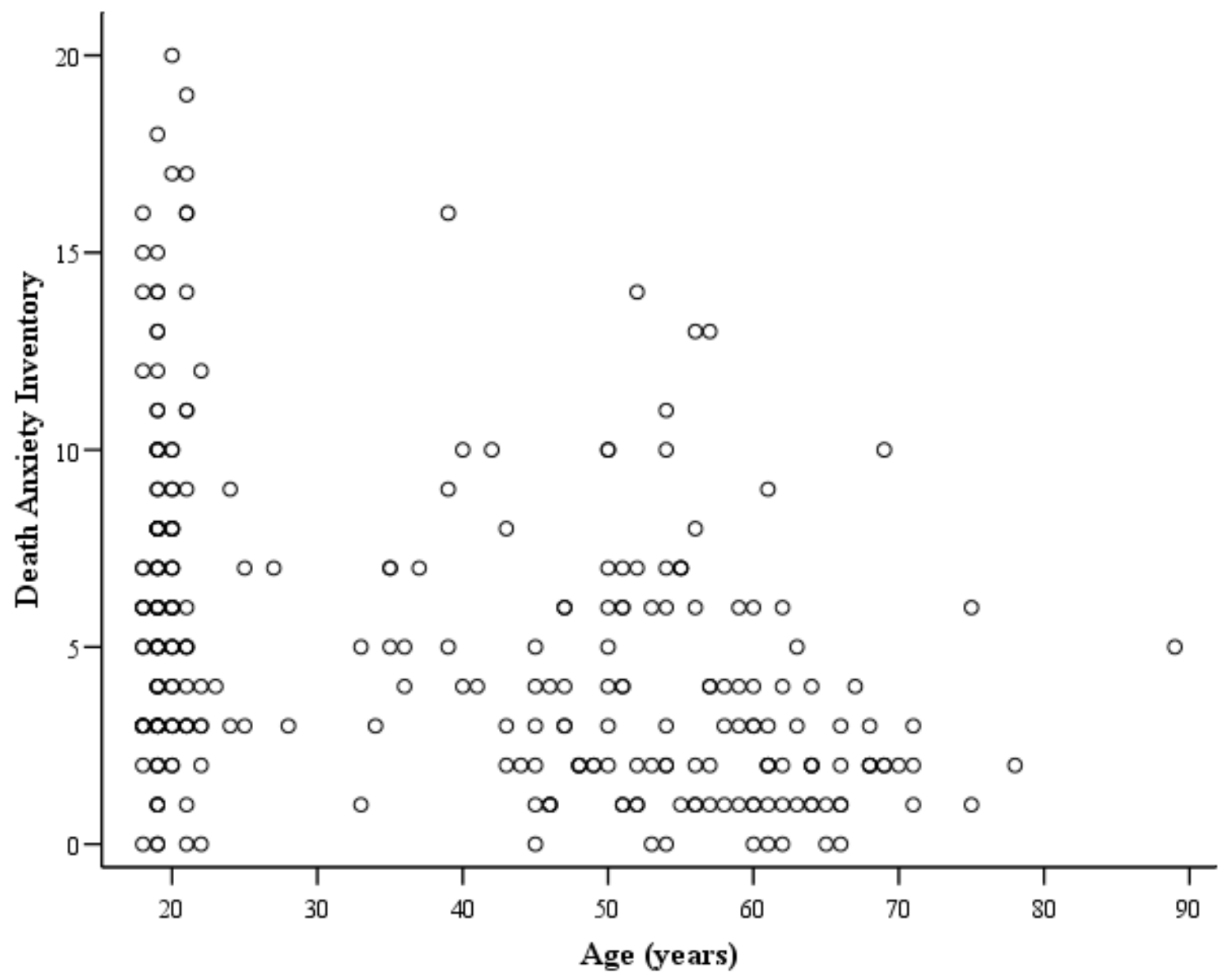


Appendix AF: Figure 18

Graph of Means from Tests of Trend from One-Way ANOVA with Age Groups predicting Death Anxiety Scale-Extended scores.

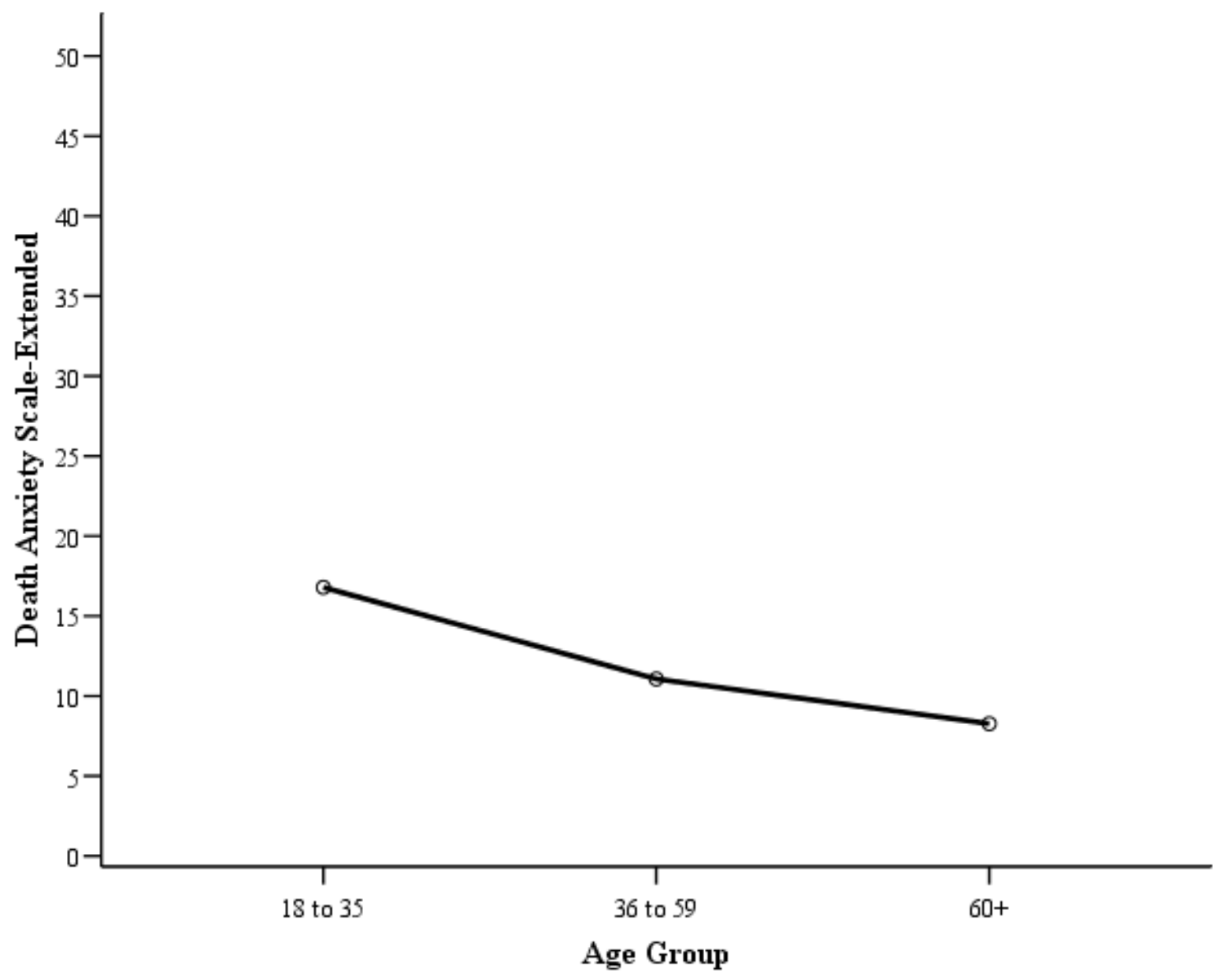


Appendix AG: Figure 19

Graph of Means from Tests of Trend from One-Way ANOVA with Age Groups predicting Death Anxiety Inventory scores.

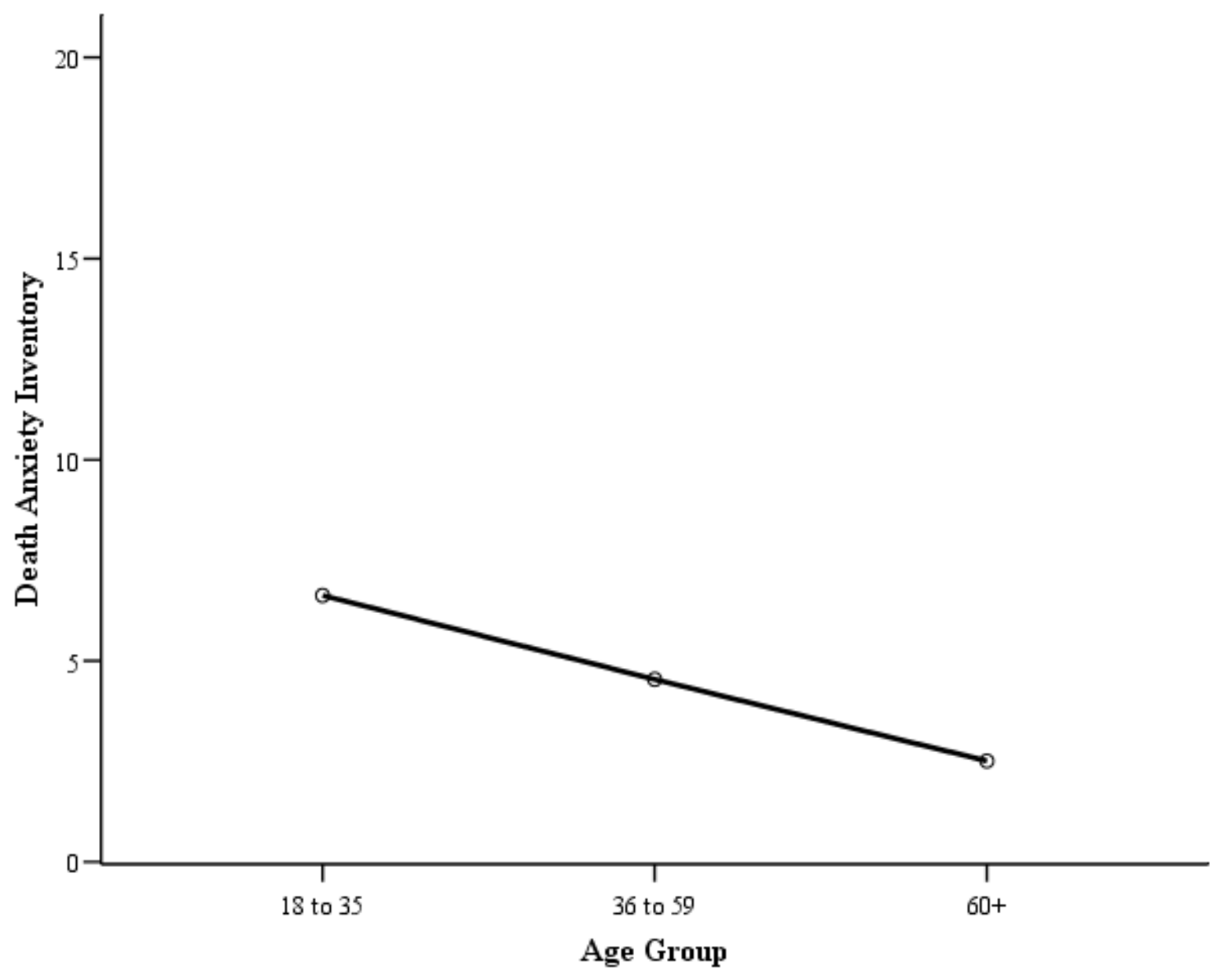


Appendix AH: Figure 20

Graph of Curve Estimation with Participants' Age predicting Death Anxiety Scale-Extended scores.

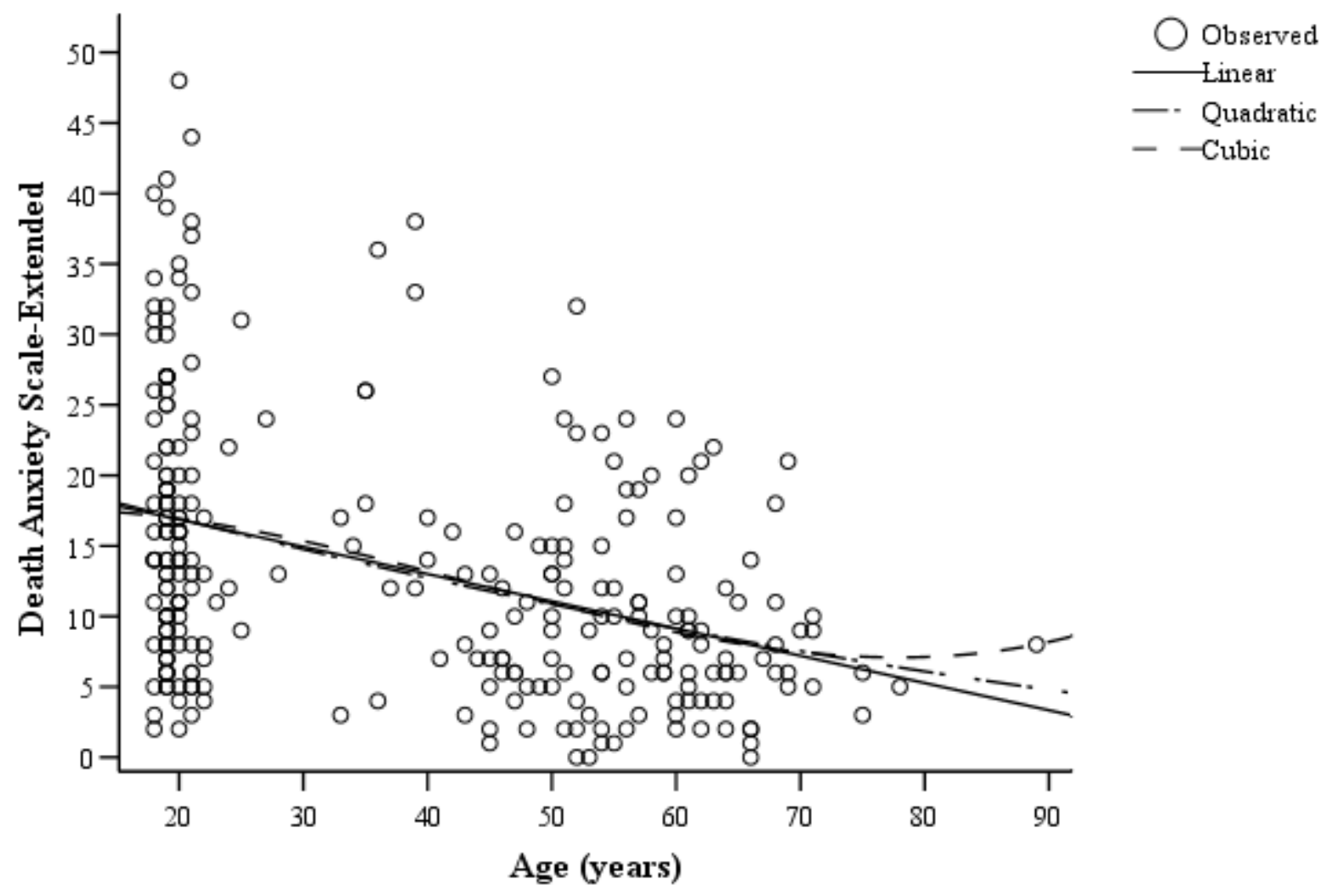




\section{Appendix AI: Figure 21}

Graph of Curve Estimation with Participants' Age predicting Death Anxiety Inventory scores.

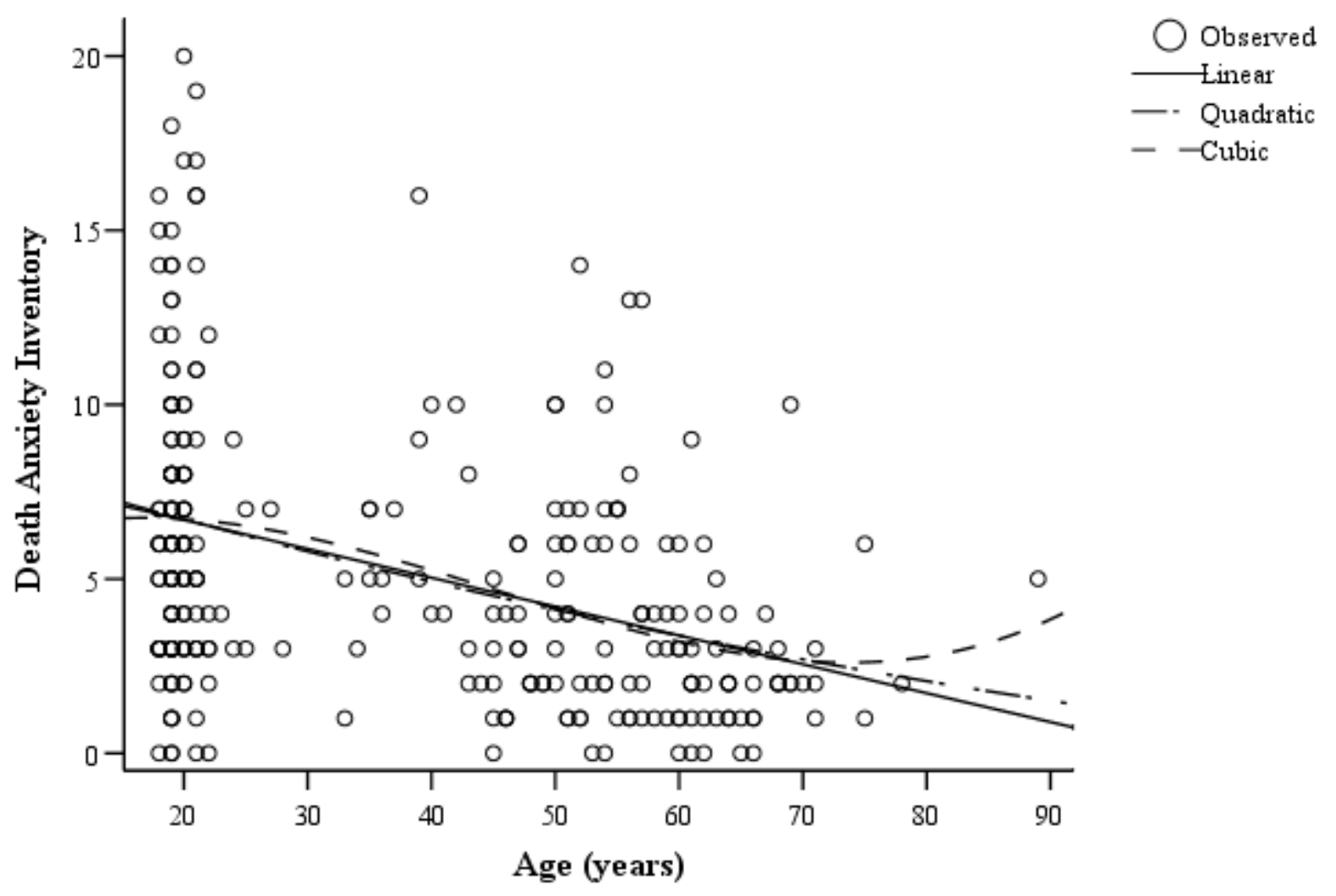


Religion and Death Anxiety 98

Appendix AJ: Figure 22

Scatterplot of Age (X) and Trait Anxiety (Y).

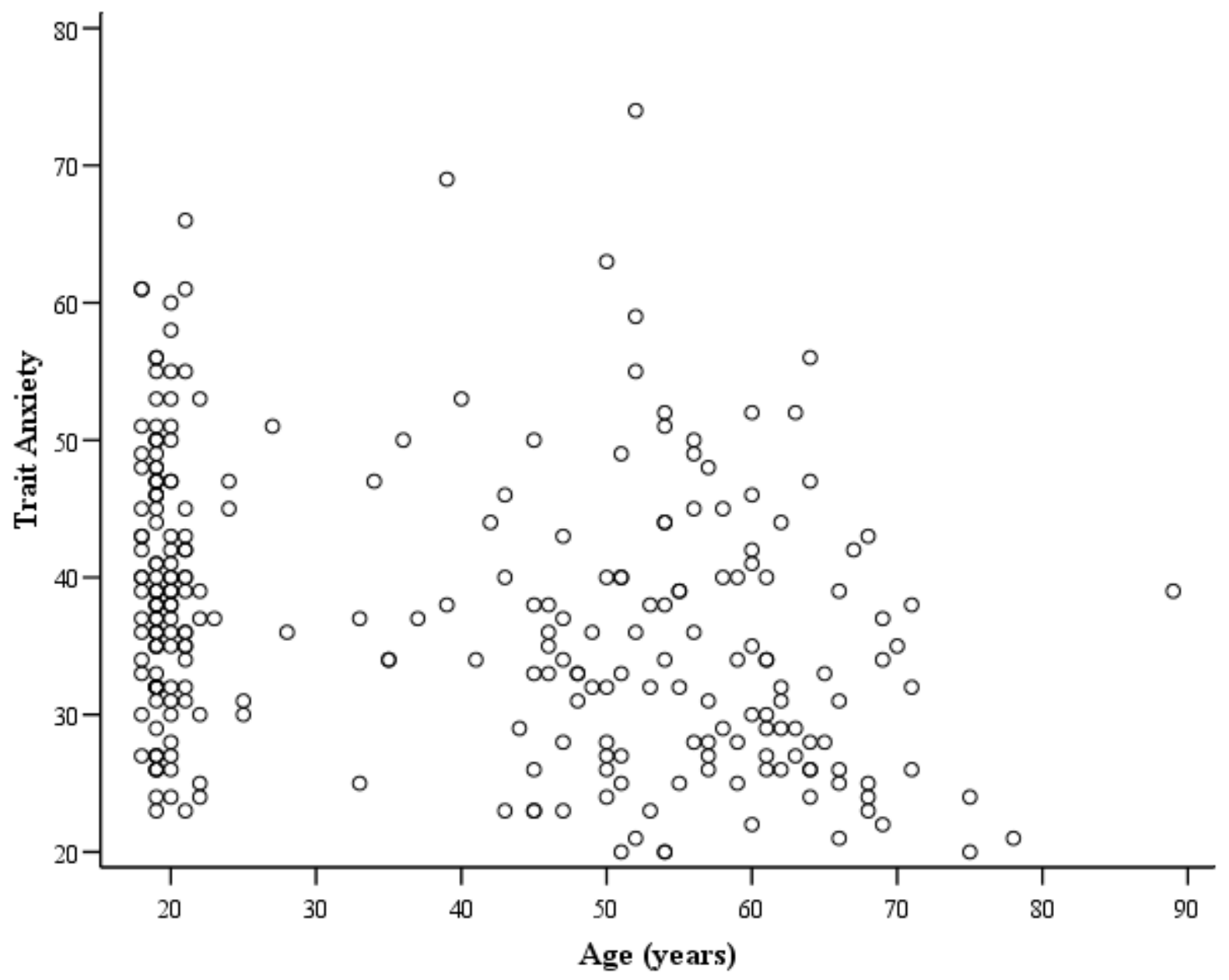


Appendix AK: Figure 23

Graph of Means from Tests of Trend from One-Way ANOVA with Age Groups predicting Trait Anxiety scores.

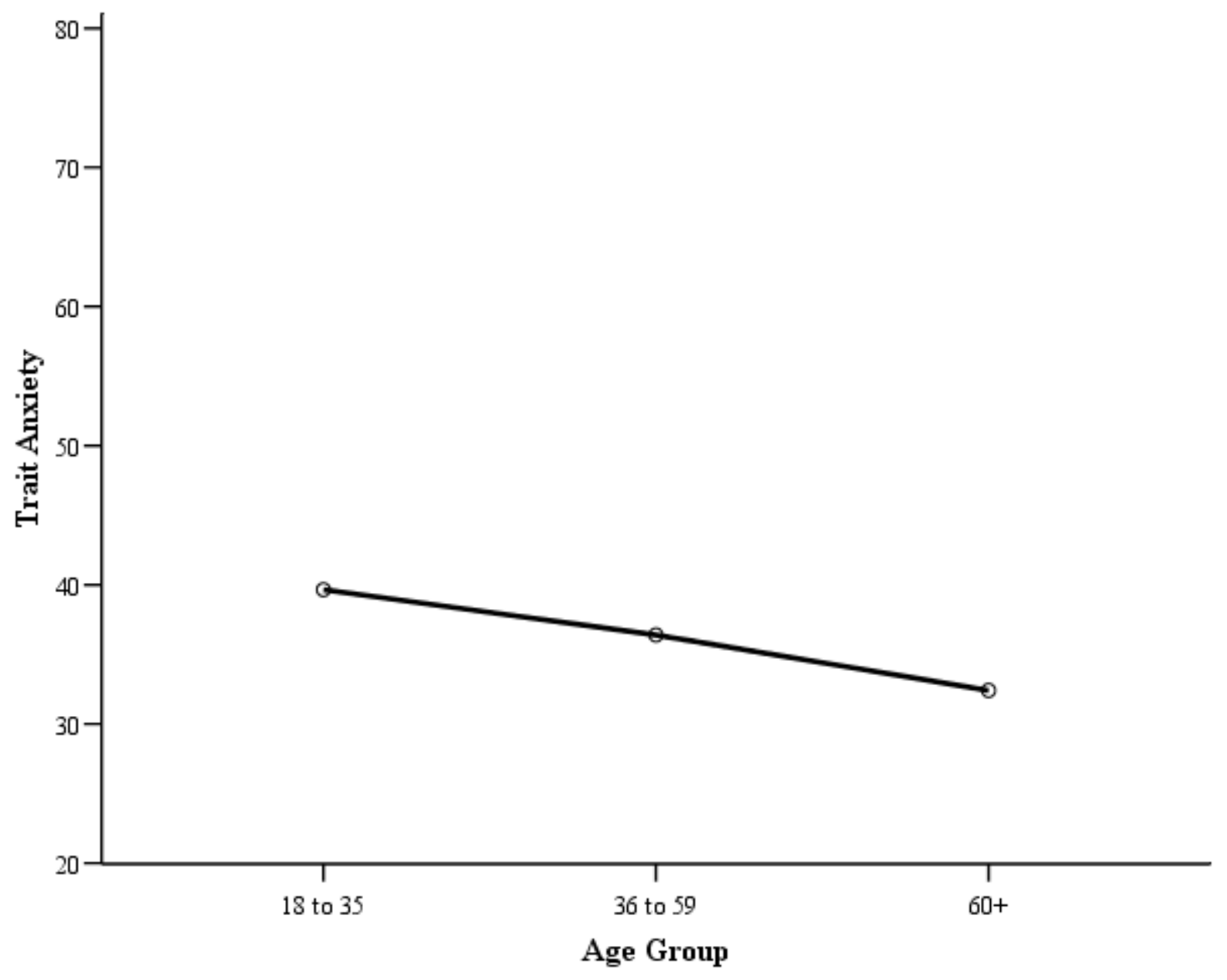


Appendix AL: Figure 24

Graph of Curve Estimation with Age predicting Trait Anxiety scores.

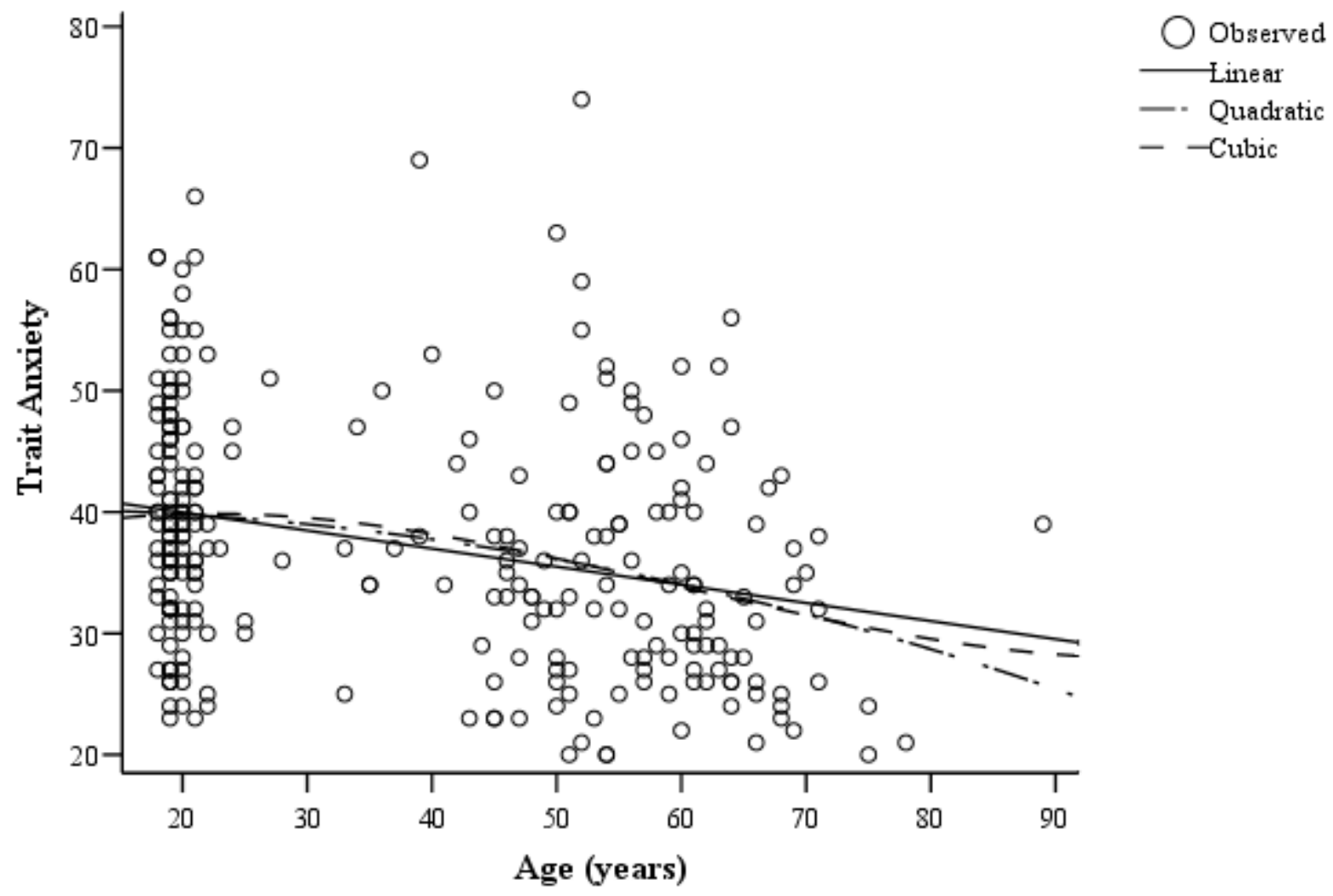


Appendix AM: Demographic Questionnaire

The first part of this survey is background information about you.

1. Please indicate your current age in years.

2. Please indicate your gender.

$\square$ Male

$\square$ Female

3. Please indicate your race/ethnicity.

$\square$ Caucasian

$\square$ African American

- Hispanic American

口 Asian-Pacific Islander

$\square$ Native American

$\square$ Other

4. Please indicate your religion.

$\square$ Protestant

- Catholic

๑ Jewish

a Muslim

$\square$ None

$\square$ Other

5. If you indicated that your religion is Protestant, please specify your denomination. If you did not, please choose the "Check this box if you do not want to provide an answer for this question" option. (Approximately 20 different denominations)

6. What is your marital status?

$\square$ Single, never married

$\square$ Married

D Divorced

$\square$ Separated

$\square$ Widowed 
7. What is your primary work status?

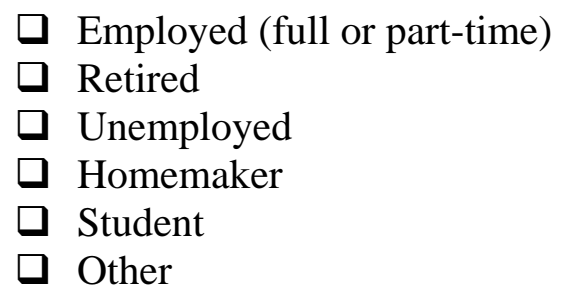

8. What is the highest grade or level of education you've completed?

9. Has a friend or close family member of yours passed away within the last year?
口 Yes
no 


\section{Appendix AN: Religious Doubt Scale}

Here are some statements about thoughts you may or may not have had concerning religion and the world. Please indicate how true these statements are for you. Choose only one response for each question.

\begin{tabular}{|c|c|c|c|c|c|c|}
\hline & & $\begin{array}{c}\text { Very } \\
\text { Untrue }\end{array}$ & $\begin{array}{c}\text { Somewhat } \\
\text { Untrue }\end{array}$ & Neutral & $\begin{array}{l}\text { Somewhat } \\
\text { True }\end{array}$ & $\begin{array}{l}\text { Very } \\
\text { True }\end{array}$ \\
\hline 1 & $\begin{array}{l}\text { Seeing evil and suffering in the world makes } \\
\text { me question the existence of a god or question } \\
\text { god's power. }\end{array}$ & VU & SU & $\mathrm{N}$ & ST & VT \\
\hline 2 & $\begin{array}{l}\text { Feeling personal pain and suffering has made } \\
\text { me question the existence of a god or feel that } \\
\text { god has abandoned me. }\end{array}$ & VU & SU & $\mathrm{N}$ & $\mathrm{ST}$ & VT \\
\hline 3 & $\begin{array}{l}\text { My prayers are being ignored, or they do not } \\
\text { make a difference. }\end{array}$ & VU & SU & $\mathrm{N}$ & $\mathrm{ST}$ & VT \\
\hline 4 & $\begin{array}{l}\text { (R) Solutions for my problems can be found in } \\
\text { religious literature (e.g., the Bible) or through } \\
\text { the help of religious leadership (e.g., the } \\
\text { clergy). }\end{array}$ & VU & SU & $\mathrm{N}$ & $\mathrm{ST}$ & VT \\
\hline 5 & $\begin{array}{l}\text { When natural disasters occur, and innocent } \\
\text { people are harmed or killed, I question the } \\
\text { existence of a god or question god's love and } \\
\text { morality. }\end{array}$ & VU & SU & $\mathrm{N}$ & $\mathrm{ST}$ & VT \\
\hline 6 & $\begin{array}{l}\text { Disagreeing with a stance taken by my religion } \\
\text { or my religious community makes me question } \\
\text { whether I want to be a part of this religion or } \\
\text { community. }\end{array}$ & VU & SU & $\mathrm{N}$ & $\mathrm{ST}$ & VT \\
\hline 7 & $\begin{array}{l}\text { Dissatisfaction with the clergy or leadership of } \\
\text { my religion or religious community makes me } \\
\text { question if I wish to continue to be involved in } \\
\text { my religion or community. }\end{array}$ & VU & SU & $\mathrm{N}$ & $\mathrm{ST}$ & VT \\
\hline 8 & $\begin{array}{l}\text { Sometimes I perceive that the teachings or } \\
\text { literature of my religion are contradictory, and } \\
\text { this perception makes me question if I wish to } \\
\text { continue to be involved in my religion. }\end{array}$ & VU & SU & $\mathrm{N}$ & $\mathrm{ST}$ & VT \\
\hline 9 & $\begin{array}{l}\text { I have felt pressured to by my religion, my } \\
\text { religious community, or the leadership of my } \\
\text { religion/community to forgive someone for a } \\
\text { transgression that I did not want to forgive. }\end{array}$ & VU & SU & $\mathrm{N}$ & ST & VT \\
\hline
\end{tabular}




\begin{tabular}{|c|c|c|c|c|c|c|}
\hline 10 & $\begin{array}{l}\text { I have felt pressured to by my religion, my } \\
\text { religious community, or the leadership of my } \\
\text { religion/community to be generous to someone } \\
\text { that I did not believe deserved my generosity. }\end{array}$ & VU & $\mathrm{SU}$ & $\mathrm{N}$ & $\mathrm{ST}$ & VT \\
\hline 11 & $\begin{array}{l}\text { I have experienced doubts concerning the } \\
\text { existence of god and/or the truth about the } \\
\text { religion I practice }\end{array}$ & VU & $\mathrm{SU}$ & $\mathrm{N}$ & $\mathrm{ST}$ & VT \\
\hline 12 & $\begin{array}{l}\text { I have felt pressured to by my religion, my } \\
\text { religious community, or the leadership of my } \\
\text { religion/community to be compassionate } \\
\text { toward someone for whom I felt no sympathy. }\end{array}$ & VU & $\mathrm{SU}$ & $\mathrm{N}$ & $\mathrm{ST}$ & VT \\
\hline 13 & $\begin{array}{l}\text { (R) When the views of my religion contrast } \\
\text { with the views of scientific research or theory, I } \\
\text { side with my religion. }\end{array}$ & VU & SU & $\mathrm{N}$ & ST & VT \\
\hline 14 & $\begin{array}{l}\text { I have felt pressured by my religion, my } \\
\text { religious community, or the leadership of my } \\
\text { religion/community to change the way that I } \\
\text { live against my will. }\end{array}$ & VU & SU & $\mathrm{N}$ & ST & VT \\
\hline 15 & $\begin{array}{l}\text { For some people, certain events have caused } \\
\text { them to experience doubt in the truth of } \\
\text { religious teachings or the existence of a higher } \\
\text { power. Have you ever had an experience like } \\
\text { that? If yes, please describe that experience and } \\
\text { how/why it provoked doubt. }\end{array}$ & & & & & \\
\hline
\end{tabular}

*Items starting with (R) are reverse coded 